\title{
DIGNITY IN THE WORK LIVES OF CLINICAL NURSES by
}

\author{
Jane Alison Lawless
}

\begin{abstract}
A thesis submitted to the Victoria University of Wellington in partial fulfilment of the requirements for the degree of Master of Arts (Applied) in Nursing
\end{abstract}

Victoria University of Wellington

2009 


\section{Abstract}

This descriptive study examines how clinical nurses understand, experience, and sustain dignity in their work lives. Nursing has embedded dignity, particularly the dignity of others, as a core professional value. However, while the practice of nursing is deeply concerned with the achievement of patient dignity, dignity as a self-regarding professional right is not well articulated. Hodson's (2001) model for dignity at work provided a lens through which to examine the relevant nursing literature. It was revealed that the dignity of nurses as an intrinsic human and worker right has received little explicit attention, and that the significance of this is possibly not sufficiently well understood.

A qualitative descriptive approach was used to further investigate the area of nurse dignity. Seven nurses were recruited to participate in facilitated workshops to explore the research question, 'How do clinical nurses understand, experience, and sustain dignity in their work lives'? The data were analysed using directed content analysis and presented as a descriptive summary.

Dignity, for the participants, was strongly associated with the worth, value, and meaning that nurses attach to their profession, to the work that they do, and to themselves personally. This was shown to be central to their understanding, experience, and achievement of dignity in their work lives. Each encounter, each moment, was seen to be invested with the potential to maintain, affirm, erode or infringe personal dignity.

The nurses perceived nursing to be a meaningful, worthwhile endeavour, but frequently struggled to extract a sense of dignity when working in environments that they perceived as not supporting their agenda of care. Being seen as a 
respected professional, enjoying daily positive interactions with colleagues and being successful in the act of nursing, had the strongest association with the ability to extract worth, value, and meaning from the work experience. The absence of a perception of the participants' need to regard managerial colleagues was an unexpected finding.

It was concluded that dignity should be pursued as a right in any context including the work context of nurses, both as a moral and pragmatic imperative. It is suggested that the current dominant approach that interests itself in the needs of nurses primarily as a means to achieving health care outcomes for patients may be neglecting an important dimension. Future inquiry into the area of nurse dignity should begin from the premise that to understand the meaning that nurses attach to dignity, one first has to understand the meaning that nurses attach to nursing, and in particular the nature of the social compact that nursing holds with society.

Key Words: dignity, nursing, work, respect, workplace environment, work context, social compact 


\section{Dedication}

\section{To working nurses who apply their knowledge, skill, and humanity, every day, to make a positive difference to the lives of others}

The nurse must have methad, self-sacrifice, watchful activity, lave of the work, devotion to duly (that is, the service of the good), the courage, the coolness of the soldier, the tenderness of the mother, the absence of the prig (that is, never thinking that she has abtained perffection or that there is nothing better). Qhe must have a three-fold interest in her work: an intellectual interest in the case,

a (much higher) hearty interest in the patient, a technical (practical) interest in the patient's care and cure. The must not lock upon patients as made for nurses, but nurses as made for patients.

(Florence Nightingale, cited in McDonald, 2004, p. 215) 


\section{Acknowledgments}

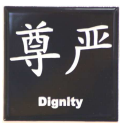

My family, for offering me the time, space, and love needed to complete this journey

尊严

My colleagues and friends for inspiration, listening, and support

My academic supervisors and reviewers for their wisdom, critique, guidance, and encouragement

The nurses Crystal, Quartz, Emerald, Pearl, Diamond, Moonstone and Ruby $^{1}$ who participated in the research and made this thesis possible through sharing their time, wisdom, and practice experiences

\footnotetext{
${ }^{1}$ Non-de-plumes have been used to protect the confidentiality of the participants.
} 
Dignity is a human concept that relates to worth, value and meaning. Dignity is defined and sustained individually but is influenced, supported or eroded by others.

(Research participants' group definition)

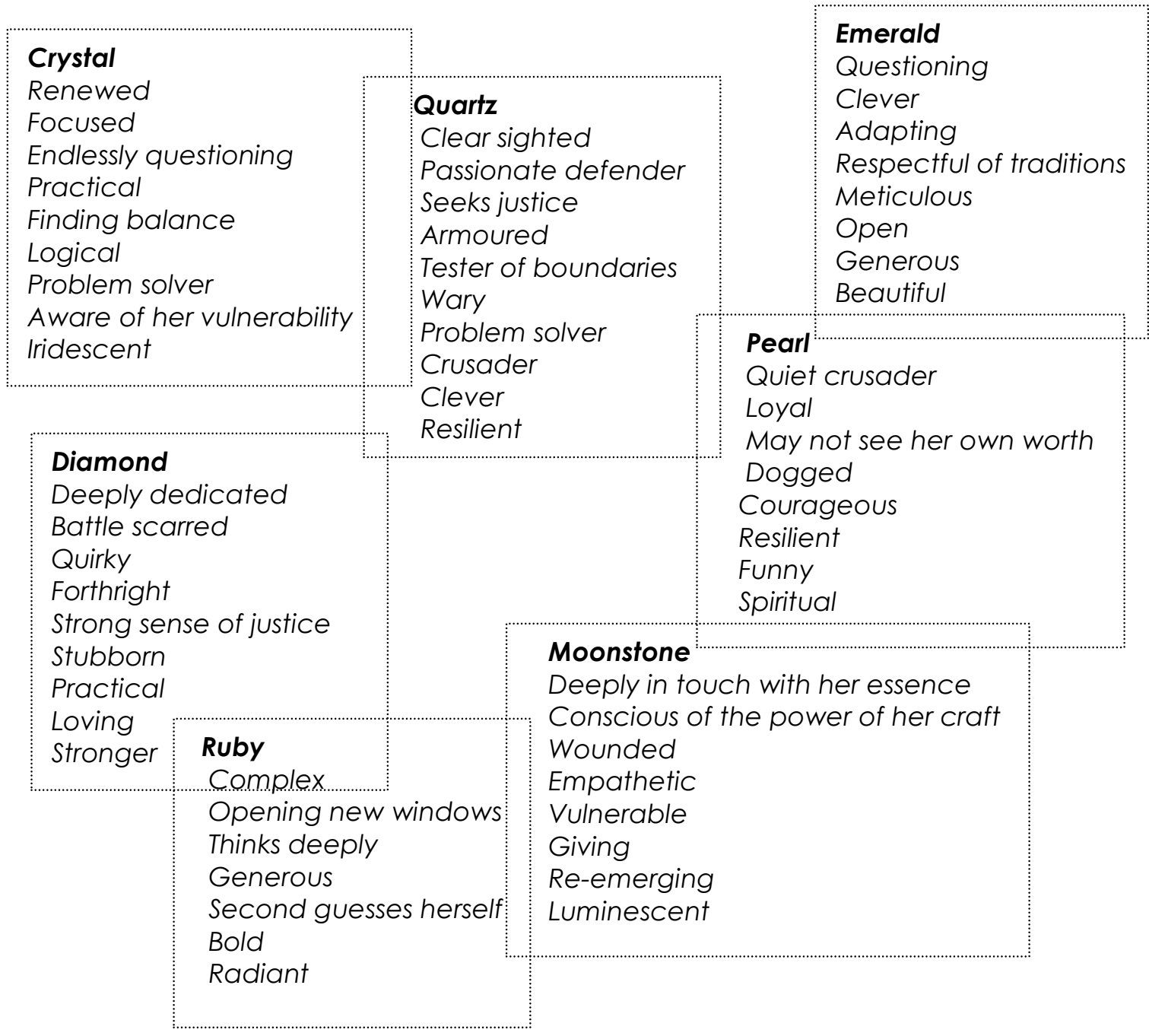

Nurses bring a body of specialised knowledge and skills and value for our shared humanity to provide care that aims to make a positive difference in the delivery of health care. The essence of nursing is the specialised expression of caring

(Research participants' definition of nursing) 


\section{Table of Contents}

TITLE PAGE.........................................................................

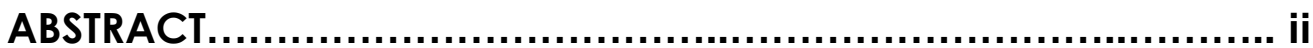

DEDICATION................................................................

ACKNOWLEDGMENTS........................................................

TABLE OF CONTENTS...................................................... vii

FIGURES AND TABLES................................................

CHAPTER 1: INTRODUCTION......................................... 1

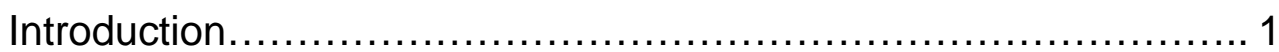

From interest to inquiry.......................................... 1

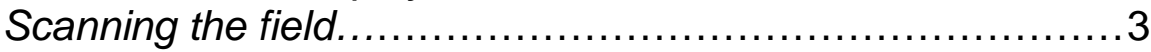

Positioning the study........................................ 3

Designing an approach...................................... 3

Exploration, discovery, and representation....................4

Reconciliation and journey's end............................ 4

CHAPTER 2: $\quad$ SCANNING THE FIELD.............................. 5

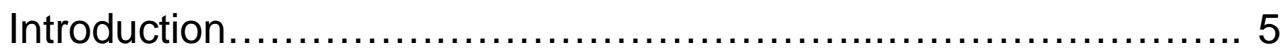

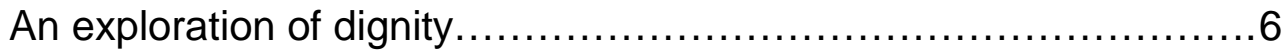

Dignity as a human right...................................... 6

The evaluation of dignity.................................... 8

Dignity as a personal and social construct..................... 8

Dignity as expressed through mutual regard....................8

Dignity as context specific.................................. 9

A working definition of dignity.............................. 10

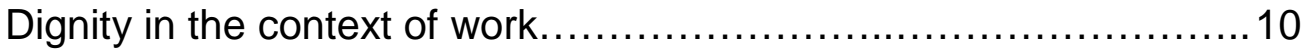

Work as socially constructed............................... 10

Dignity at work .............................................. 12 
Relating dignity to the context of nursing work $\ldots \ldots \ldots \ldots \ldots \ldots \ldots 13$

Dignity as a concept and value in nursing..................... 13

Hodson's theoretical model for dignity at work.................. 15

Dignity within the context of nursing work.................... 17

Synthesis of the literature and Hodson's research..................22

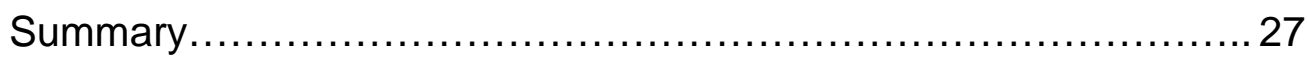

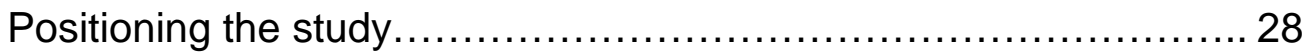

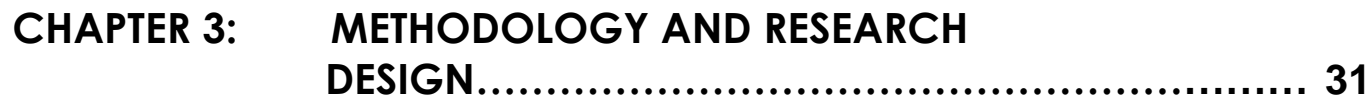

Research question................................................. 31

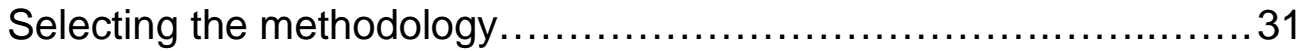

Overarching orientation.........................................

Qualitative description....................................... 33

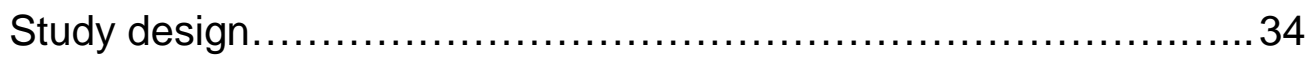

Ethical considerations..................................... 35

Treaty of Waitangi considerations and obligations............. 35

Setting........................................................

Recruitment and sampling strategy........................ 36

Inclusion criteria.............................................. 37

Data collection............................................... 37

Challenges relating to the generation of data................... 38

Challenges relating to the wellbeing of the participants........ 38

Designing the data collection phase.......................... 40

Crafting the facilitated group process......................... 40

Facilitation as a research approach............................ 41

Facilitation as a practical approach to data collection.......... 42

Workshop design................................................ 42

Managing safety considerations in the process............... 43

Data analysis................................................ 45

Qualitative content analysis.............................. 45

Presentation of findings....................................... 47

Ensuring the quality of the design........................... 47

Summary................................................. 50 
CHAPTER 4: PREPARATION, DATA COLLECTION, ANALYSIS, AND REPRESENTATION.....................52

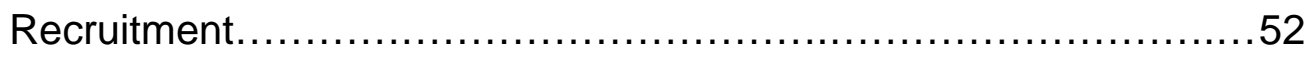

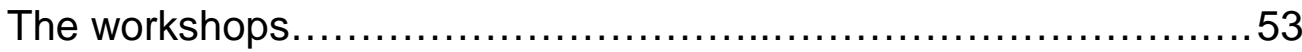

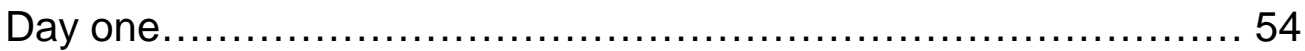

Introductory session: Setting the scene...................... 54

Theme One: Conceptualising dignity...........................55

Theme Two: The purpose of nursing work.....................5 56

Theme Three: Self and other-regarding dignity ................ 57

Theme Four: Dignity and others............................ 58

Theme Five: Dignity and the environment......................59

Theme Six: Infringing our own dignity ........................ 60

Theme Seven: Sustaining one's own dignity....................61

Final session: Review and reflection......................... 62

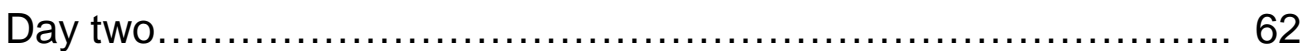

Reflection and identification of narratives.......................62

Moments and narratives.............................................6 63

Exploring the dignity of nursing................................64

Reflection and closure.......................................65

Reflections on the facilitated process.................................6

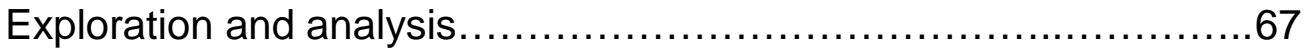

Data transcription and participant review......................6 67

Data analysis.................................................. 68

Organising the data......................................... 68

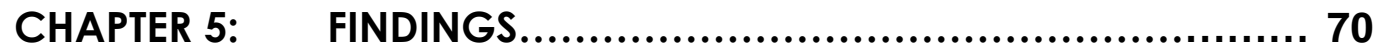

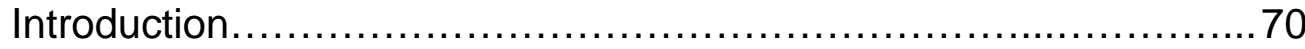

Part one: Beliefs and expectations about dignity

in the work context............................................ 71

Developing a construction of dignity ........................... 71

The personal self.............................................. 74

The professional self...................................... 77

The nurse in practice....................................... 82

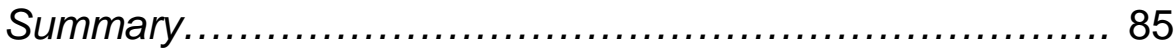

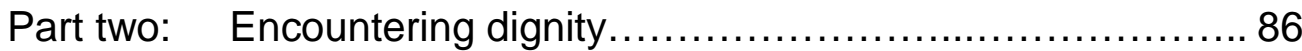

Dignity in congruent encounters................................ 88

Dignity in contradictory encounters.......................... 98 
Part three: The balance between congruence and contradiction................................................... 107

Encounters with patients.................................... 107

Encounters with nurse colleagues............................ 109

Encounters with medical colleagues...........................109

Encounters with other colleagues............................. 109

Encounters with managers and the organisation............... 109

Part four: Summary of findings....................................... 111

Understanding dignity ....................................... 111

Experiencing dignity ......................................... 112

Sustaining dignity ........................................... 114

The research findings as 'end-product' and 'entry point'....... 114

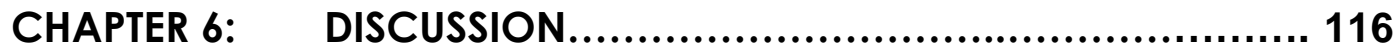

Finding synthesis with what is already known......................... 118

Is the pursuit of dignity important?................................................. 119

Deepening understanding ............................................. 119

The role of the social compact................................. 119

Dignity as mutually invested in the nurse-patient interaction.. 120

The contested terrain of the nursing work context.............. 121

The role nurses play in sustaining their dignity................ 125

The road ahead ......................................................... 126

CHAPTER 7: CONCLUSION............................................. 129

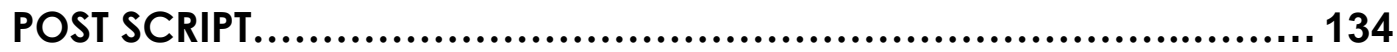

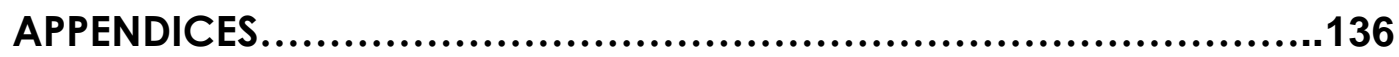

Appendix 1: Ethics approval...................................... 136

Appendix 2: Invitation to participate in the study .................. 137

Appendix 3: Information sheet................................... 138

Appendix 4: Consent and eligibility form......................... 140

Appendix 5: Workshop plan.........................................144

Appendix 6: Prompt card......................................... 150

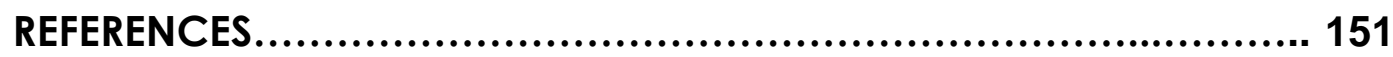




\section{LIST OF FIGURES}

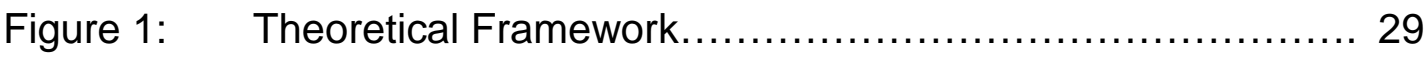

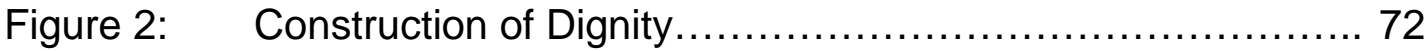

Figure 3: $\quad$ Construction of Dignity (amended) ..............................73

\section{LIST OF TABLES}

Table 1: $\quad$ Giving and Receiving Regard.................................. 85 


\title{
Chapter 1: Introduction
}

\author{
So many roads, so much at stake \\ So many dead ends, I'm at the edge of the lake \\ Sometimes I wonder what it's gonna take \\ To find dignity. (Bob Dylan, 'Dignity')
}

\section{Introduction}

What is dignity? However I position myself, I have been taught that dignity is my human right. I am a person in the world. I am a New Zealand citizen. I am a mother, a wife, a sister, a friend. I am a nurse. So what does dignity mean to me individually, socially, and professionally? How does one acquire it? How is it experienced? These questions underpin this study which explores dignity in the context of the work lives of clinical nurses.

\section{From interest to inquiry}

My interest in dignity for nurses is grounded in a nursing career that has spanned more than 25 years. When I first began working as a registered nurse, every work day was anticipated with pleasure, and this continued for some 10 years. However the 15 years that followed have seen healthcare subjected to turbulence and constant reform. Concomitantly I experienced a loss of connectedness with my work. Current literature suggests that my personal journey is similar to the experiences of many colleagues world-wide (Aiken \& Patrician, 2000; Duffield, 2007; Kramer \& Schmalenberg, 2008a). Nursing is generally accepted to be in a state of perpetual crisis ("Healthcare at the Crossroads", 2002). Much energy locally, nationally, and internationally has gone into understanding what constitutes the crisis. There has been a focus on the context in which nursing takes place, the role that nursing plays, and the effect of nursing work on patients and on nurses themselves. There is no shortage of ideas on how to improve the situation. What is lacking is evidence that we are applying these ideas successfully and achieving sustained 
improvement that goes beyond isolated local gains. Despite intensive scrutiny and multiple interventions, it appears that "overall there are few indicators that front-line nurses are experiencing a better working life" (Priest, 2006, p. 21). There is either a general lack of success at sustaining the identified interventions or perhaps there is more to be discovered. What remains to be located and explored?

Over some years I directed energy towards understanding and redressing the changes I was experiencing in my work life. I made attempts to reshape the work environment, offered support to others experiencing similar distress, resisted further change, and undertook self development; all with the ultimate purpose of reclaiming what I feared may have been lost forever. Throughout this journey (as a nurse, union delegate, advocate, educator, activist, manager, practice developer and more recently scholar), I have been delving into areas such as moral distress, burnout, disengagement, error, nurse retention, healthy workplace environments, safe staffing, and advanced nursing practice. During this period of empirical and theoretical interest in the effects of nursing on nurses I discovered the work of Randy Hodson (2001), whose seminal research investigated and proposed a model for dignity at work. It was as a result of reading Hodson's research that I developed the specific focus on dignity in nursing that has been the catalyst for this study. Hodson defined dignity at work as "the ability to establish a sense of self-worth and self-respect and to appreciate the respect of others" (p. 1). His research illuminated the central role that work plays in our lives as "an essential building block for a life well lived" (Hodson, p. 4). I began to see synergies between Hodson's findings on dignity and such things as the distress or joy that nurses experience as a result of their work, their resistance to change or the push to expand practice, their drive to innovate, or their attachment to historical practice. This thinking evolved into a desire to explore a number of areas: dignity as a central moral and ethical value in nursing; the notion of dignity as a self and other-regarding concept; dignity as a work related construct for nurses; and the consequences of the maintenance or infringement of dignity for nurses. The purpose of the study was to begin to investigate these areas and to inform understanding of 
the role that dignity plays in the work lives of nurses. In other words, how dignity is understood, experienced, sustained, and challenged.

\section{Scanning the field}

In order to position the study in the context of what is already known in this area, a literature review was undertaken (Chapter 2) that focused on the key elements being explored, dignity, and dignity as experienced in nursing work. Hodson's (2001) research provided a theoretical framework to examine what is currently known about dignity for nurses in their work lives. The literature review provided an entry point and also shaped the study by providing some early insights into how nurses may view and experience dignity in the context of their work. Reviewing the nursing literature through the lens of Hodson's findings, it became apparent that the dignity of nurses as an intrinsic human and worker right, has received little explicit attention, and that the significance of this is possibly not sufficiently well understood.

\section{Positioning the study}

These and other insights gleaned from the literature supported the development of a theoretical framework to support the research. The framework, presented in Chapter 2, provides an illustration of the area under inquiry; the intersect where work and dignity meet for nurses, and also positions the central question of the study:

How do clinical nurses understand, experience, and sustain dignity in their work lives?

\section{Designing an approach}

Chapter 3 presents the next stage of the research journey involving investigating research methods to identify and craft a design that would enable exploration of the central question. The insights gained through the literature review and my own preferences as the researcher influenced the decision to 
employ qualitative description as the methodology and a facilitated group workshop approach as the vehicle for data collection. Directed content analysis was chosen as the approach to managing the data.

\section{Exploration, discovery and representation}

In Chapter 4, the application of the research design is presented. The process proved to be an illuminating experience that included the privilege of spending two full days with the nurse participants. I was positioned in the study as researcher and facilitator, journeying with the group using narrative and group exploration to develop our collective understanding of dignity in the work context of nursing. Through immersion in the data and the application of coding, patterns and themes emerged that over time provided an organised description of how the participants understand, experience, and sustain dignity in their work lives. Through articulating their beliefs and expectations about dignity and the congruence and contradictions encountered, the participants painted a picture of the role and importance of dignity in their work lives.

\section{Findings}

The findings are presented and discussed in Chapter 5 in the context of the central research question. The participant's beliefs and expectations about dignity are articulated, and congruent and contradictory encounters with dignity that the nurses experienced are explored.

\section{Reconciliation and journey's end}

The research journey necessitated that to reach an end it was necessary to return to the beginning and consider how the new knowledge and insights that had been generated could find a 'fit' with what is already known. The two final chapters (6 and 7) provide a reflection on how my thinking has been shaped, what key insights need to be brought through and how this thread of inquiry might usefully be advanced. 


\section{Chapter 2: Scanning the Field}

Someone showed me a picture and I just laughed

Dignity never been photographed. (Bob Dylan, 'Dignity')

\section{Introduction}

When I first became interested in the area of dignity for nurses, it was with little direct or intimate knowledge of how nurses perceive dignity in their work lives. Accepting that dignity will always to a degree be a personal construction, I began by drawing on what dignity means for me as a nurse in practice. I was informed by my shared humanity, by my history, the culture I identify with, the society I live in, my experiences, and my emic perspective as a nurse. This tentative and personal understanding was then broadened through inquiring into what is known about dignity generally, about worker dignity specifically, and through relating this knowledge to what is known about dignity in the context of nursing work.

The overall aim of the literature review was to identify what is already known about dignity for nurses in the work context, to use this knowledge as the basis for identifying a central question, and to design a research method to support the inquiry. At first the approach appeared deceptively simple. After all, 'dignity' is a term familiar to most, 'work' appears to be accepted as a central human endeavour in which most engage in some form, and nursing is an area where I can claim some knowledge and familiarity. However, an initial survey of these three fields, 'dignity', 'work', and 'nursing', established that consistent definitions were needed before the relationship between and across could be meaningfully explored. Therefore in order to ground the key areas under study, the literature review began with an overview of the areas of dignity and work, followed by dignity in the context of work. The purpose of this overview was to provide a base level of understanding of these areas and to provide an entry point to explore the contemporary nursing literature. Hodson's (2001) 
theoretical model for dignity at work is presented and used as a lens through which to explore the relevant contemporary nursing literature.

\section{An exploration of dignity}

\section{Dignity as a human right}

Concepts of dignity preceded a word to enshrine it. It has been suggested that the idea of human dignity may have emerged from an evolving consciousness of the ability to be able to act to avoid pain or humiliation (Arora, 2008). Over time, dignity has been variably described and interpreted but remains a contested concept (Aldergrove, 2000; Lebech, 2004; Wood, n.d.). Various justifications have been made for assuming the right to dignity, among these the Christian view that dignity relates to man being made in the image of God (Zuniga, 2003) or that dignity relates to the superiority of the human species (Wood). Kantian ethics suggest that:

Dignity is a value that is incomparable and absolute. It cannot be measured against other values in this way, because it can never rationally be sacrificed or traded away for anything at all, not even for something else having dignity. Though human beings come and go, the value of a human being is absolute and irreplaceable. It cannot be substituted for, even by the value of another human being. (Wood, n.d. para. 5)

Whether a religious or secular perspective is taken, the central tenet has remained reasonably constant; dignity is considered to be a right that is conferred on us on the basis of our being human (Lebech, 2004; O'Neill, 1998).

The word 'dignity' itself is derived from the Latin, decus, relating to honour (Lebech, 2004), and also to dignitas, which originally related to a meritocratic concept that dignity is something that is earned, and associated with rank or status (Hodson, 2001; Sayer, 2007). The modern Western interpretation, democratised dignity, is the one that we are more familiar with in healthcare, particularly as it relates to patients (Mairis, 1993). The democratised version of 
dignity is enshrined in Article I of The Universal Declaration of Human Rights (1948) and relates to all human persons being invested equally with dignity:

\section{Article I: Universal Declaration of Human Rights}

All human beings are born free and equal in dignity and rights. They are endowed with reason and conscience and should act towards one another in a spirit of brotherhood.

Human dignity is proposed here as the foundation underpinning the justification for all other human rights (Lebech, 2004).

Dignity as a concept is commonly associated with worth, value, and autonomy (Gallagher, 2004; Griffin-Heslin, 2005; Sayer, 2007). Beyond this level of common agreement, dignity is a somewhat subjective concept that challenges attempts at definition (Gallagher; Griffin-Heslin; Mairis, 1993; Walsh \& Kowanko, 2002). Indeed Macklin (2003) goes so far as to describe dignity as "a useless concept in medical ethics" (p. 1420), arguing that most references to dignity are simply based on "respect for persons or for their autonomy" ( $p$. 1420). A reasonable counter to Macklin's argument would be that her own description provides a satisfactory definition, lacking ambiguity and far from "useless" in application.

Part of the difficulty associated with establishing a single concept based definition is that dignity is also a construct that has no meaning other than that which we choose to invest in it (Sayer, 2007; Zuniga, 2003). For example while Bayertz (1996a) holds that consciousness, autonomy, and will are the three central elements that "constitute dignity in Modern philosophy" (p. 76) he acknowledges the need for translation into "more precisely defined mores and values [and that even then] blurred edges necessarily remain" (Bayertz, 1996b, xix). Thus while the basic premise is seldom challenged, the meaning of dignity becomes the subject of interpretation, relating primarily to the social mores, culture, and values that allow it to exist, and the context in which it is experienced (Lebech, 2004). 


\section{The evaluation of dignity}

The evaluation of dignity relies on an individual's subjective perception of the presence or absence of specific characteristics that constitute dignity in a particular situation (Franklin, Ternestedt, \& Nordenfelt, 2006). As an example, Walsh and Kowanko (2002) in a study of nurses' and patients' perceptions of dignity found that both groups placed considerable importance on patient privacy as dignity promoting. Thus, while dignity is accepted conceptually to be a human value that should be upheld, the challenge is to be able to understand and articulate how dignity is constituted personally, socially, and in particular situations or contexts.

\section{Dignity as a personal and social construct}

Our personal construction of dignity is something that we acquire as part of a continuous social process that is shaped and affirmed by ourselves and others (Sayer, 2007). Therefore how we come to feel about our sense of self-worth and develop self-respect relates concurrently to how others show their respect and perceive our worth, and also to our personal interpretation (Lebech, 2004). Of these aspects, three areas primarily shape our constructs of dignity. First, dignity is linked to values, our own and others. Second, dignity is linked to rights, those we assert and those that others allow. Third, dignity relates to our personal beliefs and the beliefs of others. Essentially, dignity is both a self and other-regarding value involving moral reciprocity (Aldergrove, 2000; Jacobs, 2001).

\section{Dignity as expressed through mutual regard}

Lebech (2004) suggests that dignity "enjoys general acceptance all round the globe as a basic ethical and legal principle because it draws upon the universal experience of the dynamics of recognition" (p. 60). Thus it is of mutual benefit for people to subscribe to the idea that dignity exists in all persons and is sustained by reciprocal regard. With this idea of dignity as a self and otherregarding value in mind, the idea of 'personalism' was seen to go some way to reconciling this relationship. Personalism is a school of thought that evolved in 
the early $20^{\text {th }}$ century and has been interpreted from both a Christian (man as the son of God) and secular perspective. While not presented explicitly as a descriptor for dignity, personalism encompasses a description that is closely aligned to common concepts of human dignity; 'human persons, adequately regarded' (Burke, 1993; Jans, 1996). Where personalism differs fundamentally from individualism is that as well as recognising rights, it also encompasses the notion of duties, that is, responsibilities to others (Burke, 1993; Jans, 1996). Kantian moral philosophy is essentially personalist in that it "demands equal respect for all persons and forbids the use of another person merely as a means to one's own ends" (Schulman, 2008, p.10). Kant's moral philosophy articulates dignity as integrally linked to the rights of self and others.

In considering the statement 'human persons adequately regarded', the first part, 'human persons' is the least contested in our society. To be human is to have a right to dignity. The second part, 'adequately regarded' requires us to consider the implications from both a social perspective and to view dignity in the context in which it occurs. To feel 'adequately regarded', to establish and sustain a sense of dignity, we require the input of others (Haddock, 1996). Dignity therefore is both self and other-regarding; I hold it within myself and I also have the power to bestow it on others. Therefore, whether we are considering our own dignity, or acting to uphold the dignity of another, some basic shared understanding applies. Our personal construction of dignity and our understanding of what others might desire is shaped by our shared humanity, by history, the culture we identify with, the society we live in, our social group, and our experiences (Haddock, 1996; Sayer, 2007; Walsh \& Kowanko, 2002). For nurses, the construction of dignity is also influenced by the values, beliefs, and expectations shared by the professional group.

\section{Dignity as context specific}

As stated earlier, the conceptual right to dignity as a 'human person' is rarely contested in our current society (Sayer, 2007). How we view 'adequately regarded' is an ongoing social construct which ideally would be esteemed and protected in all contexts. In reality, dignity is understood, esteemed, and 
protected in some contexts more than others and is a source of ongoing tension and negotiation. Nursing for example has enshrined patients' dignity as a given. As a citizen or worker on the other hand, the right to dignity is somewhat conditional on conforming to societal expectations. For example the status that is accorded to the unemployed and the notion that somehow they have contributed to their own situation, or the worker being expected to earn respect (Sayer, 2007). These attitudinal or conditional approaches to dignity would appear to relate more closely to the meritocratic interpretation of dignity than the democratised version. The key point is that dignity, while widely accepted as a human right, is vulnerable to both interpretation and prejudice in particular contexts. For the purpose of this study, the context of most interest is the work setting.

\section{A working definition of dignity}

The working definition applied to the study interprets dignity as a human right that is commonly associated with worth, value and autonomy. Further, dignity is considered as both a self and other-regarding value that is perceived individually, sustained through social interaction, and is specific to both the individual and the context in which it is experienced.

\section{Dignity in the context of work}

To understand the relationship of dignity to work it is necessary to clarify the meaning of 'work'. The notion of work and the influence that it plays in our lives and societies has been a subject of interest for millennia.

\section{Work as socially constructed}

The division between labour and leisure was possibly established in hunter/gatherer societies but was accentuated by a move to agriculture and farming (Donkin, 2001; Hill, 1996). As communities became more formally organised with clear demarcation of roles and activities, work emerged as distinct from simply "what needed to be done" (Donkin, p. 8). 
Mankind's understanding of 'work' has changed over time and has been subject to political, cultural, and religious influences. The Judeo-Christian belief system is underpinned by the idea of work as "punishment by God for man's original sin" (Hill, 1996, p. 3). This has strongly influenced Western attitudes to work. Of the more recent influences, three are of particular relevance. First the influence of the Protestant work ethic that idealised work as virtuous in its own right (Hill). This influence saw a significant shift from valuing work because the product of the work was meaningful (crafts, guilds, food production), to viewing the act of work as meritorious, regardless of the product of the labour (Donkin, 2001; Hodson, 2001). The Protestant ethic emphasised "diligence, punctuality, deferment of gratification, and primacy of the work domain" (Hill, p. 6). The belief of work as virtuous supported the rise of capitalism and contributed to the idea of work as a "social duty" (Hill, p. 6).

Hard work brought respect and contributed to the social order and well being of the community. The dignity with which society viewed work brought dignity for workers as well, and contempt for those who were idle or lazy. (Hill, p. 6)

Second, and also arising from the Christian perspective was the notion of work as a 'calling', an idea that has been particularly pervasive in nursing (Donkin, 2001; Hodson, 2001). The third but no less powerful influence arose from the widespread industrialisation of labour that resulted in a focus on streamlined production, profit, role enlargement, and work intensification (Donkin; Hill, 1996). Collectively these three influences have contributed to contemporary attitudes to work, including nursing, which emphasise hard work and altruism as virtuous and worthy of respect, while having the potential to reduce the worker to the status of an instrument of production. There are inherent tensions between these perspectives. 


\section{Dignity at work}

Much energy and attention continues to be applied to understanding modern work and the modern worker. However, the idea of dignity in the context of work is a relatively recent feature in the management and social science sectors (Hodson, 2001). Until recently the sociological focus has been on how work and the environment of work impacts on workers as a predominantly passive process (Sayer, 2007). As will be shown, workers are active agents, individually and collectively shaping and resisting external forces generated by the work and the work environment (Donkin, 2001: Hodson; Sayer).

Hodson (2001) believes that the work environment poses inevitable challenges to worker dignity and the rise of the labour movement has been argued to have been as much about respect and recognition as about material gain (Sayer, 2007). Sayer argues that "the instrumental and unequal character of organizations make relations of respect and recognition and hence, dignified employment, difficult to achieve" (p. 566). The notion of instrumentalism is implied in the common work title 'employee'. "By definition, the employees are hired as a means to their employers ends, not out of a sense of benevolence or respect" (Sayer, p. 569). This, Sayer contends, coupled with the hierarchical and unequal power relationships that define many workplaces, poses considerable challenges to workers achieving dignity.

There is a sense that the dominant version of dignity in the work context may be more meritocratic than democratic. Dignity in the work context is generally assumed to be a personal responsibility earned through one's efforts and actions (Hodson, 2001; Sayer, 2007). This raises the possibility that the dignity of a worker is viewed as conditional on the worth attached to their work, rather than their personhood. Haddock (1996) raises this possibility when she states that while the humanity of nurses is appreciated, '"good' nurses have qualities of 'knowing' and 'doing', with little acknowledgment of them 'being', or even existing in the same human capacity as patients" (p. 294). 


\section{Relating dignity to the context of nursing work}

A literature search was undertaken to identify where dignity appears in research relating to nurses and the work of nursing. Multiple databases were searched including, the Cumulative Index to Nursing and Allied Health Literature (CINAHL), MEDLINE, Health Business, Psychology and Behavioural Sciences Collection, Soclndex and the Nursing and Allied Health Collection.

\section{Dignity as a concept and value in nursing}

The literature review revealed that the nursing profession has taken a particular interest in dignity as a concept and a value. References to dignity appear extensively in nursing professional codes and literature relating to the practice of nursing. The finding of a dominant focus on dignity from the patient perspective was not surprising as nursing holds the concept of patient dignity as a central moral and ethical value (Franklin et al., 2006; Kalb \& O'ConnerVon, 2007; Walsh \& Kowanko, 2002). The privileged intimacy that characterises the relationship between nurse and patient connects the actions of the nurse with the patient's experience of dignity:

The tradition of nursing care is lodged in an explicit value - that it is our job to help others do what they would do for themselves if they had the strength, will, or knowledge...dignifying the individual with all his personal history, idiosyncrasies, needs, values and desires. (Diers, 2004, p. 202)

Nursing then, has embedded dignity, particularly the dignity of others, as a core value for practice. Jacobs (2001) goes so far as to suggest that "Nursing is [emphasis added] respect for human dignity" (p. 26).

While the practice of nursing is deeply concerned with the achievement of patient dignity, the inclusion of dignity in nursing literature as a self-regarding professional right was much less well articulated and where it did appear, interpretation of how dignity is constituted was uncommon (Gallagher, 2004; 
Mairis, 1993). A secondary search of nursing and health databases using search terms including 'worker dignity,' 'professional dignity' and 'ethical workplaces', combined with 'nursing' yielded few results suggesting that there has been little research looking explicitly at the notion of work-related dignity.

However the literature was not completely silent on the notion of nurse dignity. Hofmeyer, in a 2003 opinion paper, touched on elements of dignity in making the case for improving the work life quality for nurses as a "moral imperative" (p. 11). This introduced the possibility that dignity in the context of nursing work goes beyond the 'duty' of the nurse to protect and uphold the dignity of the patient. The idea of the workplace as requiring a shared moral order introduces in a lateral sense the notion of dignity as a mutually regarding social process (Paley, 2004; Peter, Macfarlane, \& O'Brien-Pallas, 2004). The American Nurses Association Code of Ethics makes a more direct reference to dignity as a self-regarding value. "The nurse owes the same duties to self as to others, including the responsibility to preserve integrity and safety, to maintain competency, and to continue personal and professional growth" (Milton, 2003, p. 301). Kalb and O'Conner-Von (2007) in a study of graduate nurses explored their understanding of respect for human dignity including respect for one's own dignity. Similarly, Gallagher (2004) explored the idea of dignity in nursing practice as both self-regarding and other-regarding and proposed that:

When the worth, value or dignity of nurses is not respected in tangible ways then their own self-respect may be compromised and their ability to respect the dignity of patients, families and colleagues is reduced. (p. 592)

Gallagher (2004) was expressing an opinion that by being self-regarding, a nurse is more able to be other-regarding. However, Gallagher goes on to suggest that dignity as a self-regarding value involves principally benefit to the self, while dignity as an other-regarding value involves benefiting others. This apparent contradiction may be at the heart of an ongoing tension for nurses seeking to balance their own needs and the needs of patients. This sits with the Christian interpretation of personalism which "particularly stresses duties 
towards other persons, and sees the fulfilment of these duties also as a means of personal growth and self-fulfilment" (Burke, 1993). What Burke was suggesting was that regard for the dignity and rights of others is an integral component in achieving personal dignity. In a 2005 study examining dignity in the work lives of caregivers, Stacey makes a case for the sense of dignity of the care worker being in part drawn from "constant and often very intimate, social interaction" (p. 850). The provision of care, and in particular undertaking 'dirty work' translates into a "sense of pride and even moral authority" (p. 850) that supports the caregiver's sense of dignity. These studies suggest that the complex role that altruism may play in nurses' constructions of personal dignity merits further exploration (Fagerrmoen, 1997; Haddock, 1996).

In summary, there was agreement that dignity as a concept is commonly accepted to be a human right, and there did not appear to be dissent regarding nurses' right to dignity. However based on the paucity of research on this topic, it appeared that our current understanding of nurse dignity both as a concept and a construct is poorly described and under-explored. Furthermore, it seemed likely that nurse dignity is linked in complex ways to the achievement of patient dignity and that the implications of this are not well understood.

In the absence of evidence that explicitly addressed the idea of nurse dignity, one could have concluded that because direct references to dignity in nursing work could not be established, there would therefore be nothing of substance in the nursing literature to inform this study. However, Hodson's (2001) seminal research into dignity at work provided an entry to the nursing research to ascertain whether nurse dignity is indeed receiving research attention in other approaches, but is being obscured by the use of alternative language and descriptors. Hodson's work merits further discussion as it provided this study with a theoretical lens through which to examine the nursing literature.

\section{Hodson's theoretical model for dignity at work}

Hodson's (2001) research into dignity at work provides an empirically grounded theory that describes both the characteristics of dignity and the importance of 
dignity in workers' lives. Hodson defines dignity at work as "the ability to establish a sense of self-worth and self-respect and to appreciate the respect of others" (p. xiii). Hodson's research involved a major study; the Workplace Ethnography Project. The study resulted from Hodson's desire to better understand "the daily struggle for dignity at work and the central place it occupies in workers' lives" (p. xiii), and from there to develop a model of workplace dignity. The achievement of dignity at work according to Hodson, is through workers engaging in "creative and meaningful productive activities" (p. 264).

Key theoretical influences for Hodson's (2001) research were provided by eminent workplace theorists and included Marx's views on worker exploitation and alienation; Weber's ideas on rational calculation; and Durkheim's perspectives on work anomie and the need for a shared moral order. The methodology involved undertaking a quantitative, systematic review of published, book-length, English language workplace ethnographies that focused on the nature of work or the labour process (Hodson \& Roscigno, 2004). Through in-depth analysis of the ethnographies in the study, Hodson identified the behaviours that workers employ to "adapt to, challenge and make sense out of the structures they confront" (p. 50) in the pursuit of workplace dignity. Inclusion criteria required ethnographic observation to have taken place over at least six months, to have been based on a single organisation, and to have focused on at least one specific group of workers. A total of 204 cases were used in the analysis.

The active pursuit of dignity at work occurs according to Hodson (2001) within an organisational framework that is defined by "management behaviour, organisational structure, and technology" (p. 20). The research found the principal challenges to working with dignity to be: mismanagement and abuse, overwork, limits on autonomy, and contradictions of employee involvement. The principal strategies that workers use to maintain and defend their dignity against these challenges were identified as: personal agency, expressed as either resistance or citizenship behaviour; the creation of independent meaning systems; defence of autonomy; and the development of social relations at 
work. Analysis of the significance of the interplay between various configurations of the challenges and strategies provided the basis for the conclusions of the study and subsequent post-research analysis (Hodson \& Roscigno, 2004).

Hodson (2001) concluded that the mechanism through which worker dignity and organisational success are achieved is a "complex interaction of structure and agency [that is characterised by] a simultaneously collaborative and conflictual agenda of production" (p. 20). This notion of worker agency is studied as a key theme that supports understanding of not only the social structure of work but also the role of workers' active agency in pursuit of working with dignity. Agency is defined by Hodson as "the active and creative performance of assigned roles in ways that give meaning and content to those roles beyond what is institutionally scripted" (p. 16). The degree to which agency will manifest as collaboration or conflict was found to be closely related to characteristics of both the workplace environment and the workgroup itself. For example, Hodson identified that in rigid, controlling, or poorly managed workplaces, resistance behaviour predominates; while under better organised, participatory regimes, citizenship behaviour is employed and positive worker agency is a feature.

There was much in Hodson's (2001) research to challenge thinking about how the influence of organisations, the work of nursing, and the actions of nurses may relate to the constitution of nurse dignity. Hodson's theoretical model for worker dignity was used in this study to review the contemporary nursing literature. In particular, the factors that Hodson identified as sustaining or infringing worker dignity and the notion of worker agency were probed for using multiple databases.

\section{Dignity within the context of nursing work}

An initial search elicited evidence of extensive investigation into the work environments of nurses from multiple perspectives and employing diverse methodologies. In fact, the volume of information proved problematic. Nursing 
has been described, measured, analysed, quantified, and deconstructed using both qualitative and quantitative approaches, possibly to a greater degree than any other health professional group. Accordingly this section of the literature review took the form of a literature overview focusing on identifying relevant examples from within the wide range of published research. Selected examples are used to illustrate the main approaches that were uncovered.

While it was found that nurse dignity as a distinct concept did not feature in the literature, the collective body of nursing, management, labour studies, organisational, and related health research provided rich description of the structural and social organisation of nursing work. Factors such as coherent work organisation, autonomy, freedom from abuse, and reasonable workloads that were identified by Hodson (2001) as the cornerstones of worker dignity have been extensively examined in nursing from a variety of perspectives. The main perspectives included the relationship between nursing, nursing work environments and the patient experience (particularly outcomes), the impact of workplace characteristics on the maintenance of the nursing workforce, and the effect of specific workplace characteristics on nurses themselves. In the interests of coherence, selected examples that illustrate these main approaches are cited, followed by a section linking the research to Hodson's findings.

\section{The relationship between nursing practice, nursing work environments and the patient experience}

It is generally accepted that there is a direct and critical relationship between nursing work, nursing work environments, and the patient experience, particularly patient outcomes. Consequently, significant research attention has been given to understanding this area. Approaches that consider workplace characteristics include for example, 'magnet hospital' research, nurse sensitive indicators, workplace culture, and error. The 'magnet hospitals' research has arguably provided the foundation for much of the related international body of published research examining nursing workplace characteristics that has been undertaken in the past 10 to 15 years. 
Research into 'magnet hospitals' identified measurable characteristics of nursing work, such as nurse autonomy, skill-mix, inter-professional relationships, and work organisation that relate to nurse satisfaction and consequently to patient outcomes (Aiken \& Patrician, 2000; Aiken, Sloane, Lake, Sochalski, \& Weber, 1999; Flynn, Carryer, \& Budge, 2005; Friese, 2005; Kramer \& Hafner, 1989; Kramer \& Schmalenberg, 2008a; Laschinger, Shamian, \& Thomson, 2001; Needleman, Buerhaus, Mattke, Stewart, \& Zelevinsky, 2002). An allied body of research interested in the relationship between nursing practice and specific 'nurse-sensitive' patient outcomes has identified elements relating to nurses' work environments including autonomy, organisational culture, work organisation, and relationships (McCloskey \& Diers, 2005; McGillis Hall, 2005; "Safe Staffing”, 2006).

Workplace culture has been studied using various research approaches and has linked factors such as; trust, autonomy, teamwork and empowerment; with organisational effectiveness, nurse outcomes, and patient outcomes (Allen, 2004; Ash \& Seago, 2004: Fox, Henderson \& Malko-Nyhan, 2005; Kramer \& Schmalenberg, 2003; Kramer \& Schmalenberg, 2008b; Laschinger et al., 2001).

International interest in patient safety, risk, and error in healthcare has also resulted in a body of research examining specific characteristics of nursing work environments. For example, the Institute of Medicine (IOM) in a widely cited 2004 report identified that "the typical work environment of nurses is characterized by many serious threats to patient safety...relating to organizational management practices, workforce deployment practices, work design, and organizational culture" (Page, 2004, p. 3). Other similarly oriented research identified that factors present in nursing work environments such as overwork, time-pressure, unlimited production, and workplace culture can be linked to an increased risk of adverse events and to negative nurse outcomes (Amalberti, Auroy, Berwick, \& Barach, 2005; Cohen, 1999; Friese, 2005; Goodman, 2003; Hughes \& Clancy, 2005; Katz-Navon, Naveh, \& Stern, 2005). 


\section{Workplace characteristics and the maintenance of the nursing workforce}

The need to attract and retain nurses globally has spawned a body of research interested in positive workplace characteristics. In 2002 the Joint Commission on Accreditation of Healthcare Organizations made recommendations for redesigning workplaces and workplace cultures with the aim of empowering, valuing, and rewarding nurses ("Healthcare at the Crossroads", 2002). Among the more recent publications on this topic is a 2006 report undertaken by the Canadian Health Service Research Foundation, reviewing six major research documents relating to workplace characteristics (Priest, 2006). While the primary interest of the inquiry was the effect of the current nursing shortage on healthcare, the report found that the working environments of many nurses have deficiencies relating to workload, health and safety, ineffective management, relations with other professionals, leadership, professional development, and work life balance. The report concluded that "overall there are few indicators that front-line nurses are experiencing a better working life" (p. 21). Related research has reached similar conclusions, identifying meaningful work, employee involvement, stakeholder support, models of work organisation, the provision of education and the 'culture' of nursing as significant factors in nurse satisfaction and retention (Harulow, 2000; Health Canada, 2007; "Safe Staffing", 2006; Van Laar, Edwards, \& Easton, 2007). In 2007 the International Council of Nurses produced an information and action tool kit aimed at supporting the development of positive practice environments. The publication brings together evidence linking workplace quality to the quality of patient care (Baumann, 2007). The stated purpose of the toolkit was to "raise awareness and stimulate action" (p. 59) around the need for quality work environments for nurses. 


\section{The effect of specific workplace characteristics on nurses}

Research examining how workplace characteristics affect nurses has been undertaken, although in a much smaller volume than the research primarily focused on patient outcomes or the maintenance of the nursing workforce. Rose and Glass (2006) in a study examining the relationship between emotional wellbeing and satisfying professional practice suggest that "nurses' wellbeing [is] not afforded the same status or health care priority as that of their clients" (p. 27). The major areas of interest have focused on the negative effects of workplace environments on nurses, including elements such as overwork, lack of autonomy, workplace bullying, professional error, values conflict, stress and gender oppression (Cheng, Kawachi, Coakley, Schwartz, \& Colditz, 2000; Corley, Minick, Elswick, \& Jacobs, 2005; Davies, 1996; Davies, 2003; Kidd, 2008; Laschinger, 2001; Peterson \& Wilson, 2002; Wolf, Serembus, Smetzer, Cohen, \& Cohen, 2000).

Considine and Buchan (1999) articulated the negative consequences to nurses of overwork. Similarly Cheng et al. (2000) identified better health status in nurses with higher levels of job control, lower levels of job demands, and higher levels of work related social support.

Workplace bullying, often referred to as horizontal violence, has attracted an increasing amount of interest in nursing over the past ten years. Bullying is generally accepted to be a significant workplace issue for the nursing profession involving both co-workers and supervisory levels (Hofmeyer, 2003; McKenna, Smith, Poole, \& Coverdale, 2005; Sweet, 2005). Particular characteristics of professional or occupational groups have been found to contribute to the incidence of co-worker aggression (Griffin, 2004, Hodson, 2001). For example in nursing, oppressed group behaviour has been cited as a contributory factor in horizontal violence (Gallant-Roman, 2008; Griffin, 2004, Kidd, 2007). Roberts (cited in Gallant-Roman) attributes this phenomenon to "nurses' lack of autonomy, accountability, and control over the nursing profession" (p. 450). Martin (2008) found that co-worker aggression "has a negative effect on patient satisfaction, staff performance, and - in more recent 
studies - quality of care" (p. 23). Martin, for example cites a 2004 study by the Institute of Safe Medication Practices that showed that "7\% of respondents had been involved in a medication error in the past year in which intimidation played a role" (p. 24).

Phenomena such as burnout, moral distress, values conflict, and absenteeism have been researched in an attempt to link workplace characteristics with negative outcomes for nurses, patients, and organisations (Altun, 2002; Corley et al., 2005; Kelly, 1998; Lutzen, Cronqvist, Magnusson, \& Andersson, 2003; Schluter, Winch, Holzhauser, \& Henderson, 2008; Takase, Maude, \& Manias, 2005; Verplanken, 2004; Zuzelo, 2007). A body of inquiry arising from the sociological literature has examined the effect of gender on nursing from professional, political, and feminist perspectives (Davies, 1996; Davies, 2003).

Relatively recent work initiated by labour unions in bi-partite relationships with employers has contributed to raising the general profile of the effect of workplace characteristics on nurses through the promotion of 'healthy workplace environments'. A recent example from the New Zealand context was the commissioning of a national joint employer/union committee, tasked with investigating and defining the essential components of safe staffing and healthy workplaces required by nurses ("Safe Staffing", 2006). The committee concluded that a range of elements including the cultural environment, a focus on quality and safety for all, appropriate authority and leadership, and suitable technology and support, are required to deliver a "well organised, healthy, care delivery environment" (p. 8).

\section{Synthesis of the nursing literature with Hodson's research}

The large amount of research attention examining both dignity and nursing workplace environments suggests that both are areas of current interest and concern. The collective body of research has generated significant knowledge and data. However, while there is a large degree of coherence between nursing research and Hodson's (2001) findings, the conclusion that nurse dignity has received attention as an important concept for nurses themselves 
could not be supported. Reviewing the nursing literature through the lens of Hodson's findings, it becomes apparent that the dignity of nurses as an intrinsic human and worker right has received little explicit attention.

Why might this be so, given that the connection has been made in the nursing literature between the achievement of patient dignity, promotion of nurse wellbeing, and nursing work environments? Part of the answer may be, as already mentioned, that research into the dignity of workers has only recently been given significant attention in the management and social science disciplines. The current body of nursing research may reflect this trend (Korczynski, Hodson, \& Edwards, 2006). However, the literature review raised the possibility that the clear and dominant patient-focused discourse that is present throughout much of the nursing-related literature may be presenting an impediment to the explication of nurse dignity. This discourse appears to consistently privilege patient dignity over nurse dignity (Haddock, 1996). Even within research that purports to focus on providing a quality work environment for nurses, there is a strong tendency to cite patient outcomes as the primary justification for bettering the work environment. While this is understandable given the purpose of nursing work it raises the question that neglect or infringement of nurse dignity may be tolerated because there is an unacknowledged discourse, both organisational and professional, that nurse dignity should be subordinate to patient dignity.

There is some evidence to support this position. The altruism and professional commitment that characterises nursing and other professional groups leads, according to Hodson (2001), to a professional and public expectation that professionals will "put their clients' interests above their own when necessary" (p. 143). Hodson found that excessive hours of work are also associated with professional workers and that this helps to "substantiate the professional worker's claim to altruism - to self sacrifice for the benefit of clients" (p. 144). This fits with the findings of the literature review, which found that references to dignity in the nursing literature are often accompanied by a statement on the value of altruism in the nursing profession. In a study of 767 nurses, Fagerrmoen (1997) found that nurses hold patient dignity as a core value and 
that "the value of altruism or care for the patient's health and well-being [appears] to be an over-riding value" (p. 440).

It is worth considering whether the way nurses themselves construct their professional role and the way that society supports this view may be getting in the way of giving explicit attention to nurse dignity as an ethical and moral value. This perspective may also help to explain the degree of distress among many nurses that is currently evidenced by research. If we accept Hodson's model of worker dignity, it is reasonable to extrapolate that when deeply held professional imperatives are combined with negative workplace characteristics such as conflicting values, low levels of organisational coherence, and limits on autonomy, the scene is set for work environments that constitute significant challenges for nurses in relation to upholding and preserving their dignity.

Looking at the wide range of research, it is also impossible to ignore the role that environmental characteristics play in influencing how nurses carry out their work as well as their experience of work. Terms to describe positive work environments such as autonomy, control, empowerment, work organisation, and effectiveness recur throughout the literature and are generally associated with positive nurse, patient, and organisational outcomes. These findings concur with Hodson's (2001) finding that workplaces with the highest levels of worker autonomy, indirect supervision, and participatory decision making also exhibit the highest levels of citizenship behaviour and organisational effectiveness (Hodson \& Roscigno, 2004). Hodson's work and the nursing literature are in accord in finding that the work environment that nurses will find most effective is one where excellent organisation and structure are combined with low levels of bureaucratic and supervisory control and high levels of autonomy. Conversely, research into negative nursing environments frequently describes conflictual relationships, disorganisation, and unrealistic production targets (Lutzen et al., 2003; Priest, 2006). Hodson identified that in workplaces where there are chaotic systems of production, workers are more likely to withdraw co-operation through absenteeism and resignation and are less likely to engage in citizenship behaviour. Hodson found that the cycle of poor organisational coherence and worker resistance can become "part of a stable 
pattern of relations...intrinsic to such systems" (p. 87), and this therefore becomes the culture of the workplace and the organisation.

A second key finding from Hodson's (2001) research on worker dignity that supports nursing research findings was that low levels of autonomy, and high levels of direct supervision and bureaucratic control, impact negatively on nurses. Diers (2004), commenting on the role and power of autonomy in nursing practice suggested that:

It is a useless and draining exercise for a nurse to have the responsibility, but not the authority, or the accountability without the responsibility. When those three come together, the work role becomes coherent and the potential impact not only on patient care but on system reform is revealed. (p. 205)

This is in accord with Hodson (2001) who suggests that "the defence of autonomy is of utmost importance to professional and craft workers [and that] managers frequently seek to limit the autonomy of professional and craft employees in order to gain control of work and to organize it according to their own agendas" (p. 140). The nursing literature has consistently demonstrated the importance of autonomy to nursing practice. It has been identified that nurses require a coherent, participatory structure to support their work, and then expect to be given the trust and autonomy to carry out their professional roles.

The third area where nursing research and Hodson's (2001) research find a substantial level of agreement relates to the impact of overwork. Overwork was identified as a major challenge to worker dignity (Hodson \& Roscignol, 2004) and is currently one of the foremost issues cited by nurses (Lutzen et al., 2003; Priest, 2006). Gordon (2005), in her insightful book, Nursing Against the Odds, summarises overwork in nursing thus:

The first condition for easing the nursing crisis is to assure that the workload of working nurses will not crush them - that they will have 
the time and the psychological and physical energy to be effective on the job, to empathise with patients and to keep them safe from harm. (p. 496)

This statement epitomises the significance of the issue of overwork in many nursing work environments where there are no upper limits to production and little respite for efficiency. This means that one of the consequences of successfully managing workload is likely to be increased workload (McCloskey \& Diers, 2005; Priest, 2006; "Safe Staffing", 2006). This situation can be traced back to the move to a cost control focus in health care which began in the late 1980s and early 1990s. The new agenda fundamentally changed the way nursing work was organised and valued (Beil-Hildebrand, 2002; Hofmeyer, 2003; McCloskey \& Diers, 2005; Ritchie, 1995). Nurses were faced with either working harder or neglecting "their own ideas and standards about what is appropriate to adequate hospital care" (Beil-Hildebrand, 2002, p. 267). The result has been a chronic pattern of overwork for many nurses that has been demonstrated through anecdotal and research evidence (Lutzen et al., 2005; Priest, 2006). Applying Hodson's (2001) model, it seems likely (if not predictable) that any changes to work environments that result in a loss of shared values between nurses and their organisations will not only result in overwork, but also to increased levels of resistance activities, lower levels of citizenship, and an increase in phenomena such as moral distress and burnout. Hodson identified the consequences of overwork as a reduction in worker skill, autonomy, creativity, and work meaning with a resultant rise in absenteeism and resignations. All of these factors have been identified in the literature as prevalent in nursing.

It was clear that the characteristics identified by Hodson (2001) as the cornerstones of worker dignity, such as coherent work organisation, autonomy, freedom from abuse and reasonable workloads, have been identified and researched in the context of nursing work. However a common understanding of how dignity for nurses is constituted and experienced was absent and, I believe required further investigation. 


\section{Summary}

The literature review attempted to define and position the concept of dignity within the work of nursing. Few direct links were able to be established and the conclusion reached was that neither a definition nor construct of dignity in the work lives of nurses is currently explicable. However, while a direct fit was not achieved, by examining the current nursing literature through the lens provided by Hodson (2001) it was possible to find areas of synthesis.

The literature review resulted in an odd feeling of being simultaneously closer and further away from gaining an understanding of dignity in the context of nursing work. Closer in the sense that technically it would be possible to draw on the large existing body of knowledge and to apply this to Hodson's (2001) generic framework for worker dignity in order to begin to construct a tangible picture of dignity in nursing. However, this approach would require a considerable leap of faith that subscribed to the view that what is known about other occupational groups would be directly transferable to nursing. Unexpected findings such as the patient focused discourse and the fact that little of the nursing research paralleled Hodson's view that ethical work environments are a moral consideration, served to widen the gap between what could be considered 'known' in this area and what would need to be assumed. This was resolved through the development of a theoretical framework for the study that positioned a central question within what is broadly known about dignity and dignity at work. The framework leaves space for both moral and practical elements to be explored. The following section presents the framework and discusses how this influenced both the research question and the research design. 


\section{Positioning the study}

Drawing on the literature relating to dignity and work it seemed likely that nurses develop an understanding of both through exposure to societal values, societal mores, societal interaction, and professional influences. In terms of uncovering this understanding, several implications were identified during the literature review that required consideration in the research design. It became apparent that one of the challenges in addressing the research question related to nurses' current awareness of the area under study. If as it appeared, nurses in the main had not given much thought to their own dignity as workers, how could one ask them to discuss and illustrate their understanding and experiences? Related to this challenge was the need to manage the potential influence of the patient focused discourse with its attendant privileging of patient needs and associated altruistic behaviour on the part of nurses. The implications of this were twofold. First there was the concern that the patient focused discourse may obscure nurses being able to differentiate their own dignity from that of the patient, and second the possible role of altruism in sustaining nurses' dignity was as yet unclear.

A final but significant challenge lay in the possibility that the process of uncovering and examining personal dignity could have an unintended and possibly distressing outcome for nurses participating in researching this area. The framework was developed in response to these concerns and was intended to provide a structured space within which to articulate what is largely an internalised or sub-conscious understanding of dignified work. The theoretical framework (Figure 1) illustrates where work and dignity meet, both conceptually and as experienced. 

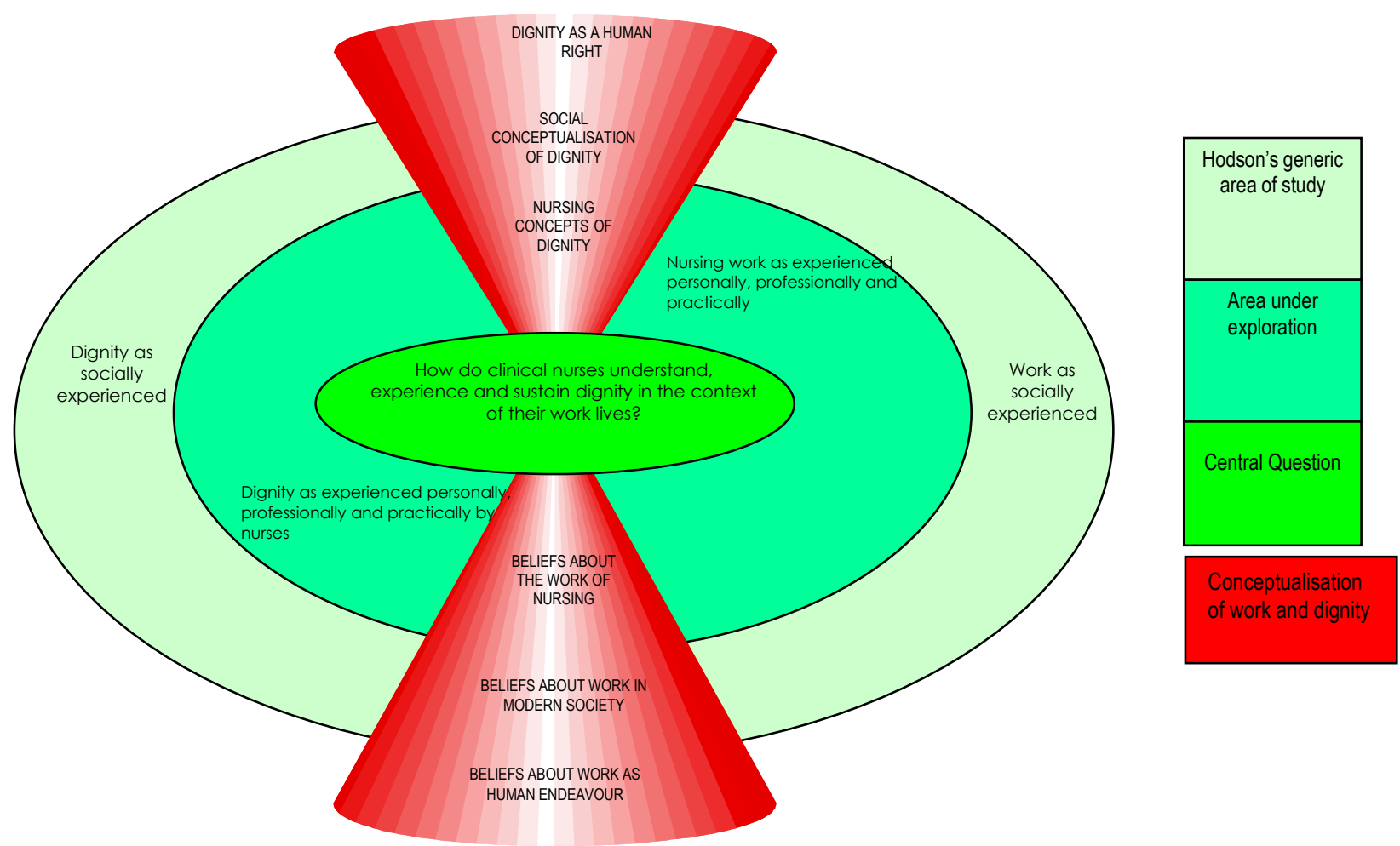

Figure 1

The red areas illustrate two lenses through which a nurse conceptualises dignity at work. The top lens represents dignity conceived broadly as a human right, as shaped by values and expectations, and by the perspectives of nursing. The base lens incorporates general beliefs about work generally and in particular the work of nursing. The ringed areas of the framework represent work and dignity as socially experienced. The outer ring corresponds broadly to Hodson's (2001) generic findings on worker dignity and to what could be considered 'known'. The middle ring represents work and dignity as experienced personally, professionally, and practically through engaging in the work of nursing. Implied within this ring are the elements that sustain or infringe dignity. The inner ring locates the central question that underpins the study: 
How do clinical nurses understand, experience, and sustain dignity in the context of their work lives?

Through exploring how nurses develop an understanding of dignity as it relates to them professionally, how they experience dignity in the context of work, and how they actively sustain personal dignity, it was hoped to provide new insights into this relatively uncharted territory. The framework illustrates an approach intended to enable the research participants to draw on their fundamental beliefs about both dignity and the work of nursing, and then to consider these in the context of their practice. 


\section{Chapter 3: $\quad$ Methodology and Research Design}

\section{Introduction}

This chapter covers the identification of an appropriate research methodology, describes the design of the study and discusses the methodological challenges that were accounted for. The use of facilitation as a valid method for data collection is explored and justified.

\section{Research question}

The first methodological challenge was the identification of an appropriate question. The question emerged from the literature review:

How do clinical nurses understand, experience, and sustain dignity in their work lives?

\section{Selecting the methodology}

The second methodological challenge in the research journey was to identify a methodology that was congruent with the area under study and which would enable valid exploration of the topic. It was evident from the literature review that exploring dignity in the work lives of nurses would require an approach that acknowledged both the paucity of knowledge in this area, as well as the inherently sociological nature of this inquiry. Hence it was not difficult to identify that a qualitative approach would be suited to addressing the research question. 


\section{Overarching orientation}

Qualitative research approaches are generally concerned with the social world, particularly relating to human experience and how this is influenced by context and situation (Connelly, 2007; Hansen, 2006). Denzin and Lincoln describe the utility of qualitative approaches in enabling us to "make sense of, or interpret, phenomena in terms of the meanings people bring to them" (2005, p. 3). Thus qualitative approaches are used not as a way of establishing 'truths' but rather to produce knowledge that allows us to make sense of the social world. Hansen (2006) suggests that "preferred methods for learning about the social world are those that emphasise human interpretation, inductive reasoning, holistic understanding, qualitative data, and contextualised explanation" (p. 6). While this general orientation clearly had a fit with addressing the area under study, this still left a daunting array of qualitative approaches to select from.

My initial preference was to frame the inquiry from a critical social perspective. This preference related to the experiences and influences that led me to initially inquire into the area of nurse dignity. As stated earlier, my interest in nurse dignity had its roots in areas such as ethical work environments, moral distress, burnout, disengagement, and error. I believed that one of the benefits of inquiring into the area of nurse dignity would be raising consciousness around the topic. Furthermore, I anticipated that continued research and discussion might enable transformation and emancipation to occur within the nursing and healthcare environment (Carr, 2005; Kincheloe \& McLaren, 2005; Manley \& McCormack, 2003). As Carr states, "the focus of critical theory is not to describe 'reality', but to change it" (p. 485). The difficulty this transformational imperative posed to my area of inquiry was that change emerges from understanding and critique, and the current lack of knowledge around nurse dignity was an impediment to both. Thus while a critical social orientation provided an underlying imperative for the study, the lack of existing data in this area led me to believe that an exploratory, low inference approach was required. Consequently, qualitative description was selected as having the ability to generate foundation knowledge within a broad critical social framework. 


\section{Qualitative description}

Qualitative description provides a low inference approach to addressing "complex, and contextually embedded questions" (Thorne, Kirkham \& O'FlynnMagee, 2004, p. 1) where there is limited understanding. It is also considered to be useful as a means of gaining new perspectives on problems or issues (Hansen, 2006; Sandelowski, 2000; Wright, 1993).

The low inference goal underpinning qualitative description aims to increase the likelihood that the knowledge generated will be free from the influence of "pre-existing theoretical and philosophical commitments" (Sandelowski, 2000, p. 337). That said, Sandelowski allows for the possibility of 'shadings' and 'hues' from other paradigms being apparent in qualitative descriptive research but without the explicit treatment or approaches required for example in a mixed method study (Broom \& Willis, 2007). 'Shadings' and 'hues' that influenced the design of this study include; issues of power, politics and social justice (critical social perspective); issues of gender and power (feminist theory); and issues relating to marginalised/oppressed groups (Kamberelis \& Dimitriadis, 2005; Roberts, 2000).

It was reassuring to discover that the low inference approach of descriptive research is able to be reconciled with a desire to address the potential need for change. "The goal of qualitative inquiry is not the mere accumulation of information, but rather the transformation of understanding" (Sandelowski, 1997 , p. 128). Sandelowski believes that while descriptive researchers seek to faithfully represent the data as it presents itself, inevitably the process of representation and featuring of the data begins to "transform that experience or event" (Sandelowski, 2000, p. 335). Thus while the goal of a low inference descriptive approach was sustained in my research, employing a process that would enable nurses to articulate their understanding and experience of dignity provided a foundation to further understanding.

Qualitative description is generally considered to be suited to areas of research where previous inquiry is limited (Sandelowski, 2000). The approach also 
provides the opportunity to deal with the data at a prima facie level (Sandelowski, 1997; Wright, 1993). The value of both characteristics to the area under investigation lay in the ability to describe the findings in a way that did not overlay particular nuances or beliefs, leaving room for ambiguity and inconclusiveness (Giorgi, 1992). Giorgi identified the risk of ascribing meaning over and above what is presented in our desire to understand or explicate, and suggests that the researcher can "in principle afford to wait out that [sic] inconclusive aspects of his or her research" (p. 130). This was of particular relevance to this study, where my intention was to begin to build understanding in an area where little knowledge currently exists. However, as Sandelowski (2000) states, the results of qualitative descriptive inquiry can be viewed as a "complete and valued end-product in itself, rather than as an entry point" (p. 335). In the case of this study, the data would provide both an end-product by faithfully articulating the understanding and experiences of the participants, and an entry point for future inquiry.

\section{Study Design}

The design of the study attempted to achieve a balance between a crafted individualised approach and the use of established methods. Within qualitative research, while there are many suggested approaches, there is no one gold standard. Sandelowski (1997) suggests that regardless of the approach, nurse researchers need to be "less encumbered by the (mythic) Scientific Method and more informed by the art of their work" (p. 127). Sandelowski is not rejecting rigour but is emphasising the need to balance strict adherence to the 'book' with the need to craft an individualised approach. The design of the research gave consideration to the four criteria for evaluating qualitative research proposed by Guba and Lincoln (cited in Zhang \& Wildemuth, 2006): credibility, transferability, dependability, and confirmability. Hsieh and Shannon (2005) also propose that transferability of methods and analysis is important to account for potential bias toward existing theory, preconceived ideas that the researcher may bring, and unintended influence on participants. This was also considered. 
The scope and size of the research design was also influenced and limited both by the parameters of the topic under study and the requirements for the thesis. These requirements determined that the study would need to be small and tightly described. This had a bearing on both the numbers of participants and also the quantity of data collected.

The research design sought to address four research imperatives: designing a process that would generate rich data for analysis; selecting a method of data analysis that was low inference and which would have a high level of internal validity; ensuring a design that would enable reporting and translation of the data in a way that was robust and accessible; and identifying and accounting for the needs and safety of the research participants. All were considered necessary to achieve an outcome that would be considered rigorous, trustworthy and ethical. The attention paid to these requirements individually and collectively is demonstrated both in the design and execution of the study.

\section{Ethical considerations}

Ethical approval for the research project was sought from and granted by the Human Ethics Committee of Victoria University of Wellington (Appendix One). In addition to the standard ethical considerations of research involving human participants, the main ethical implication identified was the potential for cognitive dissonance amongst the participants. This related to the possibility that the participants may experience a level of distress due to raised consciousness around the area of self-regarding dignity. This was accounted for in the research design through the use of a process that gave explicit attention to the participants' experience and wellbeing. The safeguards that were applied are elaborated in the section detailing the design of the data collection phase.

\section{Treaty of Waitangi considerations and obligations}

The Treaty of Waitangi is the founding document of New Zealand and confers special obligations on citizens to consider how the cultural integrity of Tangata 
Whenua is acknowledged and protected (He Wakaputanga, n.d.). This study focused on nurses as an occupational group and it was considered that the small size of the study did not provide the scope to include a specific bi-cultural dimension; however the study design allowed scope for the participants to identify cultural or indigenous perspectives as a key aspect of dignity. I acknowledge that were I to undertake future larger scale inquiry into this area, this would require exploration and inclusion of an indigenous perspective to have validity in the New Zealand context.

\section{Setting}

The study setting was chosen to be geographically manageable for both the researcher and participants. The maximum travel distance for participants was 110 kilometres. A range of clinical settings were targeted to provide diversity of data and confidentiality for participants.

\section{Recruitment and sampling strategy}

Purposive sampling was chosen as the strategy to recruit participants to the study (Hansen, 2006; Sandelowski, 1995). Sandelowski suggests that "purposive sampling for demographic homogeneity and selected phenomenal variation" (p. 182) is a valid strategy to enable small studies with limited resources to produce "credible and analytically...significant findings" (p. 182). In terms of actual sample size, Morse (1994) recommends a sample size of around six participants for qualitative studies focused on examining experiences. Sandelowski succinctly sums up the sampling goal in qualitative research as a delicate balance:

An adequate sample size in qualitative research is one that permits by virtue of not being too large - the deep, case-oriented analysis that is a hallmark of all qualitative inquiry, and that results in - by virtue of not being too small - a new and richly textured understanding of experience. (p. 183) 
Consequently, taking the goals, approach, and limitations of the study into account, it was decided that a maximum of nine participants would be recruited, and that the inclusion criteria would aim to provide a fairly homogeneous sample drawn from within a common demographic of clinical inpatient wards. The rationale to increase the number recruited from the recommended six to nine was to support a group facilitation process and also to allow for the possibility that some participants may withdraw prior to or during the research. The invitation to participate was to be included as an insert in the journal of the New Zealand Nurses Association (NZNO), Kai Tiaki (Appendix 2).

\section{Inclusion criteria}

Eligibility for participation in the study was initially based on three criteria. Participants had to be registered nurses who were currently employed in general clinical inpatient settings and who had attained proficient or expert level on the Professional Development Recognition Programme (PDRP). Participation was limited to this group for three reasons. First, this group was considered to represent the largest demographic of practicing nurses. Second, this group, having obtained 'proficient' or 'expert' level on the PDRP, would have considerable practice experience. Third, the findings of the literature review for this study suggested that the influence of a patient-focused discourse may play a significant role in how clinical nurses perceive and experience dignity. I felt that widening the criteria to include nurses working in non-clinical roles may dilute the ability to observe this effect.

\section{Data collection}

The choice of methodology, and the decision to engage directly with nurses during the research was fairly straightforward. However certain features emerged during the literature review that posed significant challenges to the research design, principally to the data collection phase. Three particular challenges were identified. Two related to the collection of data and one related to the preferences and needs of the participants. In respect of the influence that 
this had on the data collection processes, a detailed accounting of the design of the data collection phase is provided.

\section{Challenges relating to the generation of data}

The lack of existing data around nurse dignity led me to conclude that many nurses may not have given their own dignity explicit consideration. This meant that the research design needed to account for the possibility that participants might be thinking about the concept of their own dignity for the first time. Therefore sufficient time would be required for participants to 'unpack' their thinking. This influenced the choice of a facilitated group process which aimed to allow sufficient scope and time to explore the territory and surface examples from the participants' practice.

The second challenge requiring consideration related to the appearance of a dominant patient-focused discourse in the literature; in particular, the importance that nurses' place on the primacy of patient dignity as a core professional value. This posed a unique variable not accounted for in Hodson's research into worker dignity generally. If I considered that nurses are socialised to view practice through the lens of 'patient first', the implication was that this bias could hinder the participants from genuinely considering their own dignity without also thinking about the discourse that affirms subordination of personal needs in the interests of the patient. The challenge therefore was to design the research in a way that would allow participants to surface and consciously account for this perspective by exploring and describing their own experiences of dignity. This awareness again influenced the choice of a facilitated group process.

\section{Challenges relating to the wellbeing of the participants}

Consideration needed to be given to identifying the likely preferred participation styles of the participants, including accounting for the likelihood of a mainly female group, who shared the common characteristic of belonging to a profession that has been acknowledged as exhibiting oppressed group 
behaviour (Roberts, 2000). This latter characteristic was of particular relevance to this study as I considered that the process of considering personal dignity may be similar to that experienced by oppressed groups undergoing an empowerment process. The study was designed to allow for the potential effect on participants of awakening consciousness around personal dignity. This influenced the decision to adapt an established facilitation model that involved group exploration and narrative in order to engage the group and manage the dynamics of the process.

Chase (2005) describes narrative as having the power to move beyond description, providing a medium to express "emotions, thoughts and interpretations, [and as a method of] retrospective meaning making" (p. 656). Hodson's (2001) key findings on citizenship and resistance behaviour among workers as an expression of agency in the pursuit of dignity, suggested that a methodology providing space for such narratives to surface would generate rich data. Second-wave feminist methodology suggests that focus groups can raise consciousness on the topic under discussion and that "one key function of focus groups within feminist work has been to elicit and validate collective testimonies and group resistance narratives" (Kamberelis \& Dimitriadis, 2005, p. 897). The value of these narrative descriptions to the study was considered vital. Until relatively recently, according to Hodson:

The founders of sociology...were only secondarily concerned with workers' struggles to achieve dignity. They focused on the social structures that limit workers' lives and limit their dignity and wellbeing. (p. 50)

Hodson argued that workers are "not passive victims of social structures" (p. 50) but are constantly exhibiting active agency in pursuit of dignity at work. In order to generate descriptive data the research design needed to create space for narratives of both resistance and citizenship to emerge. 


\section{Designing the data collection phase}

Collectively, the challenges outlined above coupled with the need to surface rich data, signalled the need for a researcher-led approach that was crafted to give sufficient regard to the preferred style and needs of the participants. The participants were, after all, the central data source for this study. Thus a decision was made to adopt a facilitated group process that would provide scope for the emergence of quality data within a safe setting. This was considered the most appropriate way to account for both the aims of the study and the methodological challenges. Denzin and Lincoln (2005) support the use of mixed approaches in identifying the need to adapt methodology and design to the area of interest:

We now understand that the civic-minded qualitative researcher uses a set of material practices that bring the world into play. These practices are not neutral tools. This researcher thinks historically and interactionally, always mindful of the structural processes that make race, gender, and class potentially repressive presences in daily life. (p. 1084)

Considering both the aims of the study and the methodological challenges identified, the facilitated group process that was chosen aimed to enable participants to; explore the concept of dignity as a concept in a safe supportive environment, identify narratives and moments from practice that exemplified dignity, and to have the opportunity to reflect on the implications of their raised consciousness.

\section{Crafting the facilitated group process}

Employing researcher as facilitator is an established qualitative research approach (Hansen, 2006). However the choice of a facilitated group process as the vehicle for data collection requires discussion as this represents a variation on more accepted qualitative approaches such as focus groups, action research, or interview. The nature of this study posed an interesting conundrum 
for me as the researcher. On the one hand, the overall aim of the study was descriptive and low inference. On the other hand my previous inquiry into the area surfaced the possibility that the process of exploring personal dignity might result in unintended consequences for the participants. The following section discusses the rationale for the choice of a facilitative design as methodologically sound as well as a valid approach for data collection and managing the safety of the participants.

\section{Facilitation as a research approach}

Facilitation is a method of supporting individuals or groups to achieve an agreed purpose. According to Hunter (2007):

Facilitation is the body of expertise associated with leading cooperative groups and cooperative processes. It is based on values of equal worth, full participation, consensus and celebration of difference. (p. 25)

The role of the facilitator is as an active guide on a journey towards achieving collective goals (Hunter, 2007). My personal experience as a facilitator was gained through my current role as a Practice Development Facilitator and supported by undertaking facilitation training. While facilitation, as described by Hunter is not commonly employed as a research method, the emergent discipline of Practice Development (PD) describes a methodological approach termed emancipatory PD (ePD), which employs facilitation as a central component.

Emancipatory Practice Development is utilised primarily as an evaluation method and emerges from the Fourth Generation Evaluation approach described by Guba and Lincoln (1989). In keeping with traditional facilitation goals, ePD as a method aims to transform and emancipate and "focuses on the social systems as well as on the individual/group's own practice" (p. 26). As previously stated, the intent of the study was not to transform or emancipate 
the experience of the participants; however it was recognised as a potential unintended consequence of delving into this topic area.

In their discussion on ePD approaches to evaluation, Manley and McCormack (2003) propose three benefits of relevance to this study: the achievement of a moral and authentic approach, valuing stakeholder contribution and the opportunity to share others' constructions, and increasing the likelihood of ownership of the knowledge generated. Similarly, Hansen's (2007) discussion on the evolving nature of interviews for data collection fits well with a facilitative approach where the process is seen as a "social occasion...whereby researchers and respondents jointly create social reality through interaction" ( $p$. 127). Thus group facilitation as a method was seen as a way to manage the risks inherent in the process, as well as resulting in a positive experience for participants and enriching the data through the opportunity for shared learning and exploration.

\section{Facilitation as a practical approach to data collection}

Advice and support around the design of the two facilitated workshops was provided by my thesis supervisor and a professional facilitator. The workshop plan was adapted and summarised from Hunter's (2007) four phase workshop design for facilitated groups, and influenced by Robert's (2000) model for working with nursing groups on issues relating to professional identity.

\section{Workshop design}

The workshop design provided a structure intended to support full participation, exploration, reflection, and shared learning. Paraphrasing Hunter's (2007) approach, the first phase focuses on getting full participation and includes, welcome, introduction, agreement on purpose, agreement on the process and clarification of group ways of working. The second phase is interested in exploring the group limits. The focus is broadly on exploring the ground to be covered, enlarging the vision, receiving input, deepening relationships, pressing the boundaries, clarifying, and summarising. Phase three is 
concerned with synergy, enlightenment, exploring possibilities, sustaining momentum, and achieving transformation of understanding. The third phase, completion, enables the group to complete conversations, declare achievements, draw out learning, reflect on outcomes, provide affirmation, give feedback on process and facilitation, and provide completion. The structure of the two workshops was designed to incorporate the key stages identified.

The format for this study differed from Hunter's (2007) model in one critical regard. This related to the purpose for which the group was to come together. Facilitation as a group process is commonly agreed to be a process to support the group to achieve their purpose. In this instance, while the participants had agreed to the shared purpose of participating in the study, the principal beneficiary and 'custodian' of the knowledge generated would be the researcher who was also in the role of facilitator. This meant that elements of the process proposed by Hunter needed to be adapted to reflect the overarching purpose of the sessions, which was to generate research data. Therefore while the process for the group-work was facilitative, it could not be considered to be facilitation in the strict definition of the term.

\section{Managing safety considerations in the process}

While Hunter's (2007) group facilitation model went some way to addressing the identified challenges, I was also influenced by Roberts' (2000) model for working with nursing groups on issues relating to professional identity. Roberts' model has been developed from existing oppressed group models and gives explicit attention to managing cognitive dissonance, enlightenment, and reconciliation. Roberts suggests that group processes undertaken outside of institutional environments provide the opportunity for "reflection on and exploration of their work worlds and the forces that influence it” (p. 78). The first phase of the model, unexamined acceptance, involves passive acceptance without any exploration. This mirrored the pre-study status of the research participants. The second phase, awareness, involves a beginning awareness and understanding. I related this to the need to provide participants with a 
range of methods to access their inner knowledge while exploring the concept of dignity. Denzin and Lincoln (2005) suggest that:

Subjects, or individuals, are seldom able to give full explanations of their actions or intentions; all they can offer are accounts, or stories, about what they have done and why. No single method can grasp all the subtle variations in ongoing human experience. Consequently qualitative researchers, deploy a wide range of interconnected interpretive methods, always seeking better ways to make more understandable the worlds of experience they have studied. (p. 21)

The third phase, connection, is the stage where Roberts (2000) suggests that "nurses make a linkage to other nurses built on the beginning of a new self and professional identity" (p. 79). The nurse seeks others to "share the emerging positive identity" (p. 79). I felt that this could be accounted for in a group process that enabled participants to develop their own definition of dignity and to begin to consider what that might look like in practice. This would then continue on the second day with the sharing of narratives and moments identified from practice.

As well as supporting the participants in their personal journey, the focus on sharing narratives, stories and moments from practice during data collection stemmed from the need to access the interior experiences of nurses engaged in the work of nursing. Hunter (2007) believes that the telling of stories in a group context is a means through which:

An individual experience may come to represent the group's shared experience. This occurs in a social space where members are exploring the narrative of their context and situation. As personal stories begin to shape the group narrative, each individual story builds on previous stories. The forming narrative becomes a new framework for thought and a blueprint for action. (p. 102) 
In the fourth phase of Roberts' model, synthesis, nurses are able to integrate new thinking with the old context in a way that does not cause discomfort. The workshop was designed so that during the final afternoon participants had the opportunity to collectively consider the implications of any changed perspectives, as well as strategies for managing them.

The final phase of Roberts' model, political action, describes an emancipatory process where "a genuine and ongoing commitment to social change occurs" (p. 80). While this phase clearly fell outside the parameters of the study, it was hoped that the process of reflection and discussion that was built into the workshops would support the participants in managing changed perspectives. In addition, all participants were to be offered the opportunity for professional supervision.

\section{Data analysis}

The approach applied to data analysis is critical to the quality of both the translation of information and the rigour of the process:

Analysis is the process by which qualitative data, such as interview transcripts, field notes and documents, is transformed into results, such as new understandings, theories and statements about the empirical world. (Hansen, 2006, p. 137)

Hansen describes the numerous approaches to data analysis as "focusing devices" (2006, p. 137) that both filter and reflect the orientation and underlying assumptions of the study. The intention was to analyse the data using qualitative content analysis that employed a mixed inductive/deductive approach.

\section{Qualitative content analysis}

Qualitative content analysis (QCA) is a "reflexive and integrative approach [that is] orientated towards summarizing the informational content of that data" 
(Sandelowski, 2000, p. 338) using a process of systematic text analysis (Mayring, 2000). QCA enables the articulation of the manifest content (themes and main ideas), as well as the latent content (contextual information) of the data (Mayring, 2000; Sandelowski, 2000).

It has been suggested that QCA "takes effect at the place where quantitative content analysis reaches its limits" (Zhang \& Wildemuth, 2006, p. 1). For example QCA may employ core features of quantitative content analysis such as content counting. However, QCA goes beyond using numbers as a prima facie finding that can be statistically manipulated. QCA requires the researcher to account for the possible meanings implied by the numbers, the process used to arrive at the meaning, or alternatively the use of numbers as confirming the discoveries (Sandelowski, 2000, Sandelowski, 2001). Thus, QCA provides an approach that is simultaneously subjective and scientific (Zhang \& Wildemuth, 2006).

QCA is not a single approach and it is necessary for the researcher to clearly describe the approach taken (Hsieh \& Shannon, 2005; Zhang \& Wildemuth, 2006). Hseih and Shannon describe content analysis as "a family of analytic approaches" (p. 1277) where the researcher chooses a style consistent with the "theoretical and substantive interests of the researcher and the problem being studied" (p. 1277). From within this 'family of approaches', Hsieh and Shannon describe three approaches that are differentiated by the degree of deductive reasoning applied. The first, conventional content analysis, is predominantly an inductive approach where themes and categories are derived from the raw data. The second approach, directed content analysis is a more deductive approach where "initial coding starts with a theory or relevant research findings" (Zhang \& Wildemuth, p. 2). By immersing him/herself in the data the researcher allows themes to emerge. This approach is seen to be useful as a method of validating or extending a "conceptual framework or theory" (p. 2). The third approach, summative content analysis, begins with content counting then "extends to include latent meanings or themes" (p. 2). 
Of the three approaches, directed content analysis (DCA) was considered the most appropriate for three principal reasons. First the study was not aiming to develop theory, but rather was interested in broadly applying existing theory about dignity at work to a specific population, namely nursing. Second, in keeping with DCA, the development of a research framework for this study offered the ability to broadly identify "key concepts [and] variables as initial coding categories" (Hsieh \& Shannon, 2005, p. 1281). Finally the expressed aim of DCA to "validate or extend conceptually a theoretical framework or theory" (Hsieh \& Shannon, 2005, p. 1281) provided a fit with the aims of the research.

\section{Presentation of findings}

In keeping with the methodology, the intention was to represent the data as a descriptive summary using the themes and categories that emerged in the analysis phase. A low inference approach was considered preferable to reduce the risk of any particular methodological orientation or preconceived views colouring the findings. With these two parameters in mind, no preconceived method of representation was selected in order to allow for the best approach to emerge during data analysis.

\section{Ensuring the quality of the design}

As already discussed, establishing the quality of qualitative research relies on applying a credible process of evaluation. For this study, credibility, transferability, dependability and confirmability were chosen as the guiding measures. 


\section{Credibility}

According to Saks and Allsop (2007), credibility relates to:

The degree to which the data accurately represents attitudes, perceptions and views of the population being studied... A qualitative study is about gaining an understanding of how some differently positioned actors talk about their experiences and the meanings they associate with particular events, actions and claims. (p. 27)

Credibility was accounted for in a number of ways. First, the facilitated process was designed to ensure that the voices of all participants would be heard. Second, careful attention was to be given to the text as a whole to identify the meanings from within the narratives. Third, the data analysis needed to identify and bring through key illustrative examples that captured not just what happened but what that meant for the participants.

\section{Transferability}

Transferability, according to Zhang and Wildemuth (2006) is not a requirement that the researcher has to meet so much as a responsibility to "provide data sets and enough descriptions to make the judgment of transferability possible on the part of other researchers" (p. 5). Other writers challenge the idea that transferability is addressed at all (Sandelowski, 2000). However, I subscribe to the view that other researchers should be able to see the potential application to other settings due to a high level of descriptive and interpretive validity. The findings of this study are transferable to the degree that it should be clear to the reader the way the data was gathered, managed and presented.

\section{Dependability and confirmability}

Dependability relates primarily to the internal consistency of the process while confirmability is "determined by checking the internal coherence of the "data, findings, interpretations, and recommendations" (Zhang \& Wildemuth, 2006, p. 
5). Thus it would be possible to judge a study dependable in terms of the rigorous process that was applied, but be unable to have confidence in the outcomes due to deficits in the actual interpretation and translation of the data. The choice of qualitative description goes some way to addressing the latter through the ability to address "complex embedded questions" (Thorne et al., 2004 , p. 1) using a low inference approach.

\section{Transparency of methods and analysis and researcher reflexivity}

The process of articulation of the study through the medium of this report provides a high level of transparency. I hope that it is evident to the reader the foundation from which the research question emerged, how the research was conducted, the rationale behind the methodology and design, and the processes used for data collection, analysis and reporting of findings. DCA as an approach acknowledges an inherent limitation "in that researchers approach the data with an informed but, nonetheless, strong bias" (Hsieh \& Shannon, 2005). The main risks are that the researcher may bias the findings towards existing theory, that participants may be influenced by the structured, preinformed approach to data collection, and that contextual features may be overlooked (Hsieh \& Shannon, 2005). The first concern was accounted for through giving attention to reflexivity and the second through the process of participant validation.

\section{Researcher reflexivity and participant validation}

In any qualitative inquiry, it is acknowledged that it is impossible for the researcher to be entirely free of his or her own personal bias and perspectives. Therefore it is important to account for how this is managed (Roberts, Priest, \& Traynor, 2006). Hansen (2006) describes researcher reflexivity as meaning that "a researcher aims to achieve explicit, self aware analysis of their own role" (p. 59). The process of declaring biases and assumptions is considered important in "allowing the reader to evaluate the impact of these on the analysis and interpretation" (Hansen, p. 48). Demonstrating reflexivity was of particular importance in this study as my own 
emic perspective (sharing common work experiences with the participants), my declared interest in the area under study, and my role as the principal researcher, posed potential issues of bias.

The potential issues were accounted for in several ways. First the choice of qualitative description, which does not attempt interpretation beyond the who, what, and how of the data, lessened the possibility of my own perspectives becoming dominant (Roberts et al, 2006; Sandelowski, 2000). Second, the design of the workshops deliberately avoided imposing any personal construction of the area under study onto the participants. Third, the facilitated group process for the collection of data placed me in the role of "holding the space" (Hunter, 2007, p. 97) on behalf of the participants so that their understanding, experience and deeper meaning could be articulated. Finally, the opportunity for participants to provide feedback on the represented data provided a safety net to researcher myopia emerging in the analysis phase. Hansen holds that respondent validation fulfils the dual purpose of accurately portraying the "experiences and viewpoints of the research participants" (p. 57), and increasing participant engagement.

Two layers of participant validation were built into the study design. The first layer addressed descriptive validity and involved participant review and amendment of the transcripts to ensure an accurate accounting of the data. The second layer addressed interpretive validity relating to the meanings participants attribute to their data, and took place when the participants attended a session to review the research findings. While these steps could not entirely eliminate the potential for bias, they enable the reader to make an assessment of the influence that this may or may not have had on the analysis and findings.

\section{Summary}

The processes involved in developing the research question, identifying an appropriate methodology and designing the research approach reinforced for me the key differences between knowledge acquired through crafted research 
as opposed to more empirical methods. The discipline inherent of having to consider and justify a preferred approach and to make that explicit to the reader resulted in a higher degree of confidence relating to both the safety of those who would be recruited into the study, the execution of the facilitated process, and the quality of the data that was generated.

Prior to moving to presenting the findings, the following Chapter expands on the applied research process. The purpose is to preface the findings and conclusion by illuminating the process of walking with the participants as they encountered, unpacked and explored the idea of their own dignity. Like the literary palimpsest the nurses in the study brought the layers of their past experiences to the process and I believe that the study is enriched through articulating their voyage of discovery. 


\section{Chapter 4: Preparation, Data Collection, Analysis, and Representation}

The process of applying the research design involved recruiting participants to the study, preparation for the workshops, facilitating the workshops, data transcription, analysis, and representation of the findings. This chapter provides detail of this part of the research journey. Verbatim extracts from the data are italicised.

\section{Recruitment}

In June, 2008, all subscribers to the nursing magazine Kai Tiaki living within the target region received an insert inviting them to participate in the study. The invitations outlined the nature and purpose of the study, the inclusion criteria, the geographic area being targeted, and details of the time commitment (Appendix 2). Nurses interested in participating were invited to make contact by phone or email to further discuss the study. Those who enquired were sent an information sheet (Appendix 3), and the consent/eligibility form, (Appendix 4). The process required that the first nine nurses who responded and met the eligibility criteria would form the participant group.

Several inquiries were made but only two nurses confirmed their ability to participate. With the workshops booked for early August and following a discussion with my supervisor, a decision was made to implement a second recruitment strategy aimed at attracting additional participants. All New Zealand Nurses Organisation delegates in the target region were sent a copy of the invitation and were asked to distribute this through their networks. This generated a higher level of responses but a number of the participants did not meet the full inclusion criteria. One week out from the date set for the first 
round of data collection, seven nurses were available to participate, and of these only five were eligible. Following consultation with my supervisor it was agreed to modify the eligibility criteria to include nurses from any clinical practice area (not only inpatient areas). The rationale for the change was that the key target group was nurses whose practice brought them into daily clinical contact with patients. Broadening the range of eligible practice settings was not considered fatal to the recruitment of a suitable cohort.

Many emails and phone calls followed until finally, all seven participants were confirmed for the agreed dates. The all female participant group ${ }^{2}$ included nurses working in nursing agency, emergency care, theatre, continuing care, inpatient mental health, and rural inpatient settings. All met the criteria regarding length of clinical experience, geographic location, and current employment in a clinical setting. All would be attending in their own time.

\section{The workshops}

The seven participants attended two one-day facilitated workshops conducted by myself as the researcher. The first was held on August $1^{\text {st }}, 2008$ and the second a week later. In addition, the participants were invited to attend a two hour follow-up session where the findings were presented and discussed. The workshops were held at a neutral venue, not related to the work environment of any of the participants.

Preparation for the workshops included developing and refining the workshop plan (Appendix 5), visiting the venue, procuring petrol vouchers for the travelling participants, and arranging food and refreshments for the day. Equipment and resources for the workshops were obtained and two recording devices organised.

\footnotetext{
${ }^{2}$ Hence the use of the feminine pro-noun in the findings and discussion.
} 


\section{Day One}

The first day followed a prepared plan. The participants explored their understanding of dignity as a concept and a construct. A group definition of dignity was developed. The group began to consider the relationship of their thinking about dignity, to their work as nurses. Participants were asked to respond to key theoretical influences on worker dignity and the theoretical framework developed for the study. At the conclusion of the first day, participants were provided with a series of prompts to take away, and were asked to consciously try to identify moments in practice when their dignity was present, being actively supported, being infringed, or where they were engaging in regardful activity toward another person.

\section{Introductory session: Setting the scene}

The room was set out with comfortable chairs in a circle. Dictaphones were set up on a coffee table in the middle of the group. The material from this part of the session was not formally recorded. The day began with a welcome and an orientation to the facility. The participants (including the facilitator) introduced themselves to the group, using a structured approach of who they were, where they worked and why they chose nursing as a profession.

I then introduced the research to the group, beginning with the purpose of the research and the research question: How do clinical nurses understand, experience, and sustain dignity in their work lives?

The rationale behind the inclusion criteria was presented. The nature of exploratory research was explained and the participants were reassured that their views would not be portrayed as representing all nurses. Finally the participants were offered the opportunity to ask questions about the study or their participation. There were no questions.

A 15 minute session to agree on group ways of working generated a list of preferred behaviours. The question the group was asked was, 'what will be 
important to you in working together to achieve the purpose'? The responses were recorded and attached to the wall.

The overall structure of the two days was shared with the group and the participants were given an opportunity to comment on and shape this. The group was then provided with a laminated copy of the framework for the study. The purpose of this was to demonstrate to the participants the way the sessions would move from conceptual considerations of dignity and nursing, through to their experiences in practice. The group then adjourned for morning tea.

\section{Theme One: Conceptualising dignity}

Following the break, participants were asked to spend 10 minutes on their own capturing words, images, or experiences that came to mind when they thought about the word dignity. Paper and felt pens were provided. The group then reconvened to share their work. Words and conceptualisations commonly associated with dignity in the literature emerged from this exercise, notably: worth, value, respect and honesty. Some participants described a predominantly meritocratic understanding of dignity. For example the use of words and phrases such as elevated, ceremony, looked up to, having a good name. Dignity was agreed to be an intrinsically held value and was also seen to be associated with context and social relationships. For example: inherent concept, socially constructed, social norms, learned, context specific.

The group were then given a phrase to consider: 'so dignity for you is about....', and were invited to work together to construct a statement that provided a definition for the word dignity. The words that the participants had already offered were used as the basis for a discussion that ultimately resulted in a group definition.

The idea that dignity could be held in the face of contextual challenges was one that resonated with most. The notion of dignity for nursing being 'earned' was familiar to the participants, and there was discussion about looking forward as 
a student to being accorded respect according to your status. The idea of dignity as a social construct was clearly new but as the conversation evolved, examples were given by the participants of context and 'others' influencing one's dignity. There was still a strong view that while it could be eroded or challenged, one would have to give dignity away to lose it. The group came to a working definition:

Dignity is a human concept that relates to worth, value and meaning. Dignity is defined and sustained individually but is influenced, supported or eroded by others. When we experience dignity we feel a sense of; self worth, mana, autonomy, belonging, integrity, purpose, meaning, self respect, genuineness, spirituality, essence, and intactness. We support the dignity of others when we give regard to; their value as human beings, their need to feel respected, their worth, their autonomy, and their right to make choices. Achieving dignity is an active process that is context specific including; culture, situation, age, social expectations (our own and others), gender, role, and values.

The group was advised that this would be the working definition that anchored further discussion on dignity as we moved from the conceptual to their actual experience of dignity in their work.

\section{Theme Two: The purpose of nursing work}

Session two explored the question; 'what lies at the heart of the work of nursing'? The session aimed to develop a group description of what nursing is. The purpose of the exercise was to provide an anchor for subsequent discussions about dignity in the context of nursing work. The dominant descriptor was undoubtedly caring. The participants were challenged to move beyond this to find ways to describe nursing as uniquely different from other professions who 'care'. The idea that nursing care involves specialised knowledge and skills extended the discussion. Also given weight was the goal of making a positive difference to the patients' experience of care. The notion 
of privilege was introduced by one of the participants and there was agreement that it is a privilege to be able to practice nursing. A definition was emerging but the group was not satisfied until one of the participant's reintroduced care and compassion into the conversation. This evolved into a thread about nursing being based on the notion of valuing humanity. The final definition that reflected the groups' shared understanding was:

Nurses bring a body of specialised knowledge and skills and a value for our shared humanity to provide care that aims to make a positive difference in the delivery of health care. The essence of nursing is the specialised expression of caring.

The session closed with a review of the morning's journey.

\section{Theme Three: Self and other-regarding dignity}

\section{Regarding others' dignity}

After lunch the two definitions were revisited and agreed. The participants were then invited to identify characteristics of dignity that would be important to patients. The group easily generated a list. When asked whether they were thinking about a patient, or themselves as patients during this exercise, the majority had a vision of a patient in their mind. The notion of other-regarding dignity was introduced. There was discussion around how as a profession we are primed to give a great deal of thought to patient dignity. The group was facilitated to discuss reframing their thinking away from this dominant paradigm in order to consider their own dignity as nurses.

\section{Regarding one's own dignity}

The second exercise in this session asked the participants to consider what they and their colleagues need to sustain dignity. The contrast to the first exercise was stark. The responses came slowly, quietly, and hesitantly, with an upward inflection on the end of each statement, as if they were asking a 
question. Eventually, a fairly comprehensive list evolved. The similarity to the patient list was discussed. Reviewing the list, it became obvious that while the intention was for the participants to consider dignity in a self-regarding way, the list was almost exclusively made up of things that other people needed to do in order for the nurse to feel dignity. For example: to feel valued, to be included, to be supported, to be protected, to be trusted, to be listened to.

The contradiction between their earlier views about dignity being intrinsically felt and sustained was explored. One participant offered that during the exercise she was reacting to what you need to resist that represents challenges to dignity. So when the participants were thinking about their own dignity, it may have been with their particular work context in mind, and in particular the challenges that are inherent in that context. In order to avoid a bias in the data collection towards only looking at dignity as passively received, the participants were asked an unscripted question: 'What do we need to do ourselves to feel dignity in our workplaces'? A rich and comprehensive list was created by the participants. The discussion included a growing discovery that their initial instincts were sound; that dignity begins with a personal construction and needs to be pursued with active personal agency.

\section{Theme Four: Dignity and others}

Session four provided an opportunity to begin applying the evolving understanding of dignity to situations that the participants had experienced. Participants were asked to recall situations where they felt that during an interaction with another, their dignity had either been affirmed or infringed. They were asked to tell the story of what happened, how that felt, and whether the encounter had an influence on their practice.

Overwhelmingly, the encounters that were positive related to times when someone else affirmed the participant's practice. Examples were provided where the 'other' was patient, family, nurse colleague or medical colleague. The participants were often surprised to receive unsolicited affirmation, saying that they were just doing their jobs. Often the encounter had not stood out in 
their own minds as out of the ordinary. Affirming encounters made the participants feel both validated and valued, and several spoke of the positive impact on practice, motivating them to go the extra mile.

The encounters that were related where dignity was felt to be infringed were invariably associated with a deep sense of distress. Participants could recount in great detail, incidents that occurred over a decade ago. Phrases such as I felt sick; I felt shocked; or that terrible sinking feeling were used to describe the personal impact. Of interest was that most of the stories related to single interactions where the participant was left feeling demeaned, as opposed to sustained incidents of bullying. All of the encounters involved other members of staff; principally managers, medical colleagues or fellow nurses.

The group reflection was that both affirming and infringing encounters had the ability to evoke powerful responses and that this suggested that social encounters may have a significant part to play in how dignity is experienced in the workplace.

\section{Theme Five: Dignity and the environment}

This session asked the participants to consider their definition of dignity in relation to the environment of practice, for example the way the work is supported with resources, recognition, or opportunities for development. As with the previous session, participants were asked to consider situations where their dignity was affirmed or infringed.

The group was slower to engage with the idea that the environment may have a relationship to their dignity. The first examples given were around poor resourcing and shabby environments. The participants reflected that these things cause a low level grumbling irritation. They felt that these deficiencies reflected a lack of appreciation of the value of their work on the part of managers or the employing organisation. 
As the session progressed, more specific instances were uncovered, which the participants were able to link to dignity being infringed or affirmed. For example, one participant described her appreciation of the level of support that she had been given for ongoing education. Another participant expressed her anger and distress at being denied an opportunity. The participant relating the positive story used words such positive, validity, pride, appreciation, value and gratitude. The participant felt that this translated into an increased sense of responsibility and commitment. The participant who had her education request declined talked of feeling indignant, of closed doors, anger, and powerlessness. The effect on practice included a degree of disengagement, and questioning whether she wanted to continue to work in that environment.

A further thread that emerged related to the degree to which policy and protocol enabled practice and patient care. Examples were provided where local policies felt enabling or demeaning. For example an extended analgesia standing order was seen as affirming the nurse as a responsible professional, while an annual requirement to re-certificate in order to be able to drip a bit of wee on a stick, was seen as demeaning, unnecessary and devaluing. Where compliance education was seen as unnecessary or demeaning, participants related resistance strategies such as not completing required re-certification or using each other's log-ins in order to be able to carry out the procedure.

\section{Theme Six: Infringing our own dignity}

The sixth session probed for times when the participants may have infringed their own dignity in the interests of supporting patients' needs. Initially the participants found it difficult to identify such encounters. The situations that were recalled generally involved situations where a patient was not in a position to sustain their own dignity through a loss of cognition. The nurse had to act in a way that put her at risk. The significance of these stories was found to relate not so much to the voluntary infringement but whether or not the nurse received support and validation for the action subsequently. 
As the discussion evolved, a thread emerged around having to move the goal posts of what constituted good nursing care. The participants articulated the link between achieving the standard of care that they desired for patients, and their sense of personal achievement. This rather complex association appeared to relate to the notion that nurse and patient dignity are inextricably linked; that nurse dignity is in part linked to the patient's experience of care. The 'organisation' was cited as not sharing the same agenda. For example where a nurse worked voluntary overtime to complete work and was then criticised, what initially began as a voluntary altruistic action became a dignity infringing outcome. Participants described how the angst that is generated between nurses and their organisations not only demoralises but sucks energy away from patient care.

\section{Theme Seven: Sustaining one's own dignity}

The final theme of the day was around identifying actions that nurses take to sustain their own dignity. This theme was deliberately left until last so that the participants had the opportunity to balance the weight of the stories relating to how others infringe or support their dignity. The list of self-regarding behaviours that was constructed earlier in the day was revisited:

inform ourselves, learn, take ownership, be prepared to change, have a positive attitude, be confident, know our place or part in it all, advocate for ourselves, find our own culture, construct our own professional identity, model behaviours that reflect who we are and our values, work on our relationships, command respect, protect ourselves, support and regard our colleagues, lead by example, promote self belief, affirm ourselves

One of the participants shared a very powerful vignette about how she employs many of the strategies, every day, in a job that she finds extremely satisfying and fulfilling. The participant also recounted a time in her earlier professional life when she employed few of the strategies, and ended up taking stress leave and having to rebuild her professional career. This example set the scene for 
the other group members to draw on specific examples of affirmative action from their own practice. These included choosing a positive attitude, employing humour, and cultivating an individual image.

\section{Final session: Review and reflection}

The workshop ended with a round of all participants inviting their reflections on the day. All participants reflected positively on their experience, and no-one was leaving with any sense of distress or disequilibrium. Several commented on the value of the discussions in helping them to unpack the topic and as one said, it's like we're going deeper into the iceberg. There was a sense amongst the group that the research had the potential to contribute positively to the work experience of nurses.

Each participant was given a pocket sized card to take away (Appendix Six). The card contained information to prompt their reflection during the week they would spend back in practice. The prompts related to the themes under discussion. Participants were encouraged to also look for examples not covered by the prompt cards.

\section{Day Two}

The second workshop took place one week later. The session began with a review of the process and an exercise to refocus the group on the topic. The day then moved into reflection and narrative. Each session concluded with a reflective discussion, exploring the insights and importance of the stories. The final session offered the opportunity to reflect on the process and on changed perspectives, including the potential implications of raised consciousness. Participants were reminded of the availability of professional supervision.

\section{Reflection and identification of narratives}

Participants first talked about the experience of going back into practice with the first day's reflections providing a lens through which to view personal dignity. Several of the participants had found it very difficult to separate the 
patient's experience of dignity from their own. The terms used to describe this included turmoil, confusion, and elusive. The idea of a reciprocal relationship emerged, where nurses are both giving and receiving dignity through the nurse-patient interaction. There was a level of agreement that their experience of dignity was somehow related to the achievement of the 'heart of their work'.

The participants were invited to give a brief précis of the moments and stories they were intending to share. The majority related to interactions between the nurse and another person but also to encounters with their employing organisation. A new thread emerged near the end of the session relating to the choice that many of them had had to make ten years ago when there was widespread industrial action involving nurses: ...it was just turmoil; Gut wrenching; Because we were trying to find the answer to that question about how important it was to their professional dignity if they [the nurses] didn't go to work, their relationship with patients - how would you live with yourself professionally? This conversation spoke strongly to the idea of nursing holding a social compact ${ }^{3}$ with society that expects nurses to deliver skilled, intimate care in return for society's professional esteem.

\section{Moments and narratives}

The following two sessions lasted for several hours and ranged across many different manifestations of encounters with dignity. Stories of how a nurse is constructed in the image of a professional nurse were interspersed with deep and often intimate narratives about profoundly affirming or profoundly

3 'Compact' is used in preference to 'contract' as it provides a less contested meaning. The meaning of a social contract is that an individual tacitly consents to certain restrictions on autonomy in return for remaining a member of society. However, the philosophical concept of social contract can be confused with modern contract theory that requires the individual to explicitly give consent. The term 'social compact' while often used interchangeably with 'social contract', addresses this potential confusion. 
distressing encounters involving patients, peers, colleagues, and managers. Threads emerged about how nurses feel personal distress for things that do or don't happen for patients, even when it is clearly beyond their control or influence. The power of nurse-patient interactions featured as did the distress associated with being professionally disrespected.

Over time a picture of the workplace as contested territory emerged, with many contradictions between the participants' beliefs and expectations and what is experienced in everyday practice. The moments and stories were full of the hope, humour, distress, bewilderment, joy, and satisfaction that are part of being a nurse and nursing. By lunchtime a question was forming that I put to the participants as an unscripted deviation. The question they were asked to consider over lunch was, 'thinking about your work, the work of nursing, your work, what makes your work dignified'?

\section{Exploring the dignity of nursing}

This session resulted in deep discovery about nursing, the purpose of nursing and how it is positioned in our society. The two central ideas were of nursing as skilled, esteemed and trusted, and of the privilege of being allowed to nurse. The nurses used terms like widely respected in the community; appreciated; a profession with its own body of knowledge, skills and behaviours. The idea of privilege was reinforced, that it is a privilege to be a nurse: It's the special nature of the work nurses do, of the job; The profession is very privileged and very personal.....work is perceived as a privilege to us, to touch our patients, they give us permission - permission to touch them which we wouldn't do normally [outside the nursing role]; Our tone of voice, our body language, privacy, our knowledge, our confidentiality.

The conversation turned to the myriad challenges of achieving the social compact in the workplace, and the contradictions that nurses experience in endeavouring to deliver care the way they perceive it should be. 


\section{Reflection and closure}

The final session provided participants with the opportunity to reflect on the experience of participating in the research and to make any final contributions. Without exception, the participants expressed that participating in the research had been a positive experience. Several talked of a sense of empowerment:...and it's [the research] come at a really good time in my practice. To look at it because of the things that have been said to me in the past few months, could have just turned it the other way. I could have just chucked it all in.

The participants discussed how they had been unable to come to a 'tight' definition but all agreed that they had a strong inner sense of what dignity 'is': It sort of makes you wonder how we know what dignity is. Because our mothers didn't sit us down and say, 'right darling, dignity today'! How do we know...? The conversation came full circle with a return to the central ideas about shared humanity, the aim of making a difference, and the social compact: “...we give a part of ourselves. And we don't lose anything because we always get something back; I think we forget to see it...claim it, on a daily basis; That mundane act of feeding that old person in a respectful way...that actually saw them as a person, was meaningful to them. But we can lose that can't we in the everyday business of what we do.

By way of closure, the participants were invited to share the one thing that they would change (if they could) in their workplaces as a result of thinking about the dignity of nurses. One self-regarding thread came through from the discussion, one other-regarding and one thread about being regarded as a nurse. Self-regard was around being consciously more positive of claiming the joy of the work of being a nurse. The other-regarding thread was around sharing with colleagues a sense of the power they have to be positively influential. The thread around being regarded was to be able to 'wave a magic wand' and change the attitudes of managers to be more understanding of the work of nursing. 


\section{Reflections on the facilitated process}

The facilitated group process was crafted to provide synergy between the requirements of the research and the needs and wellbeing of the participants. The process was successful in supporting participants to explore, extract, reflect and review the research topic from a number of perspectives, and could in retrospect be considered a strength of the research design. The facilitated process also proved successful in giving explicit attention to the well-being of the group, including the opportunity for in-depth reflection, and closure at the end of the process. As already discussed, the potential for participants to experience strong responses as a result of exploration of their own dignity necessitated employing a process that regarded and accounted for this. A facilitative approach, with its preference for dialogue and narrative, provided an opportunity for "sharing experiences and engaging in learning through deeply and consciously being together in a communal setting" (Hunter et al., 2007, p. 97).

Based on the reflections of the group, it appeared that the facilitated group process provided an opportunity for participants both to explore the notion of dignity as a concept, and to surface narratives or moments from practice when dignity was either supported or infringed. The purpose of spending time on exploration was based on two assumptions; first my belief that the participants would not have spent a lot of time thinking about personal dignity in their work lives; second, in addition to dignity in work-life being a poorly understood area for workers generally, nurses have also been conditioned to view dignity through the lens of patient dignity as a principally other-regarding value.

I began from the position that the patient-focused, patient-first discourse could act as a distraction to nurses when considering their own dignity and may even covertly encourage subordination of dignity. Therefore the purpose of first spending time exploring dignity as a concept, and then exploring the context of nursing work was partly to emancipate the participants from the dominant paradigm. A second area that was identified principally from the work of 
Hodson (2001) was the likelihood that resistance narratives, and narratives recounting injustice would be surfaced. It was an important part of the facilitation process to also probe for narratives where dignity was actively sustained, either by self-regarding action or by others. This meant that while working within the methodological umbrella of qualitative description, the decision to adopt a facilitated group process for data collection worked effectively to bring together the scope of the study, the skills of the researcher, the wellbeing of the participants and the need to generate rich descriptive data.

\section{Exploration and analysis}

\section{Data transcription and participant review}

All structured sessions were audio-taped and transcribed verbatim. The data consisted of 11 hours of audiotape and a bundle of material generated during the exercises on the first day. Transcription took four weeks of concentrated effort, generating 140 pages of text. The original intention to use a transcriber was not ultimately adopted due to difficulty with the quality of the audio tape. A decision was made not to individually identify the participants, partly because of the difficulty of doing this with any accuracy, but more because I considered that the transcript should be considered as the collective discourse of the group.

While analysis did not formally begin during the transcription, notes were taken to identify initial key ideas and moments as they were transcribed. The transcripts of the interviews provided the data for the study. Copies of the transcripts were sent to the participants electronically. Participants were asked to review and return the transcripts with any changes marked. A 10 day period was allowed to read and correct the transcripts. Only minor transcribing errors were returned as suggested amendments. 


\section{Data analysis}

A classical qualitative research approach was taken to managing the data. The process began with the previously described preparatory stages of formulating the research question, sample selection, and data acquisition. Coding began concurrently with immersion in the data. As outlined, the research design incorporated directed content analysis (DCA) as the method for working with and analysing the data. DCA was chosen as best fitting an approach that was informed by other research and theory (Zhang \& Wildemuth, 2006). However as the process of coding and analysis progressed, it became clear that a more inductive process was required that allowed the themes and categories to emerge unencumbered. Ultimately an approach that was primarily a progressive focusing approach was employed, where the emergent themes provided an entry to deeper layers of content. The theme of dignity was adopted as the unit of analysis for the study.

\section{Organising the data}

The initial coding process was developed from the literature review and drew on Hodson's (2001) model for worker dignity. Thus the initial intention was to begin coding based on the characteristics that Hodson found sustained or challenged dignity. However this evolved into a more conventional approach where categories and themes were identified inductively from the data. There was no intention to create a hierarchy of the categories, but it was interesting in retrospect to see the order in which the categories emerged:

Management, abuse, the organisation, belonging to the professional group, professional respect/identity, advocacy, personal professional integrity, social compact, reciprocity/support/affirmation, making a difference to others, being recognised for citizenship, being recognised for the good nurse I am, having the time and support to do a good job, being recognised for being great nurses, giving without getting enough back, ascribing accountability, the environment, professional autonomy/trust, education/professional knowledge, patient 
responsibilities, maintaining professional standards, acting professionally, altruism, self advocacy/putting me first, being myself, constructing a professional identity, holding dignity in the face of infringement, erosion/cumulative effect

It emerged from these initial categories that whether the participants were 'in' dignity or not, could be explored through analysis of their expressed beliefs about dignity, the expectations that arose from those beliefs, workplace encounters, and their responses to these encounters. It also became apparent that dignity is something that is understood, experienced, and responded to as either congruent or contradictory with one's beliefs and expectations. It is this dynamic and contested social interplay that provides the experience of dignity. The process of organising the data was framed by the participants' beliefs and expectations about dignity, and underpinned by their experiences of, and responses to, congruent or contradictory encounters. These findings are presented in the following chapter. 


\section{Chapter 5: Findings}

Dignity is a human concept that relates to worth, value and meaning. Dignity is defined and sustained individually but is influenced, supported,

or eroded by others.

(Research participants' group definition)

\section{Introduction}

The study set out to address the question: How do clinical nurses understand, experience, and sustain dignity in the context of their work life?

The data showed that clinical nurses understand, experience, and sustain dignity in the context of their work lives through a complex, interactive, and dynamic interplay of their beliefs, expectations, encounters, and responses. These four elements cannot be ranked by hierarchy or order of development. There was no logical starting point because all are continually shaping and being shaped by each other. Therefore each new encounter is subtly different from the one before and the response will shift as a result.

This chapter is presented in four parts. In part one the participant's descriptions of their constructions of dignity, the beliefs associated with these constructions, and the expectations that follow of how dignity should be experienced in the context of their work lives are presented. Part two focuses on how the nurses encountered dignity in their work context and introduces the idea of dignity as either congruent with or contradictory of beliefs and expectations. Every workplace encounter described by the participants could be seen to be invested with either congruence or contradiction that resulted in a sense of equilibrium or disequilibrium. For example, where the dominant encounters overall provided congruence with the nurse's expectations and beliefs about how dignity should be experienced, nurses enjoyed a sense of equilibrium 
which translated into particular patterns of responses. Conversely where the encounters were contradictory to the nurses' beliefs and expectations, the nurses expressed a sense of disequilibrium. This too translated into particular patterns of responses. The ways in which the nurses interpreted and responded to both congruent and contradictory encounters are presented. Part three presents the participants' perceptions of the relative balance between congruent and contradictory encounters. Part four summarises the findings. Verbatim extracts from the data are italicised and where quoted in full references are identified by day, session, and transcription line.

The process of data analysis drew heavily on the two definitions that the participants developed. The first, a definition of dignity established by the participants, associated dignity most strongly with four words; worth, value, meaning and respect. These four associations are implicit in references to 'dignity' from this point forward. The second definition related to a group description of the purpose of nursing work that described the 'positive difference' they were seeking to make. The achievement of this positive difference emerged in the analysis as a major determinant of whether the participants experienced dignity in their work context.

\section{Part One: Beliefs and expectations about dignity in the work context}

\section{Developing a construction of dignity}

The framework that was developed prior to data collection proposed that the participants' perspectives on dignity would have been shaped by their beliefs and experiences as people in society, by their beliefs and experiences of nursing, and by their experience as employees. This proposition was supported in the findings. In fact the differences encountered were more marked than expected. Rather than nursing perspectives on dignity being merely blended into the individual's own, the basis for those perspectives was found to be differently positioned. Two distinct constructions were identified. These have been labelled 'the personal self' and 'the professional self'. The two 
constructions come together within the 'nurse in practice'. Figure 2 illustrates this relationship.

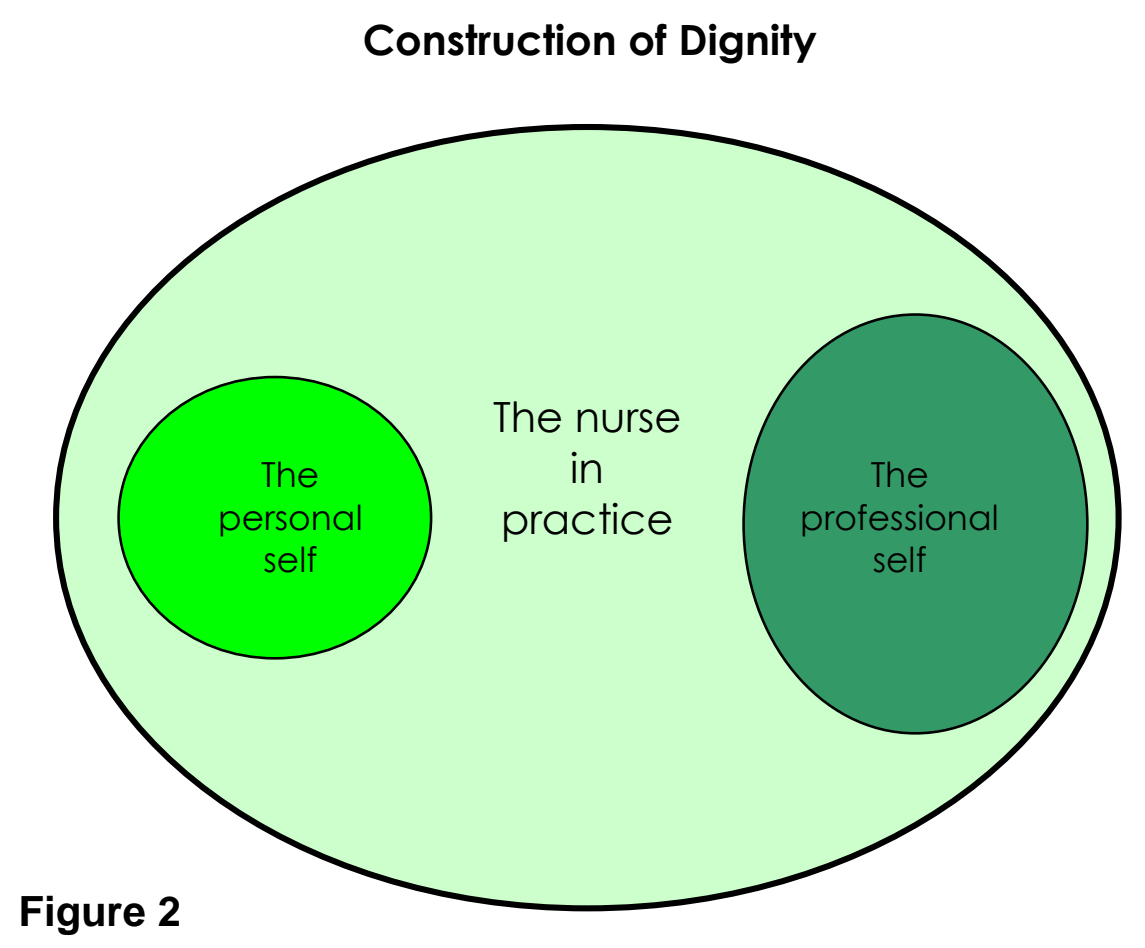

The participants described the way that they bring the two constructions through into their work context. Beliefs and expectations about dignity and the personal self could be seen to have been shaped over the participants' lifetimes as people living in society. The construction of the professional self was predominantly influenced by the beliefs, traditions and expectations constructed by nursing as a professional group. The nurse in practice, (hereafter referred to as 'the nurse'), is constructed from the personal self, the professional self, and the experience of being a nurse. Interestingly it was not possible to completely subsume the personal self and the professional self into a single 'nurse' construct. Each could be identified individually in the experiences and encounters offered by the participants.

The absence of a third construction, the 'employee self', was an unexpected finding. It was expected that the participants would articulate beliefs, expectations and behaviours associated with being employed as a nurse; that 
would contribute to how worth, value and meaning were measured. While the employee self was not overtly declared, it was revealed by what was not said rather than what was said. Significantly the participants did not appear to attach any worth, value, or meaning to being an employee of their organisation. The silence around the employee self does not imply that the employee self is not part of how the individual nurse understands, experiences and sustains dignity in the work context. Its absence suggests a fundamental tension between the nurses and their employing organisations. In the subsequent exploration, the participants did not articulate a role for themselves in affirming the worth, value or meaning of one particular group; their managers. The implications of this are beyond the scope of this study but would certainly merit further exploration. In respect of this, the earlier model suggesting the presence of two constructions was revised to incorporate the silent third (Figure 3).

\section{Construction of Dignity (amended)}

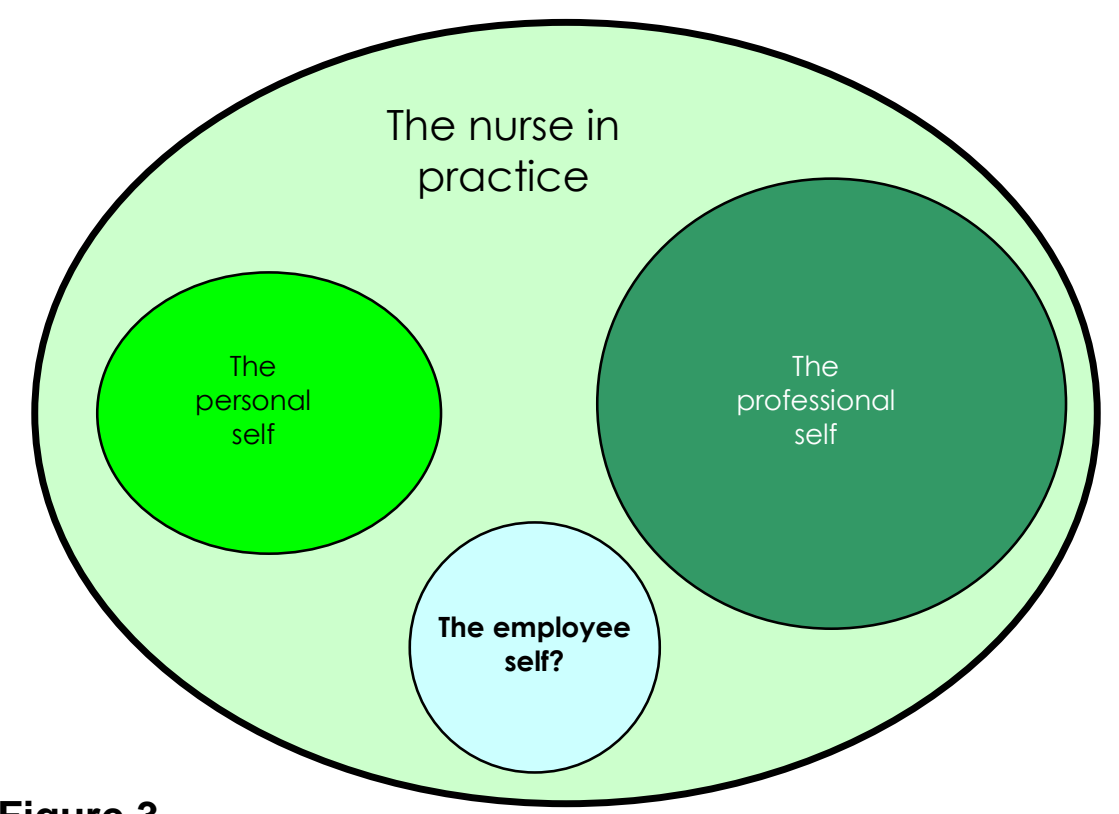

Figure 3 


\section{The personal self: Beliefs and expectations about dignity}

The participants expressed personal beliefs about dignity that generally reflected the modern democratised version relating to the worth and value of all human persons. Commonly held beliefs in the group centred on the innate nature of dignity, dignity as socially constructed (values, mores), dignity as socially enacted, and dignity as changing and evolving. However when considering their personal dignity in the work context, the participants did not articulate a balanced, reciprocal expectation. The participants' expectations of how dignity would be expressed, differed based on who they were socially interacting with.

\section{Dignity as innate}

Participant beliefs about the innate nature of dignity were reflected in the language used to develop a group definition of dignity. This included words such as embodied, intrinsic, innate, essence, mana, yourself, spirituality, intactness, humanity, consciousness, felt, sensed and core. The unifying theme relates to the idea that dignity is a human right that exists at all times within an individual. The participants' understanding of dignity as innate included the idea of dignity as inviolable but simultaneously vulnerable ${ }^{4}$.

\section{Dignity as socially constructed}

Participant beliefs about dignity as socially constructed could be identified through descriptions relating dignity to a range of ideas: values, respect, context (age, situation, gender, culture, roles etc), worth, integrity, belonging,

4 'Inviolable' can be interpreted as unable to be violated - indestructible, or alternatively as not to be violated - sacred. The participants' understanding of the meaning is the latter as the former is incompatible with their belief about the vulnerability of dignity. (YourDictionary.com, n.d.) 
demeanour, propriety, honour, learned, taught, experienced. The participants believed that one acquires an understanding and sense of dignity as a consequence of being a participant in a social world.

\section{Dignity as socially enacted}

The participants clearly viewed dignity as relational and requiring reciprocity to exist. Dignity was seen to be predicated on respect. Within this was the notion that in order to experience dignity, there is a requirement to experience respect through either self-regard, regarding others, or by enjoying the regard of

others. ${ }^{5}$ Language that supported this view included social norms, given and received, active, reciprocal, allow for others, influenced, guides behaviour and attitudes, and socially constructed. The participants discussed and rejected the idea that dignity can be invested through power.

\section{Beliefs and expectations about dignity as a self-regarding individual}

Self-regarding dignity was believed to relate to both how one claimed it, and to how one presented and conducted oneself in the world. There was a range of perspectives expressed: a 'look', modest, proper, humbleness, taking pride, having a good name, reflection of a good upbringing, claim for yourself, individually defined, individually experienced, autonomous self, sustained by self, integrity, honesty. The participants clearly saw themselves as bringing through their sense of 'self' into the work context. While they identified with nursing as a body, there was still an expectation of the need to act in ways that they saw as personally promoting dignity. Even though the mantle of 'nurse' was assumed, the participants still regarded themselves as individuals with all of the attendant rights as human beings of worth.

\footnotetext{
${ }^{5}$ The terms 'respect' and 'regard' are used here somewhat interchangeably. 'Respect' is used to describe the underpinning imperative while 'regard' denotes the action.
} 


\section{Beliefs and expectations about regarding others}

Considered from the perspective of the nurse as a personal individual, the participants did not have much to say on the subject of regarding others. If this material was present it was obscured (overwhelmed) by the 'nurse mantle'. Of the material that was there, in terms of regarding colleagues and others (not patients), the sense was of offering the common courtesies and regard due to each other as people in the world; for example regarding others' feelings and their right to exercise reasonable choice and autonomy. Regarding the dignity of others was seen primarily as a balanced and reciprocal expectation based on regard and respect for others as fellow human beings. Language to describe this included allow for others, given, shown, imposed by others, genuineness, autonomy, choice, worth.

\section{Beliefs and expectations about being regarded as an individual person}

Beliefs about how others should offer regard to nurses, related to both the idea of reciprocity, and the effect of others' actions on ones own dignity: supported or eroded by others, offered, given, respect. Expectations about how they should be regarded as a person were mixed. There appeared to be an expectation that patients and families would regard them in their role as nurse rather than as an individual (although perhaps as an individual nurse!). Colleagues in contrast, were expected to offer personal regard, for example, allowing the expression of personal views and acknowledging their uniqueness. The dominant expectations related to how the participants expected to be regarded by their employing organisation and by their managers. The overarching expectation was that managers and the organisation would see and treat them as individuals, with personal needs and responsibilities, both within and outside the work sphere. 


\section{Dignity as dynamic and evolving}

Participants reflected that they thought of dignity as dynamic and evolving. Language used to describe this included evolving, shapes, changes, metamorphosis, coloured. However an interesting dichotomy emerged between the participants' expressed beliefs and what became evident when considering the data as a whole. While the participants' expressed beliefs were of dignity as constantly being shaped and evolving, the narratives that spanned many years of practice suggested otherwise. One possible explanation is that while dignity is developed from the time of birth, there comes a time when constructions of dignity become fairly set. What changes is not so much the person's belief but the person's response. It could be suggested that an inability to evolve and change beliefs about dignity is a cause of distress in contexts that change and challenge at a rapid pace. This was reflected for example in the participants' difficulty in reframing their expectations about what currently represents a 'good' level of patient care.

\section{The professional self: Beliefs and expectations about dignity}

The literature review established that the concept of dignity is enshrined in nursing as an other-regarding duty towards patients. Therefore it was expected that the participants' beliefs and expectations about dignity would be directly or indirectly shaped by the perspectives of the nursing profession. Three central beliefs emerged: first, nursing as embodied within both the profession's values and purpose and within nurses themselves; second, beliefs about dignity relating to and shaped by perceptions about nursing's relationship with society; and third, how the participants saw nursing as a profession enacting its role within society. The expectations that evolved from these beliefs reflected both the meritocratic and democratic perspective. Possibly because of the juxtaposition of these two perspectives, the expectations of how dignity would be experienced varied significantly depending on contextual factors. 


\section{Dignity as innate/embodied within the profession of nursing, the purpose of nursing and nurses themselves}

The participants developed a definition of the purpose of nursing:

Nurses bring a body of specialised knowledge and skills and value of our shared humanity in providing care that aims to make a positive difference in the delivery of health care. The essence of nursing is the specialised expression of caring.

Embedded within this statement are central beliefs about nursing: specialised, knowledge based, skilled, shared humanity, based on an ethic of care. This was further supported by references to how these central beliefs are embodied within the profession: 'caring' care, vocation, holistic, bring life experiences to nursing, sisterhood, calling, commonality of purpose. Being a nurse appeared to imply embodying, and at times privileging, the professional beliefs and purpose embedded in nursing. Valuing nursing traditions also featured frequently: I think that's how we were taught to be nurses. So we have continually developed our behaviours around this [regard for patient's dignity] for decades probably (1:3:18). The belief was expressed that belonging to the nursing profession involved more than putting on and taking off the nurse mantle. The participants regarded nursing as deeply meaningful and worthwhile.

\section{Dignity in the profession of nursing as socially constructed}

Dignity, from the professional nursing perspective was seen as constructed around an implied relationship between nursing and society; what is termed here as a 'social compact'. The social compact as expressed centred around nurses holding an esteemed and trusted position in society and in return enjoying the privilege of being allowed to provide skilled and intimate nursing care to patients. Language associated with this included esteemed/valued in 
our society, appreciated, revered, of worth, profession with own body of knowledge, trusted, shared empathy, privileged, special, crosses boundaries, holding patients' lives in our hands, allowed. The unexpected and interesting finding here was that in contrast to the beliefs relating to the personal self, a more meritocratic view of dignity was being expressed that included the belief that the profession of nursing has inherent dignity. This encompassed the idea of nursing holding a higher duty to advocate for and protect the dignity of patients. However, while a meritocratic perspective was applied to nursing, the perspective applied to patients was democratic, i.e. all patients have inherent and equal worth as human persons in the world. Traditional beliefs about altruism also surfaced:

The thing is, I don't know about today, but in our day we never answered back. We used to turn the other cheek. You knew your place and some patient would say something to you and you just held your tongue and went to the office and hit the wall. (1:3:158)

\section{Dignity as socially enacted in the profession of nursing}

The participants articulated beliefs about how dignity within the profession of nursing would be enacted. Unsurprisingly these beliefs also combined the meritocratic and democratic perspective.

\section{Beliefs and expectations about being internally professionally regarding}

The participants' beliefs centred on how the nursing profession presents and conducts itself in a way commensurate with the dignity of the professional role. This was expressed for example as confidence, constructing a professional identity, modelling behaviours that reflect who we are and our values, commanding respect, challenge our own culture, demeanour, stature, integrity.

We were moulded as nurses...you had to stand up for anyone who was more senior than yourself so in those days you stood up for 
everybody... and you looked forward to when you earned that right... and people respected you in that way. (1:1:32-36)

The participants shared predominantly meritocratic expectations about what constituted professionally regarding actions and behaviour. To professionally regard the dignity of the profession involved, for example, presenting a tidy professional demeanour, acting with integrity, constructing a nursing culture, modelling behaviours that reflect who we are and our values, thus drawing worth and meaning from being a member of the nursing profession.

\section{Beliefs and expectations about professionally regarding others}

How the profession should regard others was strongly focused towards patients and patient care. The dominant central belief was that nurses hold a higher duty to actively uphold and protect patient dignity. The dignity of patients was seen as vulnerable and requiring active protection. Language supporting this view included altruism, advocacy, duty, and protection. There was little material to suggest that the participants believed that they needed to offer anyone other than the patient (and their families) special regard for their dignity over and above that due to them as human persons of equal worth. This was not entirely borne out in the subsequent encounters that were described.

In keeping with their expressed beliefs, the participants' expectations about how the professional group should regard others showed marked variation depending on the recipient of the regard and on the expectations implied by the social compact of care that mandates a higher duty towards the dignity of patients:

I think it's about how we were taught to be nurses. [Dignity] is stuff that we continually think about and have developed our behaviours around for decades probably. (1:3:18) 


\section{Beliefs and expectations about receiving professional regard}

Beliefs about how the profession of nursing should be regarded related to fellow nurses (intra-professional) and others. Intra-professional regard related to the belief that nursing sustains dignity through reciprocal regard between nurses, expressed by more than one participant as the sisterhood. Being regarded by those outside the profession involved a more meritocratic belief that others should actively appreciate and esteem the profession's contribution to society: esteem, respect. How that esteem and respect should be demonstrated varied depending on who was offering the regard. For example there was a belief that managers would show regard through actions that supported the nurse to be positioned professionally. On the other hand, the participants articulated a belief that patients regard nurses primarily through the act of allowing themselves to be nursed. These beliefs are further explored.

The expectation of the participants that others should act to construct the nursing profession in its societal role, may stem from their beliefs about the meritocratic positioning of nursing in society as a result of the so-called social compact. How this regard should be expressed related to who was offering the regard.

Patients fulfilled their obligation to regard nursing, for example, by playing the role of the 'good' patient, not actively disrespecting nurses, and by the act of allowing themselves to be nursed. The participants expected society to demonstrate regard for the profession of nursing, for example the way nursing is positioned socially and legally with protected titles and scopes of practice. Employing organisations were expected to regard the profession through actions such as providing the time and tools to do the job, supporting nurses in the construction of a professional image, policies that enable the expression of the nursing body of knowledge, and meaningfully involving nursing in decision making. Other colleagues were expected to show regard by demonstrating respect for nursing's worth and value. 


\section{The nurse in practice: Beliefs and expectations about dignity}

The participants described 'being' a nurse as a construction that combined their embodied concepts of their personal self as well as embodying concepts and principles relating to their professional self. The democratic and meritocratic perspectives were reconciled (uneasily at times) within the construction of the nurse in practice. Of the two, the professional self appeared to dominate the personal self within the context of the work environment. There was some suggestion that this was reversed in life outside of work where the personal self becomes dominant but the professional self is still evident.

Looking at what the participants said that they believed about dignity in their construction as a nurse, it was interesting to see the juxtaposition of values and beliefs between the personal self notions of equality and reciprocity, and the professional beliefs and values based on meritocracy and the social compact.

\section{Dignity as innate/embodied}

Two embodiments were apparent. The notion of dignity as relating to human consciousness and equal human worth existed alongside the embodied values of nursing as a vocational calling.

Being a nurse is part of being me. Work is an artificial construct for nurses. Nurse is not something that you assume when you clock on and lose when you clock off. A really important part of me. (2:4:65)

What I thought was my practice was me. As a wife, a mother and the person I am outside of nursing. I bring them into my practice. (2:4:82)

\section{Dignity as socially constructed}

The participants' beliefs about the way they are socially constructed in their role of nurse drew strongly from the idea of the social compact, in particular nurses 
as trusted and esteemed, and patients as entitled to a higher regard in relation to the protection and promotion of dignity.

\section{Dignity as enacted}

Beliefs and expectations around how dignity is enacted as a nurse were dominated by the professional self.

\section{Beliefs and expectations about dignity promoting self-regarding actions}

The participants' beliefs reflected a synthesis of values drawn from their personal construction and their professional construction. The synthesis was weighted towards the professional rather than the personal self. This dual embodiment of dignity included belief in exercising choice and autonomy, genuineness, self sustained, modest/well mannered, humbleness, taking pride in what I am doing, claiming for oneself. The belief was that these strategies support the nurse to construct a dignified image that enables them to experience worth, value, and meaning.

The participants expected to exhibit self-regarding behaviour primarily aimed at constructing, maintaining, and upholding a professional image. In addition to the meritocratic representations such as exhibiting confidence, commanding respect, leading by example, demonstrating honesty and integrity, upright, controlled stature and emotions, trustworthy, set boundaries of behaviour, value own position, the participants expected to also take responsibility to learn, be informed, take ownership, change, participate, exercise choice, have a positive attitude, self advocacy, cultivating relationships, protect ourselves, lead by example, give self affirmation, be self aware, be self assured.

\section{Beliefs and expectations around how the nurse regards others}

Beliefs about the responsibility to act in ways that regard the dignity of another showed a high level of agreement between the participants, but there was wide 
variation based on who was receiving the regard. For example, the participants believed that the dignity of others was supported when they gave regard to their value as human beings, their need to feel respected, their worth, their autonomy and right to make choices. However the patient was seen as being entitled to a higher level of regard than for example a colleague or co-worker.

The participants expected to offer a high level of regard toward upholding the dignity of patients in line with the social compact: offer information, privacy, listen, right to choose, treat as an individual, ensure they feel cared about and for, meet needs and expectations, ensure they feel accepted and not judged, ensure safety. Expectations of how they would regard those other than patients were characterised by democratic perspectives such as treating all equally, respectful, valuing others, critical reflection, avoiding judgment.

\section{Beliefs and expectations about receiving regard as a nurse}

The participants were clear in their beliefs around what they needed from others in order to experience dignity, including being informed, consulted, included, supported, respected, protected, trusted, listened to, involved, accepted, given choices, recognised for what I do and who I am, able to exercise autonomy. However they did not believe that this regard needed to come from others in equal measure and this became apparent when looking at their expectations.

The participants' expectations relating to having their dignity regarded as a nurse varied depending on who was offering the regard; for example overt affirmation was expected to come more from colleagues and managers than from patients. The expectation of the participants was that others should act to construct the profession in its societal role. Patients fulfilled their obligation to regard nursing through for example, playing the role of the 'good' patient, not actively disrespecting nurses, and by the act of allowing themselves to be nursed: in giving we therefore receive (1:2:66). Colleagues were expected to provide feedback that confirmed that they were 'good' nurses and that they belonged to the professional group. Medical colleagues were expected to show 
regard through respecting the professional opinion of the nurse. Employing organisations were expected to regard the nurse through knowing her practice, supporting her professional decisions, supporting her autonomy, trusting her professional practice, and meaningfully engaging with her.

\section{Summary}

The beliefs and expectations about dignity that the participants bring to their work life are complex constructs that shape how they experience, interpret and respond to actual encounters. The key finding regarding the participants' beliefs and expectations was the variance in the way regard should be given or received. It became apparent that there is a hierarchy of regard evident in the participants' beliefs and expectations. For example the nurses clearly expect to give patients a higher duty of regard in the maintenance of dignity, and there was little expectation of equal reciprocity. Nursing colleagues were believed to be mutually deserving of a somewhat elevated level of conscious regard. The relationship with medical colleagues was interesting in that while the underlying belief was that mutual professional regard should be exhibited, the expectation that this would be the case was not strong. Other (non-nurse) colleagues were seen as requiring a basic level of reciprocity. The most surprising finding was that while participants expected a high level of regard from their managers and employing organisation, the need for nurses to offer reciprocal regard did not feature at all. These relationships are expressed in Table 1:

\section{Table 1: Giving and Receiving Regard}

\begin{tabular}{|c|c|c|}
\hline & \multicolumn{2}{|c|}{ Dignity given: Dignity received } \\
\hline & $\begin{array}{l}=\text { high } \\
=\text { high } \\
=\text { recip } \\
=\text { no n }\end{array}$ & $\begin{array}{l}\text { o regard } \\
\text { ness of need to regard } \\
\text { el of regard } \\
\text { gard }\end{array}$ \\
\hline \multicolumn{2}{|l|}{ Nurse to self } & D \\
\hline \multicolumn{2}{|c|}{ Nurse to patient } & D:d \\
\hline \multicolumn{2}{|l|}{ Nurse to nurse } & $\mathrm{D}: \mathrm{D}$ \\
\hline \multicolumn{2}{|c|}{ Nurse to medical colleague } & $\mathrm{D}: \mathrm{D}$ \\
\hline \multicolumn{2}{|l|}{ Nurse to other } & $d: d$ \\
\hline \multicolumn{2}{|c|}{ Nurse to manager/organisation } & $0: D$ \\
\hline
\end{tabular}


The fact that an imbalance in expectation was present suggested that the beliefs and expectations of the participants around how different players should demonstrate regard, might significantly influence how the nurse extracted worth, value and meaning in an encounter. It also suggested that to experience dignity, the majority of workplace encounters would need to be congruent of beliefs and expectations.

The other finding of significance was the depth of meaning and worth that the participants attach to the profession of nursing and the work of nursing. This suggested that their ability to be successful in their work would be a major factor in how they experienced dignity in their work lives.

\section{Part two: Encountering dignity}

The research participants developed a definition that underpinned their constructions of dignity and what it means to experience dignity:

Dignity is a human concept that relates to worth, value and meaning. Dignity is defined and sustained individually but is influenced, supported or eroded by others. When we experience dignity we feel a sense of; self worth, mana, autonomy, belonging, integrity, purpose, meaning, self respect, genuineness, spirituality, essence, and intactness. We support the dignity of others when we give regard to; their value as human beings, their need to feel respected, their worth, their autonomy, and their right to make choices.

The final part of the definition related to the contextual nature of dignity:

Achieving dignity is an active process that is context specific including; culture, situation, age, social expectations (our own and others), gender, role, and values. 
The study was centred on the work context of the participants. This section relates how the participants described encountering dignity in their work lives both through social interaction and through the environment.

The work contexts of the participants varied considerably but there was some consistency. Six of the seven participants worked in multidisciplinary team contexts. All shared the common work characteristic of being employees of health care organisations. Crystal and Ruby worked in a tertiary emergency department in roles that included a higher level of decision-making and autonomy than staff nurse roles. Emerald works in peri-operative nursing. Diamond worked in a rural hospital in a ward comprising inpatient acute and medium stay beds, and a small emergency department. Quartz was employed in a tertiary hospital and was involved in the administration of a particular therapy. Moonstone worked in a combined continuing care, step-down, and maternity unit. Pearl worked in an internal nursing agency in a major tertiary hospital.

Despite the diversity of settings, there was commonality in the core set of 'players' in the work context who the participants identified as the significant others that they interacted with. First and foremost were the patients (and their families), followed by nursing colleagues, other colleagues, managers, and finally the organisation ${ }^{6}$. In effect, the participants' beliefs and expectations around dignity provided a script that is played out in the social and environmental context of their work lives.

The participants were facilitated to consider dignity from a range of perspectives including interpersonal encounters, the physical context of work,

6 While an 'organisation' cannot technically qualify as a 'being', the participants positioned their organisations as sentient beings who impact directly on their experience of dignity. The decision to consider managers and the organisation as one was ultimately influenced by the way in which the participants positioned 'managers' and the 'organisation as interchangeable and representing the same perspective. 
and in terms of how they saw themselves supported. The encounters that the participants shared during the workshops illuminated vividly the complex interplay that takes place in each moment. Encounters could be categorised as dignity sustaining, dignity affirming, dignity eroding, or dignity infringing. The first two categories related to encounters that were congruent with the participants' expectations about how dignity would be experienced. The second two categories related to encounters that were in contradiction to the participants' expectations. The balance between congruent and contradictory encounters is explored.

\section{Dignity in congruent encounters}

A congruent encounter was one where the nurse was able to draw a sense of worth, value, meaning, and respect from the interaction. To be congruent, the interaction needed to broadly match the nurse's beliefs and expectations about both self-regard, regarding others, or receiving the regard of others.

\section{Congruence in self-regarding encounters}

Self-regarding encounters involved the nurse acting in a way that supported her personal or professional identity as someone worthy of respect.

\section{The personal self}

Dignity relating to the personal self was revealed in encounters where the nurse was able to express her individuality; still part of the professional group, but with personal idiosyncrasies that are respected and valued by others:

I've got a nickname of M.S. Annual Leave. Because every time I come in I say "it's annual leave for me today isn't it?" And "no, you've got to go to eight places today". And everybody laughs. And it just lifts the whole atmosphere. And even out in the corridor, "you don't want annual leave today M?" And that bit of comedy lifts it. (1:6:107) 
I do silly things at work. You might not believe it. And I wore a pen [a blue pen with googly eyes and spiky hair]. And the girls just accepted it that that's me....and everyone talked about it all day that I wore it. (2:1:42)

\section{The professional self}

The importance of physical markers of professional identify were illustrated in a discussion about nursing uniforms:

I was putting on my uniform and thinking about what a uniform means to me. And uniforms are strange things I think because they allow you to be a different person and I absolutely know that it allows me to be a different person. It's probably about that privileged intimacy with patients that we don't have with people that we bump into in the street. (2:2:12)

The importance of self-regarding action was illustrated in the following encounter that related to the nurse having to rebuild confidence following an episode of burnout. The participant makes a link between employing affirmative strategies and experiencing dignity and confidence:

I probably cultivated some of these [self-regarding] strategies over the last few years particularly. And it's allowed me to have dignity and confidence to a much greater degree than say five years ago. (1:6:96)

\section{Congruence in patient encounters}

Stories relating to the act of nursing patients were deeply connected to the nurse experiencing dignity. There was a deep and consistent understanding among the participants. Of the stories that were told involving nurse-patient interactions, all were invested with the idea of mutuality, meaning that for the 
nurse to extract worth, value and meaning from the encounter, a similar outcome needed to be present for the patient:

I met the most amazing woman who had a leaking AAA. And unless they operated on it she was going to die. And she had nobody at all in the country. And she chose not to have the surgery...It was just the most amazing, the most amazing privilege to be with her and supporting her in those decisions that she made...I felt that I was supporting her dignity and her decision making processes. I certainly felt valued and I felt as if l'd made a difference...she valued the input and support that I provided because there was nobody else to do that for her...and all she wanted to do I remember was watch the last episode of a TV programme. So I actually spent time with the Duty Manager and asked for her to go to (ward $x$ ) because she could have her own room and TV...and she saw the last episode and died. $(1: 4: 70-88)$

I thought about a palliative care patient where we involve the family in the care and after the patient had died they came and said thank you very much for all the nurses had done... that makes the whole team feel proud of what they've done and the fact that its had a good impact on the family. It hasn't been a horrible event. It's been a sad event but we've made it as memorable as possible. (1:4:110)

You know it's really difficult to separate your own dignity from that of your patient. $(2: 1: 51)$

Is there a direct relationship between giving or allowing somebody else's dignity like the patients?...there's a direct relationship back to you in the same way, l'm thinking, that if you take someone's dignity then it removes dignity from yourself. (2:1:53)

That's the thing for me is the fact that with our knowledge and skills and training and environment, we get to make a difference in 
people's lives, but you're right it is actually that intrinsic thing that is a privilege... to be able to deliver that. (1:2:39)

I can personally go home at the end of the day and it can have been a horrendous day, but there can still be incredible satisfaction in that. To me it matters, I can go home and feel that however awful the day was, I did make a difference... I contributed, I made a contribution. (1:2:40-42)

In the situations that we get into with our patients, I mean, the ability to support someone to die with dignity is a privilege. (1:2:57)

So where's what's in it for us? That's about what we give, but in giving we therefore receive. (1:2:66)

The essence of nursing is making that difference. (1:2:97)

The care is about being trusted and respected as an individual. (1:2:109)

[When thanked by patients or families] Sheer surprise - surprise because what we had done had seemed relatively small. And there was no expectation that you would be thanked or recognised or anything. You just did it! And when it was acknowledged and thanked, I was surprised. If not stunned. It validated my practice about what I do. I'm on the right track, what I do is good and that it matters. It is important to me that it does matter to patients. But that's not why I do what I do. (1:4:98-101)

\section{Congruent encounters with nurse colleagues}

There were a range of stories relating to encounters with nurse colleagues. These could be loosely divided into; belonging to the professional group; experiencing reciprocity or affirmation; and being valued as an individual. 


\section{Belonging to the professional group}

I remember being in agency when it first started and there was a feeling then - what are you doing here? You're not wanted. That was the feeling I got. But it changed over the years and they sayoh great! (1:3:179)

I walked into [ward y] yesterday - M! You're here! Great! And I thought right, I feel good. (2:2:163)

We try and have every now and then a thank you day. Just morning tea for someone. (1:4:10)I think if you receive it enough you tend to appreciate its value and dish it out more. (1:4:20)

\section{Reciprocity/support/affirmation}

When your workmates support you, you feel grateful - part of the giving and receiving. That can reduce your stress levels too and you feel more relaxed. The thing is that they're recognising you and giving you credit for your - what's special about you as a nurse. You know that you can give it your all...(1:4:33-53)

It's just the little things. Because I know as an agency nurse you go into the ward and you're given a load of patients and most coordinators say "do you think you can manage that M"? And they're not saying it patronisingly. And they say, "if you don't know something just come and ask and we'll tell you". Yes, you feel as though you're a team. (2:2:170)

[Affirmation from colleagues]. Often it reinforces your good feelings about yourself...it validates how you feel about yourself...It's our humanness I think. We do like people to affirm that what we've done 
was good... enough to make me come back to work... but if you have team affirmation it is better and it makes you want to come back at the end of the day...It nourishes. (2:2:173-176)

You think about all the different words that you might use for dignity it's satisfaction and it's equal, it's equal on both sides. (2:2:259)

If someone's thanked you for the care they've received, you tell the other staff about it so it's definitely infectious because everyone hears about it. (1:4:1)

\section{Congruent encounters with medical colleagues}

Congruent encounters with medical colleagues centred on either polite exchanges or encounters that affirmed the nurse's sense of professional worth.

Last year both our machines broke down and it meant staying on waiting for a replacement so it was ready for the next day. And the consultant came to see me and said thank you so much - it makes you want to go that extra mile - give that little bit more. (1:4:6)

\section{Congruent encounters with managers or the organisation}

There were few stories about congruent encounters with managers or the organisation. Of those that were shared, the stories invariably involved an act of regard from the manager to the nurse.

We had a manager who at Christmas would give every single worker a \$2 scratchy. Out of her own money. And it was so valued. And if you got another $\$ 6$ out of it you felt fantastic! You'd think you'd won lotto. At Easter she'd have a big basket of Easter eggs and she'd paid for them. She really valued her staff. (2:5:125) 
[On being supported with education]. I absolutely feel extremely grateful about the level of support that I have had from the organisation, I haven't always had all my costs covered but I accept that because I have a responsibility as well and I am very happy to come to the party. I don't expect support to be handed to me on a plate but as I say l've had incredible support - it's been amazing, it never ceases to amaze me. I feel really lucky (1:5:116). It does support the value that I feel in trying to keep my learning up to date it provides validity if you like which is really important to me. (1:5:118)

\section{Responses to Experiencing Congruence}

\section{Emotional responses to congruent encounters}

The participants expressed a range of emotional responses associated with encounters consistent with their expectations and beliefs about dignity. Congruent encounters were either dignity maintaining or dignity affirming. Dignity maintaining encounters contributed to a sense of emotional equilibrium, while dignity affirming encounters could be shown to lift mood, self-worth, and confidence. Responses were layered throughout the entire transcript and have been extracted to illustrate the range:

\section{Dignity maintaining encounters}

affirmed, feel focused, know I made a positive contribution, accepted, valued, comfortable, satisfied, privileged, of worth, respected, empowered, spiritual, intact, peace of mind, equilibrium, that I have something to offer, in control, grounded, inner harmony, equality, at peace, I have a purpose, sense of belonging, feel like a team, balanced, I feel in touch with my values and what is important to me 


\section{Dignity affirming encounters}

feel special, increased mood, infectious (in a good way), increased energy levels, decreased stress level, lucky, revered, satisfied, appreciated, grateful, more relaxed, successful, amazing, positive, reinforces good feelings about myself, validated, nourished, genuinely regarded, proud, positive sense of accountability, wonderful, professionally respected, validated, professionally confident

These responses suggest that congruent encounters have an overwhelmingly positive effect on the nurses' sense of dignity. An encounter that maintains dignity is not generally consciously noted. Affirming encounters in contrast, result in conscious awareness of the difference the nurse's action has made to another.

\section{Acting with agency}

In addition to experiencing an emotional response, Hodson (2001) suggested that any worker will express personal agency in pursuit of their own dignity as either citizenship or resistance. The citizenship activities cited by the participants appeared to be almost exclusively reinvested in the patient in the form of discretionary effort, or in helping colleagues to achieve their work with patients. The data showed that the outcome of experiencing congruence ranged from a sense of equilibrium that enabled the nurse to focus energy on her core purpose, to overt affirmation that inspires loyalty and extra discretionary effort. For example, I want to go the extra mile, give that little bit more, give it your all, makes me want to come back tomorrow.

The participants described experiencing equilibrium drawn from multiple repeated daily encounters with others and the environment:

...the word satisfaction, peace of mind, keeps coming to me. People ask me what I want in life and I say 'peace of mind'. And it is, it's being wanted, oh it's just everything. And you've got no qualms 
about anything. It doesn't happen a lot does it but you're at peace sometimes. I think that's what we're striking here. Dignity is satisfaction and peace on both sides and peace of mind. (2:2:255)

When I experience dignity, I have this inner sense of equilibrium. I'm not tested beyond what I can cope with, I'm not dealt with in a way that makes me feel diminished, I feel like what l'm doing is useful, so... and I think it's not a perfect balance, it doesn't have to be, but it's not tipped over to the point where I can't come back the next day, which some of us have experienced. (2:2:258)

In patient encounters equilibrium was available to the nurse simply as a result of engaging in the act of nursing. In the act of allowing themselves to be nursed, patients played a significant role in the way the nurse extracted worth, value, and meaning:

[Nursing a dying patient]. ...it was just the most amazing - privilege to be with her and support her in those decisions that she made...I certainly felt valued and I felt as if l'd made a difference. (1:4:70-74)

Affirmation of dignity was experienced in daily encounters at a more conscious level, as opposed to equilibrium, which provided the daily 'bread and butter' of a dignified work experience. Overt affirmation from patients and families was seen to be a gift and received with joy:

Well the thing is that they're recognising and giving you credit for your - what's special about you as a nurse, to that family - to that patient. (1:4:39)

Colleagues were felt to both support equilibrium and directly affirm the nurse through positive, inclusive behaviours:

It may be that day you're looking after the palliative care patients, and that patient's dying and you really need to be supporting the family. It 
may be somebody comes along and says, look give me your other two patients, you go and do what you need to do. Because you're the best person for that job at the moment. (1:4:23)

Medical colleagues maintained the nurse's dignity when they dealt with the nurse in a reasonable manner or affirmed the nurse as a skilled professional and valued member of the team:

[Interaction with a medical colleague] ...I expected him to be really grumpy when he arrived, and so I stood back and he came bowling in....and he was niceness itself! And very very pleasant. Actually thanked me, you know for spotting that this treatment hadn't been prescribed.... found him really supportive in all ways, you know, during the treatment itself, after the treatment. He was prepared to listen to what I had to say. (2:2:85)

Managers and the organisation both maintained and affirmed nurses' dignity when actions and decisions could be interpreted as supporting the nurse to be successful in the delivery of the social compact (professional regard), and/or showed regard for the nurse as an individual (personal regard).

I actually felt respected when my organisation invested in needleless systems, at huge cost... because it wasn't for the patient it was for us. (2:3:15-19)

If I was confident that those things were being given due regard - I'm going to be looked after as a person, I'm going to be looked after in terms of the work that I do, and l'm going to be looked after as part of the profession that l'm part of... that would be a good start. (2:4:204) 


\section{Dignity in contradictory encounters}

A contradictory encounter was one where the nurse could not draw a sense of worth, value, meaning, or respect from the interaction. Contradictory encounters were at odds with the nurse's beliefs and expectations about how dignity should be experienced through self-regard, regarding another, or receiving the regard of others.

\section{Encounters that are not self-regarding}

There was a definite gap between the participants' beliefs about the affirmative actions that nurses should take and a lack of evidence that this is happening in practice:

I remember a period in my career where I became overwhelmed and completely exhausted. And reflecting back on it, I didn't do that stuff [self-regarding strategies]. And once l'd recovered, I had learned that I need to do that stuff every day. And if I don't I could spiral back down again. And I need to do all those things - to greater and lesser extent every day. And l've learned that the hard way. Because I got to that bad place because I wasn't doing it. (1:6:98)

\section{Contradictory encounters with patients}

During the discussions there were several references made to the need for patients to give regard to nurses. Generally this expectation was around patients being co-operative with care and not overtly abusive towards nurses:

[Dealing with a patient in ED who refused to wait quietly for medical treatment]. We were in overload, it was heaving - just the usual. And he starts making a huge fuss because he had to wait...he wasn't prepared to listen to anybody. He was just obnoxious....Anyway he was really rude, really obnoxious. The medical registrar came out 
crying and he followed her aggressively.... asked him to take a seat and he wasn't having any of it and we had to call security... it was like the squeaky wheel. "I don't give a stuff about anybody else. I'm going to make as much noise and be as obnoxious as possible. And look what I get. I get everybody running round after me. I get exactly what I want"....certainly he took dignity from us. Anyone that he had to deal with...and it didn't matter how much people tried to explain, support - he was offered everything we had. And it was a really awful situation to be in. I was pretty angry that the Duty Manager came down and responded - it was like we were the ones that were at fault. Like we had all the responsibility and he was allowed to behave exactly as he chose. (1:6:13)

Caring relationships are about partnership aren't they. And partnership denotes equal responsibility and power. So I think that there has to be a responsibility from employers, from patients... that they're going to be a part of that partnership. Just as we've had to agree that we are going to be a part of that partnership. And so there's give and take and compromise and negotiation...But when the power difference is distorted from whoever, the patient's attitude, the organisation because of workload issues or whatever, it ceases to be a partnership anymore. (1:6:44). And when the power is unequal - power is probably not the right word - responsibility, when the responsibility becomes unbalanced then somebody's dignity is infringed. (1:6:46)

\section{Contradictory encounters with nurse colleagues}

There were few accounts of contradictory encounters with nursing colleagues. The main themes related to actions that demean or diminish the individual, or relate to a negative culture: 
If your other team mates, particularly those what are senior to you are demeaning towards you, you actually lose that self respect, that dignity its eroded and you start to feel of no value. (1:1:13)

It's easy to go down to someone's level to a negative, than to come up to a positive. Because the positive person somehow gets sucked down unless you're strong. It's hard to stay up there. (2:5:91)

\section{Contradictory encounters with medical colleagues}

Contradictory encounters with medical colleagues were predominantly around times when a doctor was verbally abusive or deliberately uncooperative:

And that incident actually - I ended up having to write an incident form because it actually interfered with patient care. And this happened years and years and years ago. But is just - I can still feel how upset it made me, and how sick I felt. And it was just the most awful, awful feeling. (1:4:127)

\section{Contradictory encounters with managers or the organisation}

The highest level of contradiction to beliefs and expectations was found in encounters between the nurses and their managers, or nurses and the organisation. Three categories of encounter emerged. Those relating to the 'organisation' as an entity, the organisation as responsible for the environment of care, and encounters where managers were perceived to be acting as instruments of the organisation.

\section{Contradictory encounters with the organisation as an entity}

I think one thing that's making it complicated is all this bureaucracy and all these compliance issues we now have - I mean, you know, we've got to have compliance to drip a bit of wee on a stick. Until you're certificated you can't do that. I just think that it's almost 
ridiculous... and the fact that there are so many compliance issues in the way of education.... when it comes to individual learning and individual interests I can see that people are going to be restricted because there is so much [expletive] going on. (1:5:120-122)

Personally I'm never going to put my hand up to say that my blood glucose certificate has expired...yeah so when your login doesn't work, you go, oh bugger! And someone will say oh here, use mine. Which is an absolute sin, an absolute no no. $(1: 5: 134,138)$

\section{Contradictory encounters relating to the environment}

I think you get a lot back from your patients and your patients' families...but then the paperwork and the computers just diminish that. $(1: 2: 8,13)$

If we can't give the patients the resources we think they need we think that we have done a bad job. (1:5:13)

[Not having the resources]. I think it does affect your dignity...because it's hard to feel efficient and professional when you expect the cuff to be there and you've got to run away and find a cuff and it will take you 10 minutes because you have been interrupted, that does affect me. (1:5:40)

We have got all these different sort of curtain rails and curtain hooks and then we haven't got enough of all the same curtains so for example in one cubicle it might be three different coloured curtains and you will be jolly lucky if they meet in the middle and it's a constant battle. They are all hanging down and its just a nightmare...it does have an effect on how proud I am of my work environment and how professional I feel and therefore...how I feel about the type of work and where I work and how I work and how efficient and effective we are and all that sort of stuff...because if you 
can't get your curtains right what hope have you got of recognising my heart attack...I mean you know...and it definitely does affect me and it is a constant niggle to me that every time that I close the curtains l've then got to find a safety pin or get someone to guard it so it doesn't gape open...it's silly little things but it does make a difference. (1:5:45)

I want my manager to understand our world and the challenges that go with that... and to understand people.... and how annoying it is to have to pin the curtains together and although some of these things seem like such little things, how huge it can actually be and the impact it can have on staff. (2:5:112-115)

\section{Contradictory encounters with managers as instruments of the organisation}

I'm starting to stand out from the crowd. I'm starting to claim for that extra half an hour of overtime - but I have been confronted in the past couple of weeks about "why is it only you that's doing overtime"? And I said, for a 100 years I haven't. I've just turned the other cheek and done it. And I thought, I'll claim now. But nobody else ever claims! But I'm still getting, "M. your time management is bad" I was told, "you've got to stop helping people", and I was the only one that was central line certificated... and I said that. But she said "you've got your own work to do". I just shut up after that. I thought, I can't fight this.. It saps your energy. It saps your positivity. And that then has an impact on everyone you have an interaction with including the patients, including other staff members, and including the organisation...they steal your motivation and they steal your energy. (1:6:64-71)

It's demoralising. I was asked to do the six monthly controlled drug audit. And I thought, okay if I get time. I was the only RN on. I had no EN, I had four hospital aides with me. So I thought, l've got to get 
this thing done. It was a frantic night, but l'd been told that it was a legal requirement...II was still writing notes at 12.30 p.m. I should have been off at eleven. In fact I had come in early to do a medicine management thing and the manager had said "oh you can go home at 10.30" but because they sent the other RN away I was in overtime already. And I filled in my timesheet for overtime and I got told that it was declined because of my time management. And that totally demoralised me. (1:6:72)

In terms of the effect and the influence on practice and care, it distracts a lot. Not that we intend it to. A waste of energy. Negative energy. You can't think positive because it's eating away at you. (1:6:78-82).

[On claiming overtime]. I feel like the odd one out. I am placid. But I am determined to see this through. They'll [the managers] probably win like they usually do but I mean to have a go. (1:6:85).

In my workplace, I think that we feel the most challenged by management...[we react]... to what you need to resist that represents challenges to dignity. (1:3:125)

At the end of last year I got my last assignment back and I got an A which really surprised me...l approached my managers about further study and I automatically sailed in there thinking they would give me the' hey go for it' kind of thing but they said no, we don't know who is on annual leave in March next year. It was just closed doors and I was just quite indignant. I had to give up the CTA funding.... I became really angry. It affected my work actually because I thought I don't want to go to you guys for anything now if you're not going to support me in wanting to study. Surely the education and the knowledge I'm getting is going to help my work, my environment and my patients...I was really angry - powerless. I felt powerless. (1:5:105-109) 
There are two common threads running through the encounters with managers or the organisation that relate to the idea of the social compact. Either the encounter infringed the participant's dignity around the professional self or it related to failing to provide an environment that supported the delivery of quality nursing care.

\section{Responses to Experiencing Contradiction}

\section{Emotional responses}

As with the consistent encounters, the participants expressed a range of emotional responses that were associated with contradictions to their expectations and beliefs about dignity. These were layered throughout the entire transcript and have been collated as either relating to erosion of dignity or being a direct infringement of dignity:

\section{Erosion}

eroded, self doubt, saps your energy, sucks energy, distracts, eating away at you, resentful, vulnerable, stressed, saps your positivity, no way to win, steals your motivation, constantly irritated, annoyed, worried, drained, exhausted, overwhelmed, lost my essence, shattered, hating it, of no worth, unfulfilled, deficient, frustrated, lost, tipped over, empty, defensive, less connected, chips at your self esteem, unsafe, unwelcome, unsupported, done a bad job, constant niggle, powerless - so powerless, not trusted, disrespected, this place sucks

\section{Direct infringement}

diminished, feel terrible, feel really really bad, criticised, hideous, upset, horrible, sick (physically ill), awful awful feeling, affected patient care, shocked, a blubbering mess, wanted to go and hide, not be a nurse ever again, standing on a diving board and someone takes it 
away, that terrible sinking feeling, mad, never going to put my hand up, infringed, no way to win, steals your motivation, at the mercy of another, can't erase it, nasty, unfair, distressed, aggravated, judged, nightmare, turmoil, gut wrenching, crappy, demeaned, pricked my heart, disappointed, attacked, shattered, not a good nurse, destroyed part of me, floored, professionally disrespected, exposed, scared, policed, misunderstood, devalued, abused, guilt, at fault, shaking inside, worried, two inches tall, indignant, really angry

Among the most interesting findings was the power of moments or encounters that did not fit with the nurse's beliefs and expectations around dignity. Contradiction was experienced in two ways, erosion or immediate infringement.

\section{Understanding erosion of dignity}

Erosion was generally experienced as an ongoing process of small frustrations or infractions relating to the overall quality of the workplace, patient care, and social interactions:

I think, you know, we can lose our dignity by giving it away, you know, the choice thing, but I think it can be eroded. We use that word in here. The eroding of it. Like over time it can be eroded or it can be sustained. Yeah, events happen over time and each time does it get eroded a bit and then finally its just gone and then what do you do? (2:2:129)

The participants also gave examples of where erosion of dignity was occurring but a single event became the tipping point:

[The nurse]...had something very dignified going on between herself and this patient - a very personal, intimate moment - she was looking past all the technology and doing something very human and intimate and someone, a colleague came and diminished it - trashed 
it - and in that moment she decided that she wouldn't do this work any more. It was the straw that broke the camel's back. (2:2:262-266)

It's that erosion thing again. Like a landslide, you can survive a few rocks". One more little bit of dirt and away...one more village. (2:2: 280-285)

\section{Understanding direct infringement of dignity}

Immediate infringement involved an overt moment in time when the contradiction was immediately apparent. A single contradictory encounter could profoundly and negatively influence the response of the nurses.

Can I give you an example of a nurse's choice and how her dignity was completely destroyed? On a particular day when the Charge Nurses said that everyone could go home 20 minutes early. And this nurse was still tutuing [going back and forth] with the patients and she decided to take her time on writing patient notes up, and the manager wrote this report that she was struggling to complete her notes. When she actually left at the right time she was criticised for it. And it made her feel really, really bad. That removed any sort of dignity she had of what she felt were her values of being with the client and taking her time and actually completing her contract with the hospital. (1:3:204)

\section{Expressing agency in response to contradictory encounters}

In terms of the agency that was exhibited in response to contradictory encounters, in many instances it was difficult to see past the distressing emotional response to identify the act of agency. The main resistance strategies that were articulated involved some form of withdrawal, whether of co-operation, withdrawal into the self, or withdrawal from the workplace as absenteeism or resignation. However the finding that ran counter to Hodson's (2001) research related to the nurse's response to infringement of 
patient dignity or needs. The most common response appeared to be increased effort. So for example, faced with the situation of insufficient nurses to care for the patients, the dominant response would be to increase effort in an attempt to achieve a good outcome for patients.

What is not obvious when these responses are taken out of context is the nuances associated with the circumstances in which the encounter occurred. For example an encounter that was interpreted as immediately dignity infringing, such as abusive behaviour, evoked an immediate negative response: diminished, angry, shocked, hideous, distressed. Lower level contradiction such as that associated with ongoing poor staffing or lack of resources invoked a more insidious response: drained, exhausted, lost my essence, unfulfilled, less connected.

It was an interesting finding that the participants constructed a list of positive strategies that they could use to sustain their own dignity, for example affirm myself, command respect, advocate for ourselves, take ownership, but there were few examples given of actually taking these actions. This suggested that their beliefs about what they could do were not well translated into selfregarding actions. This may be a factor contributing to their difficulty in achieving a sense of equilibrium in their work, because erosion or infringement is not effectively countered.

\section{Part Three: The balance between congruence and contradiction}

Earlier it was suggested that for a nurse to experience dignity, the balance of encounters needs to be congruent with beliefs and expectations. It was interesting therefore to see how unbalanced the scales are for the participants when comparing what is expected and what is encountered.

\section{Encounters with patients}

The research findings suggested that overall the participants receive a level of regard from patients that is largely congruent with their beliefs and 
expectations. The nurse expects to be regarded as a skilled professional and asks for little more than common courtesy and being allowed to provide nursing care to the patient. However the inability to reciprocate in providing an adequate level of regard for patients was a recurrent source of distress. This distress was associated with not being able to meet patient needs. Interestingly the feeling of responsibility for not achieving regardful patient care extended beyond areas that the nurse had any control over. There were several accounts where the nurse expressed distress on behalf of the patient for systems and process failures outside her sphere of influence:

So if we can't give the patients the resources we think that they need then we think that we have done a bad job. (1:5:15)

I know in the Emergency Department, 90\% of the nurses run around with this incurable guilt because the patients are waiting. (2:2:99) It's in our nature. They come to ED because they need something from you. They need you to be able to get a doctor to them. (2:2:104)

We take the responsibility that their wait is our fault. I feel apologetic - I'm constantly apologising and constantly trying to move heaven and earth to try and make the wait five minutes shorter. (2:2:105)

Our work is determined by people other than ourselves. We're basically told, here is your workplace and here is your work, now you need to make that fit...So if we can't achieve that...somehow we can be held deficient by others, or we hold ourselves deficient. (2:4:112)

So essentially the nurse attributes to herself accountability for parts of the patient experience over which she has little or no influence. It also appears that the nurses are able to extract worth, value, and meaning from patient encounters most successfully when they also believe that the quality of the encounter for the patient was successful. This came through as a significant and ongoing source of contradiction for the participants. 


\section{Encounters with nurse colleagues}

The assessment of this area was 'could do better' but on balance the feeling was more one of congruence than contradiction. It appeared that the nurse feels a somewhat higher level of duty towards regarding fellow colleagues. The four areas of contradiction that came through were; not giving each other enough direct practical support with the work, instances of collegial abuse, not being supported for speaking up, and not feeling that they belonged to the group.

\section{Encounters with medical colleagues}

This was an interesting area. The participants expressed beliefs that indicated that medical colleagues deserved to be affirmed professionally (the meritocratic perspective) and that this should be reciprocated. However the encounters showed that overall, the participants did not really expect to be professionally affirmed by their medical colleagues and in fact were grateful for simply not being disrespected. Several participants used similar language to express their response to being acknowledged: He actually thanked me; He even thanked me; Actually thanked me, you know. Basic levels of regard were interpreted by the nurse as giving strong affirmation of worth, value, and meaning.

\section{Encounters with other colleagues}

Although other (non-medical, non-nursing) colleagues received occasional mention, they did not really feature as major players. Certainly the participants did not articulate that they sought or drew significant affirmation from others in the work context over and above what would be expected in any reciprocal social interaction.

\section{Encounters with managers and the organisation}

There were two important findings in this area. The first related to the employed status of the participants, and the second to the participants' expectations of 
how managers and employing organisations should regard nurses. Given that all of the participants were employed by their respective organisations to 'nurse'; it was an unexpected finding that no part of the way they constructed worth, meaning and value in their work life appeared to be related to their role as a member of their organisation. There was not one story that indicated that the nurse experienced dignity as a direct consequence of being an employee of that organisation. The significance of this is that although, logically, one would expect to have found a construction relating to dignity that related to the employed role, this appeared to be completely absent even though it was probed for. Table 1 suggested that the nurse expects a higher duty of regard from managers and the organisation, but perceives no requirement to reciprocate. There is an inherent tension in this situation that was confirmed by the encounters. There was not one encounter where a participant described acting with intentional regard toward a manager or the organisation. Only one participant, (who has previously held a management position), offered any suggestion in the discussions that managers may benefit from being regarded in their own right.

Interestingly where an encounter with a manager or the organisation was potentially able to be interpreted as a regarding action, at times it was interpreted positively, but more often, the regarding action or decision was seen to have been made for pragmatic reasons:

Actually, I felt respected when my organisation invested in needleless systems - at a huge cost...[but]...did they decide to protect us from needles because there had been a few needle pricks and it was proving to be a hassle with health and safety? (2:3:15-20)

[On District Nurses not having mobile phones]...they felt that they had no worth...in the organisation... because they didn't matter. It didn't matter if something happened to one of them....they completely felt that their lives and safety was not regarded. (2:3:3941). 
And when they did get them, [mobile phones] I bet it didn't have the same value then, because they really had to fight to get them... so it's somewhat grudging. (2:3:46-47)

The conclusion drawn was that, far from managers and the organisation being seen as collaborating with the nurse towards a shared agenda of patient care, they were more likely to be viewed as impediments to the fulfilment of the social compact. This was illustrated for example in the stories about the uniform, where the organisation was seen as not supporting nurses to professionally present themselves, in the deep distress when the nurse was challenged for working past the end of the shift or claiming overtime, in the denial of professional education opportunities, in not providing sufficient 'tools for the job', in not providing sufficient nurses to complete the care satisfactorily, and in not supporting nurses in their professional decisions.

\section{Part four: Summary of findings}

\section{Understanding dignity}

The participants in the study described dignity as a human right conceptually relating to worth, value, and meaning. The nurses demonstrated through articulation of their beliefs and expectations the worth and meaning they attach to being a nurse and the act of nursing. To nurse is to respect and be respected in particular ways. Broadly, the nurses expect respect that is commensurate with their status as a human person of worth. Equally they expect to regard and be regarded in ways that visibly demonstrate respect for both being a nurse and the act of nursing.

The participants' constructions of dignity were drawn principally from the interlinking of the values and beliefs of the personal and professional selves. The personal self understands that dignity is based on the democratic perspective of persons of equal worth. This translates into beliefs, expectations and behaviour characterised by mutual respect, affirmation of worth and value, belonging, and being an individual. 
The professional self embodies the beliefs and expectations of nursing as a professional group. The professional self shares the basic democratic perspective of dignity as equally invested in all people. However, the professional self departs from the beliefs and expectations of the personal self in two key regards. The professional self believes in the existence of a social compact between nursing and society, that on one hand expects nurses to take on a higher duty with regard to the dignity of persons in the role of patient, and on the other hand expects nursing to be regarded and esteemed for the worth and value of the professional role. The absence of a third construction, the 'employee self', was an unexpected finding.

\section{Experiencing dignity}

The participants had clear expectations about how respect and regard should be demonstrated in the context of their work lives. In particular, the nurses held strong beliefs about the roles of others in the expression and achievement of dignity. For the participants, every moment represents an encounter with dignity. The majority of these moments pass under the radar of conscious awareness. However they can nonetheless be profound. For example, a nurse in the act of being present for a patient at a time of vulnerability is regarding another and supporting dignity. The nurse may or may not consider it of any great moment; it is just what she does. The patient in contrast may feel a profound sense of being regarded that speaks to their innate worth. A manager turns down a nurse's application for professional development. There is no intention to regard or disregard, but the nurse might interpret the decision as a judgment about her value, and the meaning of the work that she does. A doctor takes the time to thank the nurse for her part in a clinical encounter. The doctor intends to give regard but does not appreciate the magnitude of the effect of the affirmation on the nurse's sense of dignity. New tympanic thermometers arrive on the ward. The organisation supplied them as necessary tools for the job. The nurses interpret their arrival as a demonstration that the organisation values and regards them in their professional role. 
In all these interactions, the signal that is received speaks to the other's innate worth. Where the variance lies is in the expectation of who is expected to show regard and in what form. While this variance is obvious on a first level of analysis, it was also apparent that the participants had thought deeply about the relationship between work as the place of care, work as caring for the patient, and self care. This became more evident when the nurses revealed how they deal with encounters that are contradictory to their beliefs and expectations about dignity.

Each encounter, each moment, is invested with the potential to maintain, affirm, erode, or infringe personal dignity. Encounters could be seen to be either congruent with beliefs and expectations about dignity, or contradictory. Over time the balance of the encounters influence whether the nurse experiences an overall sense of equilibrium or disequilibrium. Equilibrium was associated with positive emotional responses and positive agency. Disequilibrium was associated with negative emotional responses which could be associated with either increased discretionary effort (citizenship) or various forms of resistance.

The workplace was seen as contested terrain. The nurses in the study described workplaces that are fraught with contradiction, in particular relating to a disconnection between their expectations of the regard required to support the social compact, and the reality of their work environment. The focus of discontent, the area where dignity was seen to be most significantly infringed, lay in the perception that managers and the employing organisation are failing to provide an environment that supports the nurse both as a professional and in the work of nursing. In contrast, the areas where dignity was most likely to be seen as maintained or affirmed arose from daily positive interactions with nursing colleagues and the act of nursing patients in ways that made a positive difference. Being seen as a respected professional and being successful in the act of nursing had the strongest association with the ability to extract worth, value, and meaning from the work experience. 


\section{Sustaining dignity}

The positive strategies that the nurses said that they could use to sustain dignity in their work lives were not strongly evident in the narratives that were shared. When faced with potentially dignity infringing or eroding situations, the participants often appeared unable to effectively employ the self-regarding strategies that they themselves had suggested. Strategies such as affirm ourselves, advocate for ourselves, or protect ourselves were seen to translate to situations where the participants felt vulnerable, drained, or exposed.

Because the dignity of the nurse is intertwined with the dignity of the patient, the use of altruism and extra effort was used by the participants as a way of sustaining dignity in the face of infringement associated with not being able to meet patient needs. This important strategy proved to be a double edged sword for the nurses. While useful as a short term response, when the extra effort was not acknowledged, was criticised, or where the organisational response was to intensify the work still further, the ultimate outcome was dignity infringing. This was seen to result in distressing emotional responses and resistance strategies.

Overwhelmingly, the greatest dignity sustaining strategy was to draw a sense of meaning and worth from engagement in the act of nursing. The challenge was to recognise these moments in the 'everydayness' of practice in a way that maintained and affirmed the dignity of the nurse.

\section{The research findings as 'end-product' and 'entry point'}

Qualitative description as a research approach results in, according to Sandelowski (2000), an 'end-product' and an 'entry point'. As an end-product, the findings of this study stand as they are. The study describes and represents what this group of nurses said about how they understand, experience, and sustain dignity in their work lives. Without any further interpretation, the descriptions provide fascinating insight into this area. As an entry point to further thought and inquiry, I have chosen to include a discussion that positions 
the contribution of the nurses within and beyond this study. While the findings of such a small study cannot be generalised to the entire profession of nursing, I believe that the participants have offered something of immense interest and value. There is much that could have been brought through into the discussion. In defence of my choices, I have highlighted findings that I believe provide justification for inquiry into this area, that deepen our understanding of nurse dignity, and that identify areas for future inquiry and action. 


\section{Chapter 6: Discussion}

That word respect comes up a lot. (1:1:24)

Before this work can be finally positioned and concluded, there are four questions to address; how does this knowledge fit with what is already known?; is the pursuit of dignity important?; what discoveries were made that deepen understanding in this area?; and finally, what might the road ahead look like? The first question reconciles the findings in relation to the existing body of knowledge within which this study is positioned. The second considers the value of the research area itself. The third illuminates elements of the findings, and the fourth suggests ways in which this research could be extended and applied.

The discussion is intended to be read while keeping in mind the limitations and strengths of the research. The study involved a small number of participants who shared many common characteristics. This limits the ability to generalise the findings beyond the project. However the experiences of these seven nurses can be assessed against the body of existing literature thus lending validity to the conclusions that have been drawn. Conversely the small size of the study could also be seen as a strength as it allowed rich description and deep exploration of the area under inquiry. It should also be declared that the discussion allowed me to revisit the findings through the lens of my own evolved understanding, thus giving me the opportunity to consider and reconcile the possibility of unintended distortion or bias. 


\section{Finding synthesis with what is already known}

Dignity is satisfaction, and peace on both sides, and peace of mind. $(2: 2: 255)$

The nurses in this study provided meaning to the notion of dignity through describing what is needed in their professional roles to enjoy a sense of worth, value, meaning and respect. The research confirmed that a nurse, in common with any worker, needs to be able to be self-regarding, offer regard to others, and to enjoy others' regard. This represents the mutually reciprocal social interplay that is the cornerstone of sustaining dignity in any context. More specifically it can be concluded that for the nurses in this study to enjoy a dignified work life, they require a context that is free from abuse, which offers meaningful manageable work, reasonable autonomy, and a culture of respect that acknowledges both the person and the professional.

Passing these findings back through the lens of Hodson's (2001) model for dignified work, there is a high level of consistency. The findings can also be linked to the extensive body of research outlined in the literature review relating the quality of the work context to the experience and outcomes of both nurses and patients. This small foundational study adds to the body of knowledge through the synthesis of Hodson's research and the nursing literature. Participants described the effect on their dignity of working in environments where they have little control over the agenda of production, where their autonomy can be limited by bureaucracy and managerial fiat, where they may lack the ability to mobilise resources to support patient care, and where they frequently feel exhausted, overwhelmed and unsafe. Conversely the two participants whose roles had higher levels of autonomy, and were more coherent and better structured, expressed greater satisfaction and engagement and consequently could establish a greater sense of worth, value and meaning from their work. Thus the findings of the study broadly support Hodson's generic findings on worker dignity, and the body of nursing research relating to the effect of nursing work and the context of work on nurses themselves. 


\section{Is the pursuit of dignity important?}

When we experience dignity we feel a sense of self worth, mana, autonomy, belonging, integrity, purpose, meaning, self respect, genuineness, spirituality, essence, and intactness. (Extract from participant definition)

The research findings presented purely as description could be used to generate a list of what nurses need in order to experience dignity. But to what degree do these findings justify suggesting that dignity for nurses should be pursued as an area of interest and an active workplace agenda? I would conclude that the pursuit of dignity for nurses in their work lives is justified from both the perspective of the nurse herself as a person deserving of dignity and of the consequences for whom those the nurse cares. The first justification is moral, the second pragmatic. Both are valid. The moral justification is based on the finding that dignity as a human right is widely accepted in our current society as inviolable. Thus nurse dignity should be pursued as an independent goal. The pragmatic justification is that there is evidence to show that where a nurse is working in a context that is not personally or professionally regarding, there may be direct negative consequences for patient care, and indirect consequences relating to our ability to sustain a nursing workforce.

Of the two, the moral imperative is in my opinion, of greater importance. Support for dignity, considered only as a pragmatic means to an end implies a hierarchy where one person's dignity can be seen as subordinate to another. "The value of a human being is absolute and irreplaceable. It cannot be substituted for, even by the value of another human being" (Wood, n.d. para. 5). Dignity should be pursued as a right in any context, and that includes the work context of nurses. 


\section{Deepening understanding}

The third area of the discussion relates to what was uncovered during the research which deepens the existing body of knowledge in this area. Four distinct but inter-related findings were identified; the role of the social compact in nurses' construction of dignity; dignity as mutually invested in the nurse patient interaction; the contested terrain of the work context; and the role of nurses themselves in sustaining dignity. These findings are considered important because collectively they begin to build a picture of the nuanced mores and values that define dignity for nurses (Bayertz, 1996b).

\section{The role of the social compact in nurses' construction of dignity}

Being the best that you can be and bringing your positive presence to the day, is the best, and it's enough. (2:5:73)

If we accept that to 'be' a nurse is a construction in itself, this construction becomes the touchstone of how dignity is experienced and measured. For the participants in the study, their construction of being a nurse was drawn principally from the beliefs and values associated with their personal and professional selves. Significantly, to be a nurse meant that along with retaining the rights accorded to them as a person in the world, they accepted the mantle of a social compact. The social compact expects nurses to deliver skilled, intimate, compassionate care that makes a positive difference in the lives of those they nurse, in return for professional respect and the privilege of nursing. Jacobs (2001) uses the term "covenant" similarly to my use of the term "social compact" and refers to this as a "moral commitment to respect for human dignity" (p. 32). The idea of moral agency fits with the finding in this study that the nurses privileged moral agency towards patients over personal agency or employee obligations:

The power of moral agency rests with nurses themselves and will not be threatened if the values and personal virtues that support those values are considered 'non-negotiable' in both theory and practice. 
The authenticity of nursing and its ultimate responsibility for respecting human dignity depend on the avoidance of mauvasie foi (bad faith). (Jacobs, p. 32).

Thus the nurse is bound to act in a way that supports her 'values and personal virtues' and failing to achieve this contravenes the social compact. So while the nurses in the study could articulate actions that would sustain their personal dignity, it is unsurprising perhaps that when faced with difficulties in meeting patient needs, personal agency falls victim to moral agency on behalf of the patient. This may explain why the nurses' primary response to factors such as overwork, which should prompt resistance behaviour, actually initially results in increased effort, which is a form of citizenship. Unfortunately, the increased effort is not sustainable in the long term and may eventually lead to negative effects such as moral distress, burnout, absenteeism or resignation.

\section{Dignity as mutually invested in the nurse-patient interaction}

We give a part of ourselves. And we don't lose anything because we always get something back (2:5:53)...I think we forget to see it (2:5:60)...claim it, on a daily basis. (2:5:62)

It was suggested in the early chapters of this inquiry that the 'patient first' discourse may be getting in the way of nurses explicating their own dignity. During the research I tried to get the nurses to separate their own sense of dignity from those they cared for. I failed to do so. What became evident was that the achievement of nurses' dignity is to a large degree dependent on the patient receiving dignified, regardful care. Thus nurses' efforts to make a positive difference for patients have a self-regarding aspect. I now believe that although nurses and patients experience dignity differently, the two must be considered together. If the dignity of one cannot be achieved, the other may suffer. The dignity of nursing and the dignity of those in their care are inextricably entwined and mutually dependent. Jacobs (2001) describes this relationship: 
...both the nurse and the patient have presence in the relationship, and they are unified and both ultimately changed by that presence. The gifts that are exchanged may vary, but they are unified in their purpose and outcome. (p. 32)

The 'gifts' for the nurses in the study appeared to be the privilege of being allowed to nurse and enjoying the respect that is associated with being a nurse. This is the well from which dignity is drawn. However I would suggest that while of primary importance, it is not only the nurse-patient relationship that influences a nurse's experience of dignity. The signals that allow nurses to measure worth, value and meaning are grounded in everyday interactions and experiences that convey respect and regard from all those involved in the context of the work environment.

\section{The contested terrain of the nursing work context}

I think, you know, we can lose our dignity by giving it away... but I think it can be eroded. Like over time it can be eroded or it can be sustained. Yeah, events happen over time and each time does it get eroded a bit and then finally it's just gone and then what do you do? (2:2:129)

In their current work contexts the participants appeared to be experiencing significant contradiction between their beliefs and expectations around how dignity should be experienced in the workplace and the everyday reality. The most common contradictions related to a tension between the professional self who feels bound to seek to honour the social compact, and nurses working in contexts where conflicting values and the environment of care are perceived as not supporting the nurse in achieving her purpose. Achieving the purpose of nursing implies much more than meeting the obvious technical care requirements. "A patient is not merely a piece of furniture, to be kept clean and ranged against the wall and saved from injury or breakage" (Nightingale, cited in McDonald, 2004). 
The nurses described what lies at the heart of their practice:

Nurses bring a body of specialised knowledge and skills and value for our shared humanity to provide care that aims to make a positive difference in the delivery of health care. The essence of nursing is the specialised expression of caring.

Benner (1994) argues that despite the outcomes of caring practices being hard to predict and not well understood, "this does not make them any lesser in their intellectual, moral, aesthetic, skilful knowledge" (p. 48) and that caring practices are not sufficiently accounted for in the economic structures of health care.

What became apparent through the sharing of narratives, encounters and ideas was that the achievement of nursing's central purpose is continually being frustrated in a myriad of ways. The nurses in the study clearly saw being a nurse and the act of nursing, as invested with worth, value, and meaning. The greatest challenges to dignity were found to lie not so much in the purpose but the execution. In order to enjoy a dignified work life, the nurse needs to be successful in fulfilling the purpose of nursing through leading a professional life that makes a positive difference to the lives of others.

A nurse's sense of dignity is both eroded and infringed upon in many ways, for example: not having sufficient time to provide for patients' needs, not being provided with the tools for the job, having the holism of nursing practice reduced to a series of tick boxes, not being supported to acquire the necessary skills and knowledge, not receiving professional respect. This is not to suggest that the agenda of nursing is right and the health care organisations' agenda is wrong, however the disconnection is undeniable and the difference between compromise and feeling compromised is significant.

\section{The quality of workplace social interactions}

The work contexts of the nurses in the study varied in many regards. They described nursing as both context free and context bound; free in the sense 
that being a nurse represents an ongoing social obligation that is offered where and when there is a need; context bound in the sense that in doing the work of nursing, the quality of the work context, as defined by social interactions and the quality of the work environment, has a profound influence.

The quality of workplace social interactions was seen to directly influence the nurses' experience of dignity. This is consistent with the idea that maintenance of dignity relies on mutually reciprocal social interaction. The role of the nursepatient interaction in dignity has already been discussed.

However the number of non patient-related encounters shared by the participants that involved direct conflict or abuse, suggested that this is an area of concern. While some of these interactions could be labelled as bullying, (targeted, repeated behaviour), most represented what Anderrson and Pearson (cited in Schat \& Kelloway, 2005) term 'workplace incivility'. Workplace incivility covers a range of rude, discourteous, disregardful behaviour that violates "workplace norms for mutual respect" (p. 192). These types of actions have been shown to have significant detrimental effects (Kidd, 2008). The causes of such behaviour were not explored in this study. However there is a need to better understand this area.

Also worthy of further exploration is the finding that the nurses did not appear to attach worth or value to their role as employees nor did they articulate a need to offer active regard to their managers. Managers however, were expected to tangibly offer respect and regard to nurses from both a personal and professional perspective. This finding may reflect a limitation of the data collection process or may simply be the views of this particular group. However, if this finding were replicated with a larger group of participants it would be a critical finding when we consider mutuality and reciprocity as essential elements of sustaining dignity. 


\section{The quality of the work environment}

The relationship between nurse dignity and the quality of the work environment is of interest, as it was shown to have a more subtle, eroding or maintaining effect on dignity than, for example, the immediately affirming or infringing effect of direct social interaction with another person. This was a source of significant contradiction for the participants.

The responsibility for providing an environment in which dignified work can be achieved, was clearly seen by the participants as the domain of their employing organisation. There was an expectation that a primary purpose of the organisation is to provide a context in which nursing can be successful. Where the organisation was perceived as not providing adequate time, resources, structure or professional positioning to enable the nurse to successfully provide care, or to be adequately professionally regarded, the nurse struggled to extract worth, value or meaning from her professional work; dignity was compromised. Conversely in situations where professional respect and regard was demonstrated, the nurses in the study described responding with increased discretionary effort, creativity and loyalty to the organisation.

Hodson's (2001) research findings would suggest that the dominant response to infringement of dignity through inadequate work environments would be acts of resistance. However the nurses in this study displayed a paradoxical response in one key area. Where patient needs could not be met (and therefore nurses' needs were not met), the primary response was to increase discretionary effort; to work harder or longer. Nurses and their employing organisations may fail to realise that the altruistic, self-regarding behaviour that drives this response is only sustainable in the short term. For where the strategy fails to secure the desired outcomes, over time the nurse will almost inevitably fall back on resistance behaviours that ultimately may include withdrawing from the work of nursing.

It also appears that the consequences of erosion of nurse dignity that results from repeated deficiencies in the context of care may be of equal if not more 
significance than more overt infringements such as bullying or abuse. This suggests that nurses would be receptive to organisational initiatives aimed at supporting successful delivery of the social compact. This would complement initiatives such as harassment policies, flexible hours, and family friendly work practices which are currently favoured as strategies to attract and retain nurses.

\section{The role nurses play in sustaining their dignity}

It's the special nature of the work nurses do, of the job. The profession is very privileged and very personal. (2:4:20)

The role that nurses themselves do play or could play in sustaining their own dignity remains the least well explicated in this study. While the participants articulated a number of strategies, there was little evidence that these are being successfully employed in the reality of the workplace. Possible reasons for this have been presented including the role of altruism and the fundamental driver of the privileging of patient needs and dignity. This remains an important area for further exploration.

Hodson (2001) suggests that active agency in the pursuit of dignity is an important and inevitable component of worker behaviour. Therefore it is reasonable to suggest that the more effectively nurses could engage with such behaviour, the better the outcomes for nurses themselves, the patients they care for, and the organisations they work for. One avenue that presented itself during the research was the value of nurses and nursing better articulating what nursing fundamentally aims to achieve, so that the 'patient first' agenda represents a shared and collective understanding between nurses, their employing organisations and society. 
Florence Nightingale articulated this collective purpose beautifully:

May we hope that every nurse will be an atom in the hierarchy of the ministers of the Highest! Then she must be in her place in the hierarchy, not alone, not an atom in the indistinguishable mass of the thousands of nurses. High hopes, which will not be deceived! (Cited in McDonald, 2004, p. 218)

The nurses expressed a sense of anomie; the idea that they are working in poorly organised contexts that privilege utilitarian, cost-focused approaches to healthcare delivery when they are faced each day with this patient, in this moment, with these needs. The challenge becomes how to hold on to the purpose of nursing, which is the touchstone, and also honour one's duty to oneself. As Wood suggests:

Dignity is a value that is incomparable and absolute. It cannot be measured against other values in this way, because it can never rationally be sacrificed or traded away for anything at all, not even for something else having dignity. (n.d. para. 5)

Within the sphere of care, nurse and patient dignity must be considered as independent, interdependent and mutually sustaining.

\section{The road ahead}

When I experience dignity, I have this inner sense of equilibrium. I'm not tested beyond what I can cope with, I'm not dealt with in a way that makes me feel diminished, I feel like what I'm doing is useful ... it's not a perfect balance, it doesn't have to be, but it's not tipped over to the point where I can't come back the next day. (2:2:258)

There is little question that nursing has a valuable and distinct role to play in society. When nursing is carried out in contexts that support the work to be successful, there is evidence that "nursing works" (Annals, 2007, n.p.). 
However as suggested in the introduction to this study, there is little evidence that we are achieving sector wide success in providing work contexts that support the work and therefore the dignity of nursing. This is despite a focus on the context in which nursing takes place, the role that nursing plays, and the effect of nursing work on patients and on nurses themselves.

The findings of this study suggest that this may be related to an apparent disconnect between the way the role and practice of nursing is understood by nurses and by health care organisations. Benner (1994) questions whether "examining our most exemplary caring relationships might prompt us to redesign the structures and processes of our public caregiving institutions to better facilitate caring practices" (p. 43). One of the impediments to improving the situation may relate to how we currently orient health care contexts in relation to nursing and the work of nursing.

The nurses in the study viewed the context in which care takes place as a vehicle within which the social compact is delivered. It should not be presupposed that nurses' first loyalty is to the employing organisation or that the achievement of the organisation's agenda will be the primary agenda of the nurse. I would suggest that the purpose of nursing (enacted within the nursepatient relationship), is the primary motivator that both drives and sustains nurses, and is fundamentally connected to their experiencing dignity in their work lives.

Future inquiry into the area of nurse dignity should begin from the premise that to understand the meaning that nurses attach to dignity, one first has to understand the meaning that nurses attach to nursing. Otherwise identifying what is required for nurses to express and enjoy dignified work lives, and in consequence deliver effective nursing care, will surely continue to elude us.

How might we approach this differently? Certainly further inquiry, the development of new theory, and ideas to support change are indicated. This study proposes several avenues worthy of future exploration. But for now, what 
if one were simply to ask some differently positioned questions of nurses and nursing?:

What do you need personally, professionally, and practically to be successful in this environment and to enjoy a dignified work life?

And the question that nurses and nursing could ask themselves:

What do I need to do (in terms of expressing personal, moral and employee agency) to be successful in this environment and to enjoy a dignified work life?

A declared objective of this study was that generating new knowledge around nurse dignity would have a transformational effect on the work environments and work lives of nurses. I believe that the 'why' has been established, and have offered ideas about 'what' needs to happen. That leaves the 'who' to be considered. The findings suggest that whether one is a recipient, funder, or provider of health care, there is a collective interest in promoting and sustaining the dignity of nurses. If all parties united around an agenda that is based on the premise that nurses deserve to work with dignity, the shared agenda that patients deserve dignified care becomes a mutually sustaining endeavour to the benefit of all. 


\section{Chapter 7: Conclusion}

Over many years and after working in a range of nursing contexts I have developed an abiding interest in the effect of the work of nursing on nurses themselves. My interest resulted in this inquiry examining dignity in the work lives of clinical nurses. Beginning at the conceptual level, the study has explored how nurses understand dignity, and has sought to uncover the way that dignity is experienced and sustained in day to day practice. Having reached the end of this research journey it is tempting (as with all endings) to try to parcel everything up neatly and to reach a firm conclusion.

However as Giorgi (1992) cautions, "why would one want to force a closure on something that announces itself as non-closed?" (p. 127). Our understanding of nurse dignity is far from closed. The place I have reached could best be described as an enriched understanding. The beginning of the inquiry was like looking through a murky window that offered a hint of something beyond. Through the process of reviewing the literature, crystallising a question, exploring the idea of dignity deeply with a group of nurses, and analysing the findings, I find that the window has a great deal more clarity, and the view beyond is a field of tantalising possibility. This final section provides a summary of the research journey, highlighting points of clarity and areas for future investigation.

The findings of the literature review undertaken to position the study suggested a relationship between the environmental and social context of work and nurses' experience of dignity. This was substantiated. It was confirmed that the nurses in the study, like any worker, require coherent work organisation, freedom from abuse, positive co-worker relations and reasonable autonomy to support their dignity. 
However the study moved beyond confirmatory findings in exploring the underpinning beliefs and expectations that influenced the nurses' encounters with, and responses to dignity. This allowed me to explore the question of how nurses understand dignity. The facilitated group approach that was used enabled the participants to deeply consider and identify their personal and professional construction of dignity. Dignity for the participants in this study could be shown to be strongly associated with the worth, value, and meaning that nurses attach to their profession, to the work that they do, and to themselves personally. Uncovering these beliefs was integral to making sense of the way dignity is encountered and responded to in day to day practice.

The second part of the research question centred on how nurses experience dignity. The sharing of narratives of practice uncovered the complex social and environmental interplay that influences dignity in the work lives of the participants. The work context was found to be contested terrain that on one hand offers rich opportunity for nurses to extract a sense of worth, value and meaning associated with achieving their professional purpose, and on the other poses constant challenges that can infringe or erode the nurses' sense of dignity. The nurses in the study perceived nursing to be a meaningful, worthwhile endeavour, but were struggling to enjoy a sense of achievement when working in environments that they perceived as not supporting their agenda of care. A link was tenuously made between this finding and the troubled relationship that the nurses in the study appeared to have with their employing organisations and managers.

The study illuminated the pivotal relationship between a patient's experience of dignified care and the achievement of dignity for the nurse. This relationship occurred on many levels and was based around the idea of a social compact between nursing and society that offers respect and regard to nursing in return for nurses providing skilled, intimate, compassionate care. The social compact was interpreted by the participants more broadly than direct nurse-patient interactions. It could be seen in the way nurses associated the quality of the work context as a measure of respect for their professional role and practice. It was demonstrated in the social relationships between nurses, co-workers and 
managers. It was articulated in the way nurses attributed responsibility to themselves for elements of the patient experience over which they have no control. At the most direct level it was exemplified in the way nurse dignity is maintained or affirmed through the act of nursing patients. The discovery that the dignity of nurse and patient cannot be considered as wholly independent of each other was a key finding that merits further exploration in its own right.

The third and final part of the central question concerned how nurses sustain dignity in the work context. This question was of particular interest because the literature revealed that contemporary research frequently positions nurses as passive recipients of the work environment. In fact the nurses in the study were seen to be employing active agency in pursuit of their dignity. Encounters that maintained or affirmed dignity were associated with increased discretionary effort and loyalty. Encounters that eroded or infringed dignity resulted in a range of resistance behaviour, for example lowered commitment, non compliance with policy and regulations, or withdrawal from the work environment.

Of particular interest was the finding that the nurses often exhibited a paradoxical response to situations where patient needs were unable to be met, involving altruistic behaviour and increased discretionary effort. This strategy was found to be dignity sustaining in the short term but dignity infringing where it was not acknowledged or became the expected response to managing resource shortfalls. If this finding were to be substantiated in a larger study it may have significant implications for both workload management and retention strategies.

Of concern was the finding that the nurses did not appear to be employing many effective strategies to support their own dignity. This also merits further investigation and suggests that attention could usefully be given to working with nurses on resilience and self-regard. 
In many regards this study parallels other research interested in the effects that nursing work has on nurses. Indeed nearly every individual finding could be married with the work of others. Where this study claims to add to the body of knowledge is the focus on nurses' dignity as a moral rather than a pragmatic imperative. This is in contrast to many common current approaches that are interested in the needs of nurses primarily as a means to achieving health care outcomes for patients.

A focus on nursing as a means to an end does not require that we enter the realm of nursing in a way that seeks to understand the essence and meaning of nursing, nor values the nurse as a person of inherent worth. Viewing nursing and nurses as deserving of dignity as a primary moral imperative makes it possible to bring together 'hard' indicators of quality work environments; such as nurse sensitive indicators or retention rates; and the purpose of nursing, the ethic of caring, and the primacy given by nurses to the nurse-patient relationship. The value of doing so is that if, as the findings of this study suggest, patient and nurse dignity are inextricably entwined, the outcome of supporting nurse dignity would be independently favourable for nurses, and correspondingly favourable to patient care.

I would suggest that dignity for nurses needs to be considered from the perspective of the nurse as an individual person in the world, as a member of the nursing profession, and as a nurse engaged in the work of nursing. This requires that we understand the symbols, signals and actions that support the nurse in extracting a sense of worth, value, and meaning. Based on the experiences of the participants, this might mean for example; actively upholding the values and addressing the needs of the individual; supporting the nurse to maintain professional stature and dignity; and being cognisant of and valuing the fundamental nature of the nurse-patient relationship. Equally nurses have a responsibility to understand and pursue dignity on their own behalf. 
I believe that the approach used in this study succeeded in providing rich description of how one group of nurses understands, experiences, and sustains dignity in their work lives. Their stories of joy, despair, struggle and triumph in pursuit of dignified work lives gave testimony to the importance of this field of inquiry. However I would suggest that further work is required to extend and test the findings of this foundational study before we could confidently assert a position on either the constitution of nurse dignity or the implications of this knowledge. In the interim I would conclude that the findings of the study clarify and extend our knowledge in this area and support the position that the active pursuit of dignity for nurses, as a workplace agenda is merited from both a moral and pragmatic perspective.

Nursing holds human dignity as central to the ethic of care. Dignity represents an inviolable right to mutual respect for personhood, relating to intrinsic worth, value and meaning, our own and others, in each moment and in all contexts.

I am a nurse

I nurse

I am 


\section{Post script}

Four weeks out from completing this thesis, I found myself on holiday with my family, outside a tent, with the laptop propped on a rickety camp table, looking out over a rocky headland to a peaceful sea, contemplating my findings. After this long journey, what did I really now know about dignity for nurses?

My musings were interrupted when a woman ran up, knowing I was a nurse and said; "They've just brought someone in off a boat and they're in trouble"! I abandoned the computer (and therefore my year's work) to the honesty of others and ran down to the beach to find a man under resuscitation. The latent nurse in me emerged and I joined the attempt to save this young man's life. At first, being at a remote location, we had nothing but basic CPR and the oxygen off the charter boat to offer. But the CPR was efficient. When the ambulance arrived, I felt completely at home with the tools of my trade, the IV lines, the adrenaline, the defibrillator. In my mind I was mentally running through the sequences of resuscitation. My eyes were constantly scanning the scenario to ensure no step was missed. My hands busied themselves with familiar rhythms. A group of health professionals, previously unknown to each other, worked as a team on the sand for 50 minutes. As the helicopter arrived, the decision was made that it had been too long, that we were not going to be able to save this man. We stopped our efforts.

As the ambulance, police and helicopter crew began the business of dealing with the sequelae, I walked quietly away back up the beach towards my family and my other life. I thought about this man, this stranger whose name I will never know. I felt compassion for the family who in the next few hours were going to have their lives changed forever. I noticed for the first time the entire population of the camp, ranged along the fringe of the beach, watching the drama unfold. The expression on the faces of the people lining the beach as I walked away was one of respect. 
Later, my head, eyes and hands now busy with the mundane pleasures of camping with my family, I reflected on the events of the day, on what had happened in this brief vignette of life. Despite the fact that this man had died, and not having the resources that I would normally have in this situation, I felt that he had had the best possible chance under the circumstances. He surfaced unconscious from a dive on a boat at sea, and was brought in to a beach easily a half hour from the nearest ambulance. The context offered us less than ideal options but we made the most of everything that we had. We brought to bear our skill, knowledge and experience. Everything that we did was infused with worth and meaning and a deep commitment to the value of human life.

I reflected that 'to nurse' and 'to be a nurse' means that context is almost irrelevant. Whether the context in which I nurse is a modern resuscitation room or a sandy beach, the nurse I am is the one constant. It brought home to me something that I had written about but perhaps had not fully acknowledged. Once you have chosen to be a nurse, that nurse becomes truly part of who you are. As one of the nurses in the study said; "Nurse' is not something that I can put on and take off with the uniform. Being a nurse is who I am".

I walked away from that man on the beach with a feeling of equilibrium. It was sad that this man had died, but I had no sense of futility or failure or distress. I was a skilled professional, a nurse, fulfilling my compact with society. I walked away from the beach - with dignity. 


\section{Appendices}

\section{Appendix 1: Ethics Approval}

TE WHARE WANANGA O TE ÜPOKO O TE IKA A MÃUI

\section{MEMORANDUM}

Phone $\quad 0-4-4635676$

Fax $\quad 0-4-4635209$

Email_Allison.kirkman@vuw.ac.nz

\begin{tabular}{l|l}
\hline TO & Jane Lawless \\
\hline COPY TO & Associate Professor Cheryle Moss, Supervisor \\
\hline FROM & Dr Allison Kirkman, Convener, Human Ethics Committee \\
\hline
\end{tabular}

\begin{tabular}{l|l}
\hline DATE & June 13,2008 \\
\hline PAGES & 1 \\
\hline
\end{tabular}

SUBJECT Ethics Approval: No 15671, Dignity in the work-lives of clinical nurses: a descriptive exploratory study.

Thank you for your application for ethical approval, which has now been considered by the Standing Committee of the Human Ethics Committee.

Your application has been approved from the above date and this approval continues until 28 February 2009. If your data collection is not completed by this date you should apply to the Human Ethics Committee for an extension to this approval.

Best wishes with the research.

Allison Kirkman

Convener 


\title{
Appendix 2: Invitation to Participate in the Study
}

\author{
Invitation to Participate in Research Exploring Nurse Dignity
}

- Greetings colleagues - I am a registered nurse currently studying at Victoria University towards an MA(Applied). I am engaged in research looking at dignity in the work-lives of clinical nurses. The working title for the research is: 'Dignity in the work-lives of clinical nurses: A descriptive exploratory study'.

-While patient dignity is an area that we are familiar with, dignity for nurses is an area that has not been well explored. The aim of the study is to describe and explore clinical nurses' understanding and experience of dignity in their work lives including how dignity is sustained or challenged.

- I am seeking to recruit up to 9 nurses from the Midland regions who would be willing to volunteer to participate in this research. The nurses who volunteer for this study will all be RNs who are actively working in inpatient settings and who have attained Proficient or Expert level on the Professional Development Recognition Programme.

- Through participating in the research process, this group of nurses will make an important contribution to advancing our knowledge of how the dignity of nurses is sustained and challenged in clinical practice.

- The participants will meet as a group for two full days to collectively explore how dignity for nurses is supported or infringed in clinical practice settings.

- Participation is on a voluntary basis. Refreshments for the two days will be provided and nurses travelling from outside the Hamilton area will be reimbursed for travel costs.

\section{If you can answer yes to the following questions, you may be eligible to participate in this study:}

- $\quad$ Do you work in the Waikato, Tauranga or Rotorua area?

- $\quad$ Are you are a registered nurse currently working clinically in an in-patient ward?

- Have you achieved proficient or expert level of practice?

- Would you be available to participate in two one-day workshops which will be held in Hamilton on August 1 and August 8 ?

- $\quad$ There will be a two-hour follow-up session

For further information and/or to obtain a more detailed information sheet and consent form, please contact Jane Lawless either by email, janelawless@xtra.co.nz, or by telephone, mobile 021549806 or (07) 8298202 


\title{
Appendix 3: Information Sheet
}

\section{Exploring Dignity in the Work-lives of Clinical Nurses}

\author{
Information sheet for prospective participants
}

Thank you for taking the time to enquire about becoming a participant in this study exploring dignity in the work-lives of clinical nurses.

My name is Jane Lawless and I am a student at Victoria University of Wellington. I am a Registered Nurse studying towards an MA(Applied) in nursing I and am currently enrolled in a course that involves completing a research project. The research area that I am interested in is around dignity for nurses in their work-lives. The working title for the research is: Dignity in the work-lives of Clinical Nurses: A descriptive, exploratory study.

I developed an interest in this area through discovering that while patient dignity is an area that we are familiar with, dignity for nurses has not been well explored and their may be implications of this that are not currently well understood. The aim of the study is to describe and explore clinical nurses' understanding and experience of dignity in their work lives including how dignity is sustained or challenged.

The research is an exploratory study using qualitative description for the methodology. This means that I am aiming to explore with a small group of clinical nurses, their understanding of dignity as a concept and how they experience dignity in their practice. The nurses will come together for two full days to participate in facilitated group work. The discussions and reflections will provide the data for the study and my task will be to transcribe and represent the groups' descriptions, insights and perspectives on how dignity is experienced in their work-lives.

My literature review into the area of dignity for nurses suggests that this will be the first study of its kind. Nurses participating in the study will be contributing to important foundation knowledge in this area.

The study has received ethical approval from the Human Ethics Committee of Victoria University of Wellington.

\section{The basic steps of the research process}

Step 1: 6-9 nurses recruited to participate in two one-day workshops

Step 2: Workshop day one, August 1 - 0830-1700

Houchen's Retreat, Houchens Road, Hamilton

- Welcome and introductions

- $\quad$ Agreeing on our purpose as a group

- $\quad$ Agreeing on how we want to work together and the importance of confidentiality 
- Group processes aimed at:

-exploration of dignity as a concept -exploring the purpose of nursing work -exploring dignity in the work of nursing

- Reflection on the day and preparation for day two

Step 3: For the next week, the nurses will be asked to go back into their work areas and individually and independently reflect on and note what takes place in practice that relates to the ideas that the group generated around dignity. This exercise will provide the material for the second day workshop.

Step 4: Workshop day two, August 8 - 0830-1700 Houchen's Retreat, Houchens Road, Hamilton

- Review and recap

- $\quad$ Sharing stories and moments identified from practice

- $\quad$ Reflecting on the meanings and importance of the moments and stories

- Reflecting on the key insights that have been gained from participating in the study and particularly on any changed perspectives that have occurred during the process

- $\quad$ Closure and celebration of our work together

\section{Step 5: Data transcription and review}

The tapes from the workshop will be transcribed by myself and a transcriber. The transcriber will sign a confidentiality agreement prior to commencing the transcription. The transcripts will be provided to all participants for comment. Copies of transcriptions will need to be kept confidential by the participants and returned to me by an agreed date.

\section{Step 6: Data analysis}

The data will be analysed by me as the researcher using codes and themes. While comments or examples may appear in the final presentation of the data, these will not be attributed to any person or make the participants identifiable.

\section{Step 7: Reconciliation of the analysis (Friday October 10)}

All participants will be invited to an optional two-hour session where the analysed data will be presented and discussed. Participants will be given the opportunity to advise me on whether the analysis and representation of the data has successfully described their experiences, reflects the themes of the group and has captured the critical points, meaning and perspectives. 


\section{Step 8: Submission of the thesis}

The data will be reported in a thesis provisionally titled, 'Exploring dignity in the worklives of clinical nurses: A descriptive exploratory study'. Participants will be acknowledged in my thesis as a group. No identifying details will be included.

\section{Step 9: Publication of findings}

It is a requirement that a version of the study findings is submitted for publication in a relevant journal. The thesis report will be lodged in a hard copy version in the Victoria University of Wellington library and a digital version will be available to New Zealand libraries.

\section{Step 10: Completion}

A copy will be provided to any participant who indicates that they would like a copy of the completed thesis.

\section{Professional Supervision}

The opportunity for professional supervision independent of the research will be available to any participant who wishes to access this option during the course of the study.

\section{Withdrawal from the study}

Participants are entitled to withdraw from the study at any stage.

\section{Next Steps}

If you would like to be considered as a participant for this research, please complete the attached eligibility and consent forms and return to:

Jane Lawless, 10D Bell Road, RD5 Hamilton

Note: The study design requires that the first nine eligible nurses to return their completed forms will be recruited to the study. 


\section{Appendix 4: Consent form and eligibility form \\ Consent Form for Participants}

\section{Study: Exploring dignity in the work-lives of clinical nurses: A descriptive exploratory study}

consent to participate in the above research project

1. In giving consent, I understand that I will be required to attend two full day workshops in Hamilton on August 1 and August 8, 2008

2. I agree to the workshops being audio-taped and for the audiotapes to be transcribed by the researcher and/or a transcriber

3. I agree for the transcriptions to be analysed by the researcher and used as the data for the research project

4. I understand that any written and artistic material generated through the workshops may also be used as data for the purposes of the study

5. I understand that I will be given an opportunity to review and comment on the workshop transcripts and also to attend a two-hour session on Friday October 10 to review the re-presentation and analysis of the data

6. I agree that I will keep all material that is discussed or generated through the workshops, data transcription and presentation phases confidential

7. I agree to the de-identified transcripts and workshop material being available to the researcher and the researcher's supervisors for the purposes of the study and any publications or presentations that may arise from the study

8. I understand that the data will be kept securely and will be destroyed after five years

9. I give consent for the de-identified transcripts and workshop material being used by the researcher for future research and/or study into this area 
10. I understand that if the researcher wishes to use the data from the study for any other purpose than described in this consent form, my permission will be sought

11. I understand that I have the option of receiving professional supervision during the period that I am participating in the study.

12. I understand that I may withdraw my participation in the study at any time

13. I understand that ethical approval has been granted by the Human Ethics Committee of Victoria University of Wellington

I do/do not (delete one) wish to receive a copy of the completed report

Signature of participant

Signature of researcher
Date

Date 


\section{Eligibility Form}

Name:

Contact Address:

Contact Phone numbers:

Geographical Location (circle one): Hamilton Tauranga Rotorua

Are you a Registered Nurse? Year of registration?

Do you currently work in an inpatient ward setting? Yes/No

Professional Development Recognition Programme (PDRP) Level Proficient Expert

Are you available to attend two full day workshops on August 1 and August 8 in Hamilton? Yes/No

Have you completed and signed the attached consent form? Yes/No

Please return this signed and completed form and the signed consent form to; Jane Lawless

10D Bell Road, RD5 Hamilton 


\section{Appendix 5: Workshop Plan}

\section{Workshop Plan}

\section{Session one:}

\section{0-0915 Welcome and introductions}

Welcome everyone. Introduce self (model what I want them to do in their own introductions). In pairs (or threes), talk together about who you are, where you work, and why you chose nursing as your career. Introduce each other to the whole group.

0915-0930 Agree on purpose (layered purpose)

Introduce the purpose (previously written to participants)

Building understanding of the role that dignity plays in the work-life of the nurse; how dignity is understood, experienced, sustained and challenged.

including my layered purpose that ultimately I would like to see exploration into dignity having a positive influence on the work and work-lives of nurses.

State the research question.

How do clinical nurses understand and experience dignity in their work-lives?

Why this group was selected. Reassure them that their views and experiences will not be portrayed as representing all nurses. Explain the nature of this descriptive exploratory study. Ask if participants would like to add to the purpose. Check in with their agreement to the purpose

0930-0945 How we want to work together

Group exercise: Ask participants, what will be important for them in working together to achieve the purpose. Record on butcher's paper

Butchers paper, felt pens, blue tack

0945-1000 Overall structure

Outline the overall structure of the two days. Emphasise that while the timeframes will be flexible, we will start and finish on time. Check in on the overall structure

Show them the conceptual framework and explain that we will be working from the outside in

Laminated conceptual framework

1000-1020 Morning tea

1020-1120 Conceptualising dignity

1. On your own, spend 10 minutes capturing in your own way, what words, images or experiences come to mind when you think about the word dignity pieces of paper and stick-its 
2. Put these up on the wall. Without discussing it, all to read and observe what is there. Start repositioning the words and images in ways that make sense to the group. Are there things that belong together?

3. What have we learned from this. Can we put this together in a way that constructs a phrase that for us tells us;

So dignity for you is about...(construct phrase together)

Get this to the satisfaction of the group. This will be the definition that we will stay with - it represents our shared understanding

1120-1200 The purpose of nursing work

1. In groups of two or three, take one of the hearts and begin to construct within it, what lies at the heart of the work of nursing

2. Come back into the whole group. Present the statements

3. Construct a single statement as a group. Put it on the whiteboard. Play with it with the group until they are satisfied

3. Segway to lunch. Review the morning's journey. What we now have is a shared understanding of the concept of dignity and what lies at the heart of the work of nursing. This will become our True North for the afternoon's exploration of dignity in the concept of their work as nurses. Talk about dignity being very context specific

1200-1230 Lunch

1230-1315 Self and other-regarding dignity

Exercise: Put two columns on the whiteboard. Head the first column 'patient'. Ask them to identify things that are important about patient dignity. Head the second column 'nurse'. Ask participants to identify things that are important when thinking about their own dignity as nurses. Discuss what comes up, particularly the dominance of the patient first paradigm. Reinforce that the area I am most interested in exploring is dignity for nurses in their work-lives; what they see as important. Revisit the earlier statement about dignity and see whether they want to revise it to reflect dignity in their work lives.

\section{5-1400 Part One: Dignity and others}

In this exercise we are going to start to think about the things that signal to you that your are experiencing or not experiencing dignity (restate their definition) in your interaction with others at work; colleagues, patients, your manager, coworkers, anyone really.

1. When people around you (any people) are acting in ways that support your sense of dignity (restate their definition) what kinds of things are going on? (give them cue cards)

Write down three examples of when this happens? 
How do you feel?

How does that influence your practice?

2. Can we now consider if there might be times when people around you are acting in ways that don't support your sense of dignity. (Give them cue cards to write on)

What kinds of things are going on?

How do you feel?

How does that influence your practice?

3. General discussion about this - sharing

1400-1415 Break

1415-1515 Part two: Dignity and the environment

Thinking about things in your work-life now, other than people, what sorts of things support your sense of dignity (restate their definition)? How do you feel about those things? Does that influence your practice in any way?

1. l'd like you to think now about the kinds of things that may affect your experience of dignity (restate their definition) in less direct ways; for example, the quality of your work environment, the way your work is supported with good resources, the ways your employer recognises you, that sort of thing. Does that sound okay?

What kinds of things affect your experience of dignity in a positive way?

How does that make you feel?

How does that affect your practice?

2. Can you now consider if there are situations where the opposite is happening and the quality of your work environment, the resources that you have, or the way the work is organised doesn't support your sense of dignity?

What would be an example of that?

How do you feel when that is the case?

How does that influence your practice?

3. Thinking about your work with patients now, do you think there are times when supporting patient's dignity and needs means that you feel that you have to infringe your own sense of dignity?

What would be an example of that?

How do you feel when that is the case?

How does that influence your practice?

1515-1600 Finally, I am also very interested in understanding more about the way that as nurses, we act to sustain our own dignity. If your definition of dignity is (restate), what are the ways that you keep that happening in your work-life? (prompt in a general discussion for both citizenship and resistance activities. Capture on the whiteboard).

Is there anything else that you would like to contribute to this first session?

1600-1645 Round-up and reflection 
1. What I am going to invite you to do is to go back to your workplaces with the definition of dignity that we have created today and see if you can look at your practice over the next week with fresh eyes. That is, I would invite you to actively look for the kind of things we have been talking about today that might support or challenge your sense of dignity in your work-life. You might recognise a situation as it happens, or you might remember something that happened in the past that illustrates dignity or lack of dignity for you. To help you, I have got a handout that you can use as a prompt if you want to (but you don't have to).

- $\quad$ A time when your sense of dignity was upheld by someone else

A time when your sense of dignity was not upheld by someone else

A time when your sense of dignity was supported by something to do with the way your work is supported to be successful; for example something about the environment you work in, or the resources you are provided with, or the access to opportunities that you have been given

A time when your sense of dignity was infringed by something that relates for example to your environment, the resources you are provided with, or the access to opportunities. You may think of others.

A time when you acted in a way that supported your own sense of dignity; it could be something that you see as a positive or negative action - $\quad$ A time when you infringed your own dignity

When we come back together in a weeks time, we will have the opportunity to share these stories, discuss them and reflect on their relevance. Is that okay with you?

2. l'd like us to spend a few minutes before we close, reflecting on today. I would invite you to make any comments you would like on the exercises, the discussion, any insights you have had and also on how well the process and my facilitation supported your personal sense of dignity.

3. Any questions? Thank you and see you in a week 


\section{Session Two}

0830-0930 welcome and getting centred

- Restatement of purpose

- Recap of day one

- $\quad$ Purpose of today

- Revisit the 'how we want to work together statement'. Any changes?

- Invite participants to talk about how the week has been and how they found the 'fresh eyes'. (Not stories yet).

0930-1000

- $\quad$ Ask everyone to give me a one-liner of the stories or moments they have brought back; "this is about...."

- Write them on Butcher's

- Discuss whether they fall naturally into groups, e.g. agency/citizenship, sustaining, infringing etc

- $\quad$ Ask how they would like to do the sharing of stories, e.g. all of one group and then all of another or random

- $\quad$ Do they want to do a group and then reflect, or save reflection until the end

- $\quad$ Give them notepaper to make notes as they go to allow the stories to be uninterrupted

1000-1020 Morning tea

1020-1120 Story telling and sharing moments followed by group reflection

- What struck you about these stories?

- $\quad$ Can others identify with the stories?

1120-1200 Continue story telling and reflection 1200-1230 Lunch

1230-1400 Continue story telling and reflection until a natural closure point is reached 
$1400-1430$

$1430-1445$

$1445-1545$
Something fun to re-energise the group

Afternoon tea

Reflection on the journey

- In pairs, talk about the two days, and what if anything has changed about how you think about your personal dignity? What if anything will be different for you in your work now? Is there anything about this that you would like to share with the group?

- $\quad$ In the whole group, share these reflections. Discuss strategies.

\section{5-1615 Closure}

- $\quad$ Summarise the two days

- $\quad$ Tell them of the process from here (transcription, transcripts to participants, amendment, thematic and content analysis, opportunity for the group to review)

- $\quad$ Thank participants

- $\quad$ Celebratory drink

\section{Session three}

Two hour session to put the editorial pen in the hands of the participants;

- Have I managed to access the inner experiences of the participants?

- $\quad$ Do the themes reflect what the group wanted them to?

- Is anything missing?

- Does anything need to change? 


\section{Appendix 6: Prompt card}

\section{Prompt Card}

- A time when your sense of dignity was upheld by someone else

- A time when your sense of dignity was not upheld by someone else

- A time when your sense of dignity was supported by something to do with the way your work is supported to be successful (note 1)

- A time when your sense of dignity was infringed by not being supported in your work (note 2)

- A time when you acted in a way that supported your own sense of dignity; it could be something that you see as a positive or negative action

- A time when you may have infringed your own dignity

- A time when the work itself supported your sense of dignity

- A time when the work itself infringed you sense of dignity

- Note 1: for example something about the environment you work in, or the resources you are provided with, or the access to opportunities that you have been given

- Note 2: for example things that relate to your environment, the resources you are (or are not) provided with, or the access to opportunities. You may think of others. 


\section{References}

Aiken, L.H., \& Patrician, P.A. (2000). Measuring organizational traits of hospitals: The revised Nursing Work Index. Nursing Research, 49(3), 146-153.

Aiken, L.H., Sloane, D.M., Lake, E.T., Sochalski, J., \& Weber, A.L. (1999). Organization and outcomes of inpatient AIDs care. Medical Care, 37(8), 760-772.

Aldergrove, J.R. (2000). Why we are not obsolete yet: Genetics, algeny, and the future. Burnaby: Stentorian.

Allen, D. (2004). Ethnomethodological insights into insider-outsider relationships in nursing ethnographies of healthcare settings. Nursing Inquiry, 11(1), 14-24.

Altun, I. (2002). Burnout and nurses' personal and professional values. Nursing Ethics, 9(3), 269-278.

Amalberti, R., Auroy, Y., Berwick, D., \& Barach, P. (2005). Five system barriers to achieving ultrasafe heatlh care. Annals of Internal Medicine, 142, 756-764.

Annals, G. (2007, May 12). [Keynote address]. Address to the Nursing Roundtable, Waikato District Health Board, Hamilton, New Zealand.

Arora, N. (2008). On our dignity, rights, and personal responsibility. Retrieved February 4, 2008, from http://www.shunya.net/Test/Blog/DignityRightsResponsibility.htm

Ash, M. \& Seago, J.A. (2004). The effect of Registered Nurses' unions on heart-attack mortality. Industrial and Labor Relations Review, 57(3), 422-442.

Baumann, A. (2007). Advancing positive practice environments. Geneva: International Council of Nurses.

Bayertz, K. (1996a). Human dignity: Philosophical origin and scientific erosion of an idea. In K. Bayertz (Ed.), Sanctity of life and human dignity (pp. 73-90). Boston: Kluwer Academic.

Bayertz, K. (1996b). [Introduction]. In K. Bayertz (Ed.), Sanctity of life and Human dignity. (pp. xi-xix). Boston: Kluwer Academic.

Beil-Hildebrand, M. (2002). Theorising culture and culture in context: Institutional excellence and control. Nursing Inquiry, 9(4), 257-274. 
Benner, P. (1994). Caring as a way of knowing and not knowing. In S. Phillips, \& P. Benner (Eds.), The crisis of care: Affirming and restoring caring practices in the helping professions. (pp. 42-62). Washington D.C.: Georgetown University Press.

Broom, A., \& Willis, E. (2007). Competing paradigms and health research. In M. Saks, \& J. Allsop, (Ed.), Researching health: Qualitative, quantitative and mixed methods (1st ed.). London: Sage Publications Inc.

Burke, C. (1993). Personalism, individualism, 'communio'. Retrieved 26 March, 2008, from http://www.cormacburke.or.ke/node/869

Carr, A.N. (2005). The challenge of critical theory for those in organization theory and behaviour: An overview. International Journal of Organization Theory and Behavior, 8(4), 466-494.

Chase, S.E. (2005). Narrative inquiry: Multiple lenses, approaches, voices. In N. K. Lincoln., \& Y.S. Denzin (Eds.), The Sage handbook of qualitative research (3rd ed.), (pp. 651-679). Thousand Oaks: Sage Publications Inc.

Cheng, Y., Kawachi, I., Coakley, E., Schwartz, J., \& Colditz, G. (2000). Association between psychosocial work characteristics and health functioning in American women: Prospective study. British Medical Journal, 320, 1432-1436.

Cohen, M.R. (1999). Medication errors. Washington: American Pharmaceutical Association.

Connelly, L.M. (2007). Understanding qualitative research. Academy of Medical-Surgical Nurses, 16(1), 13-15.

Considine, G., \& Buchan, J. (1999). The hidden cost of understaffing: An analysis of contemporary nurses working conditions in Victoria. Sydney: Australian Centre for Industrial Research and Training, University of Sydney.

Corley, M.C., Minick, P., Elswick, R.K., \& Jacobs, M. (2005). Nurse moral distress and ethical work environment. Nursing Ethics, 12(4), 381-390.

Davies, C. (1996). The sociology of professions and the profession of gender. Sociology of Health and IIIness, 30(4), 661-678.

Davies, K. (2003). The body and doing gender: The relations between doctors and nurses in hospital work. Sociology of Health and IIIness, 25(7), 720-742. 
Denzin, N.K., \& Lincoln, Y.S. (2005). [Introduction]. In N.K. Lincoln. \& Denzin, Y.S. (Eds.), The Sage handbook of qualitative research (3rd ed.), (pp. 1-32). Thousand Oaks, CA: Sage Publications.

Diers, D. (2004). Speaking of nursing: Narratives of practice, research, policy, and the profession. Mississauga: Jones and Bartlett.

Donkin, R. (2001). Blood sweat and tears: The evolution of work. London: TEXERE Publishing Limited.

Duffield, C. (2007). The impact of hospital structure and restructuring on the nursing workforce. Australian Journal of Advanced Nursing, 24(3), 4246.

Fagermoen, M.S. (1997). Professional identity: Values embedded in meaningful nursing practice. Journal of Advanced Nursing, 25(3), 434441.

Flynn, L., Carryer, J., \& Budge, C. (2005). Organizational attributes valued by hospital, home care and district nurses in the United States and New Zealand. Journal of Nursing Scholarship, 37(1), 67-72.

Fox, R., Henderson, A., \& Malko-Nyhan, K. (2005). 'They survive despite the organizational culture, not because of it': A longitudinal study of new staff perceptions of what constitutes support during the transition to an acute tertiary facility. International Journal of Nursing Practice, 11(5), 193-199.

Franklin, L.L., Ternestedt, B., \& Nordenfelt, L. (2006). Views on dignity of elderly nursing home residents. Nursing Ethics, 13(2), 130-146.

Friese, C.R. (2005). Nurse practice environments and outcomes: Implications for oncology nursing. Oncology Nursing Forum, 32(4), 765-772.

Gallagher, A. (2004). Dignity and respect for dignity - two key health professional values: Implications for nursing practice. Nursing Ethics, 11(6), 587-599.

Gallant-Roman, M.A. (2008). Strategies and tools to reduce workplace violence. AAOHN Journal, 56(11), 449-454.

Giorgi, A. (1992). Description versus interpretation: Competing alternative strategies for qualitative research. Journal of Phenomenological Psychology, 23(2), 119-135.

Goodman, H. (2003). A fragmented patient safety concept: The structure and culture of safety management in healthcare. Nursing Economic\$, 22(1), 44-46. 
Gordon, S. (2005). Nursing against the odds. New York: Cornell University Press.

Griffin, M. (2004). Teaching cognitive rehearsal as a shield for lateral violence: An intervention for newly licensed nurses. The Journal of Continuing Education in Nursing, 35(6), 257-263.

Griffin-Heslin, V.L. (2005). An analysis of the concept dignity. Accident and Emergency Nursing, 13(4), 251-257.

Guba, E.G., \& Lincoln, Y.S. (1989). Fourth generation evaluation. Newbury Park: Sage Publications.

Haddock, J. (1996). Towards further clarification of the concept 'dignity'. Journal of Advanced Nursing, 24, 924-931.

Hansen, E.C. (2006). Successful qualitative health research: A practical introduction. Sydney: Allen \& Unwin.

Harulow, S. (2000). Underfunding: Are nurses paying the price. Australian Nursing Journal, 8 (2), 28-30.

He Wakaputanga o Te Rangatiratanga o Nu Tireni. Retrieved June 20, 2009 from http://www.trc.org.nz/sites/trc.org.nz/files/Declaration\%20new_0.pdf

Health Canada. (2007). The working conditions of nurses: Confronting the challenges. Retrieved June 6, 2008, from http://www.hc-sc.gc.ca/srsr/alt formats/hpb-dgps/pdf/pubs/hpr-rps/bull/2007-nursesinfirmieres/2007-nurses-infirmieres-eng.pdf

Healthcare at the Crossroads: Strategies for addressing the evolving nurse crisis (2002), Washington D.C.: Joint Commission on Accreditation of Healthcare Organizations.

Hill, R.B. (1996). Historical context of the work ethic. Retrieved December 19, 2007 from http://www.coe.uga.edu/ rhill/workethic/hist.htm

Hodson, R. (2001). Dignity at work. Cambridge: Cambridge University Press.

Hodson, R. \& Roscigno, V.J. (2004). Organizational success and worker dignity: Complimentary or contradictory? American Journal of Sociology, 110(3), 672-708.

Hofmeyer, A. (2003). A moral imperative to improve the quality of work-life for nurses: Building inclusive social capital. Contemporary Nurse, 15(1), 919.

Hsieh, H., \& Shannon, S.E. (2005). Three approaches to qualitative content analysis. Qualitative Health Research, 15, 1277-1288. 
Hughes, R.G., \& Clancy, C.M. (2005). Working conditions that support patient safety. Journal of Nursing Care Quality, 20(4), 289-292.

Hunter, D. (2007). The art of facilitation. Auckland: Random House Publishing.

Jacobs, B.B. (2001). Respect for human dignity: A central phenomenon to philosophically unite nursing theory and practice through consilience of knowledge. Advances in Nursing Science, 24(1), 17-35.

Jans, J. (1996). Personalism: The foundations of an ethics of responsibility. Ethical Perspectives, 3(3), 147-156.

Kalb, K.A., \& O'Conner-Von, S. (2007). Ethics education in advanced practice nursing: Respect for human dignity. Nursing Education Perspectives, 28(4), 198-202.

Kamberelis, G., \& Dimitriadis, G. (2005). Strategic articulations of pedagogy, politics, and inquiry. In N. K. Lincoln. \& Y.S. Denzin, (Eds.), The Sage handbook of qualitative research (3 ed., pp. 887-908). Thousand Oaks: Sage Publications.

Katz-Navon, T., Naveh, E., \& Stern, Z. (2005). Safety Climate in Health Care Organizations: A multidimensional approach. Academy of Management Journal, 48(6), 1075-1089.

Kelly, B. (1998). Preserving moral integrity: a follow-up study with new graduate nurses. Journal of Advanced Nursing, 28, 1134-1145.

Kidd, J.D. (2008). Aroha mai: Nurses, nursing and mental illness. Unpublished doctoral thesis, University of Auckland, Auckland.

Kincheloe, J.L., \& McLaren, P. (2005). Rethinking critical theory and qualitative research. In N. K. Lincoln., \& Y.S. Denzin, (Eds.), The Sage handbook of qualitative research (3rd ed.). (pp. 303-342). Thousand Oaks: Sage Publications.

Korczynski, M., Hodson, R., \& Edwards, P. (Eds.). (2006). Social theory at work (Vol. 1). New York: Oxford University Press.

Kramer, M., \& Hafner, L.P. (1989). Shared values: Impact on staff nurse job satisfaction and perceived productivity. Nursing Research, 38(3), 172177.

Kramer, M., \& Schmalenberg, C. (2003). Magnet hospital nurses describe control over nursing practice. Western Journal of Nursing Research, 25(4), 434-452.

Kramer, M., \& Schmalenberg, C. (2008). Confirmation of a healthy work environment. Critical Care Nurse, 28(2), 56-63. 
Kramer, M., \& Schmalenberg, C. (2008). Essentials of a magnetic work environment Part 4. Nursing2004 34(9), 44-48.

Laschinger, H.K. (2001). Promoting nurse's health: Effects of empowerment on job strain and work satisfaction. Nursing Economic\$, 19(2), 42-53.

Laschinger, H.K., Shamian, J., \& Thomson, D. (2001). Impact of magnet hospital characteristics on nurses' perceptions of trust, burnout, quality of care, and work satisfaction. Nursing Economic\$, 19(5), 209-220.

Lebech, M. (2004). What is human dignity?. NUI Maynooth ePrints and eTheses Archives. Retrieved October 17, 2008, from http://eprints.nuim.ie/392/1/Human-Dignity.pdf

Lutzen, K., Cronvqist, A., Magnusson, A., \& Andersson, L. (2003). Moral stress: Synthesis of a concept. Nursing Ethics, 10(3), 312-22.

McCloskey, B. A., \& Diers., D.K. (2005). Effects of New Zealand's health re-engineering on nursing and patient outcomes. Medical Care, 43(11), 1140-1146.

McDonald, L. (Ed.). (2004). Florence Nightingale on public healthcare: Collected works of Florence Nightingale (Vol. 6). London: Laurier Press.

McGillis Hall, L. (2003). Indicators of nurse staffing and quality nursing work environments: A critical synthesis of the literature. Toronto: University of Toronto.

McKenna, B.G., Smith, N.A., Poole, S.J., \& Coverdale, J.H. (2002). Horizontal violence: Experiences of registered nurses in their first year of practice. Journal of Advanced Nursing, 42(1), 90-96.

Macklin, A. (2003). Dignity is a useless concept. British Medical Journal, 327, 1419-1420.

Mairis, E.D. (1993). Concept clarification in professional practice - dignity, Journal of Advanced Nursing, 19(5), 947-953.

Manley, K., \& McCormack, B. (2003). Practice development: Purpose, methodology, facilitation and evaluation. Nursing in Critical Care, 8(1), 22-29.

Martin, W.F. (2008). Is your hospital safe? Disruptive behavior and workplace bullying. HOSPITAL TOPICS: Research and Perspectives on Healthcare, 86(3), 21-28.

Mayring, P. (2000). Qualitative content analysis [Electronic version]. Forum: Qualitative Social Research, 1(2), 1-10. 
Milton, C.L. (2003). The American Nurses Association Code of Ethics: A reflection on the ethics of respect and human dignity with nurse as expert. Nursing Science Quarterly, 16(4), 301-304.

Morse, J.M. (1994). Designing funded qualitative research. In N. K. Lincoln., \& Y.S. Denzin (Eds.), Handbook of qualitative research (pp. 220-235). CA: Sage.

Needleman, J., Buerhaus, P., Mattke, S., Stewart, M., \& Zelevinsky, K. (2002). Nurse staffing and quality of care in hospitals in the United States. New England Journal of Medicine, 346(22), 306-308.

O'Neill, O. (1998). Contemporary kantian ethics. In E. Craig (Ed.), Routledge Encyclopedia of Philosophy. London: Routledge.

Page, A. (Ed.). (2004). Keeping patients safe: Transforming the work environment of nurses. Washington D.C.: The National Academies Press.

Paley, J. (2004). Commentary: The discourse of moral suffering. Journal of Advanced Nursing, 47(4), 364-367.

Peter, E.H., Macfarlane, A.V., \& O'Brien-Pallas, L. (2004). Analysis of the moral habitability of the nursing work environment. Journal of Advanced Nursing, 47(4), 356-364.

Peterson, M., \& Wilson, J.F. (2002). The culture-work-health-model and work stress. American Journal of Health Behavior, 26(1), 16-24.

Priest, A. (2006). What's ailing our nurses?: A discussion of the major issues affecting nursing human resources in Canada. Ottawa: Canadian Health Services Research Foundation.

Ritchie, J.W. (1995). The development of consultative processes and skill based pay in an industry in turmoil. In Proceedings from the Accord or Discord: Changing Employment Relations Conference. Hamilton: University of Waikato.

Roberts, S.J. (2000). Development of a positive professional identity: Liberating oneself from the oppressor within. Advanced Nursing Science, 22(4), 71-82.

Roberts, P., Priest, H., \& Traynor, M. (2006). Reliability and validity in research. Nursing Standard, 20(44), 41-45.

Rose, R., \& Glass, N. (2006). Community mental health nurses speak out: The critical relationship between emotional wellbeing and satisfying professional practice. Collegian, 13(4), 27-32. 
Safe Staffing/Healthy Workplaces Committee of Inquiry. (2007). Report of the safe staffing/healthy workplaces committee of inquiry. Wellington.

Author.

Saks, M., \& Allsop, J. (Eds.). (2007). Researching health: Qualitative, quantitative and mixed methods. London: Sage Publications.

Sandelowski, M. (1995). Sample size in qualitative research. Research in Nursing \& Health, 18, 179-183.

Sandelowski, M. (1997). "To be of use": Enhancing the utility of qualitative research. Nursing Outlook, 45, 125-132.

Sandelowski, M. (2000). Whatever happened to qualitative description? Research in Nursing \& Health, 23, 334-340.

Sandelowski, M. (2001). Real qualitative researchers do not count: The use of numbers in qualitative research. Research in Nursing \& Health, 24, 230-240.

Sayer, A. (2007). Dignity at work: Broadening the agenda. Organization, 14(4), 565-581.

Schat, A.C.H., \& Kelloway, E.K. (2005). Workplace Aggression. In J. Barling, E.K. Kelloway, \& M.R. Frone, (Eds.), Handbook of work stress (pp. 189-218). Thousand Oaks: Sage Publications.

Schluter, S., Winch, S., Holzhauser, K. \& Henderson, A. (2008). Nurses' moral sensitivity and hospital ethical climate: A literature review. Nursing Ethics, 15(3), 304-321.

Schulman, A. (2008). Bioethics and the question of human dignity. In Human dignity and bioethics: Essays commissioned by the President's Council on bioethics (pp. 3-18). Washington D.C.: Author.

Stacey, C.L. (2005). Finding dignity in dirty work: The constraints and rewards of low-wage home care labour. Sociology of Health and IIIness, 27(6), 831-854.

Sweet, M. (2005). Beating bullying. Australian Nursing Journal, 12(9), 16-19.

Takase, M., Maude, P., \& Manias, E. (2005). Explaining nurses' work behaviour from their perception of the environment and work values. International Journal of Nursing Studies (42), 889-898.

The Universal Declaration of Human Rights, United Nations, 1948.

Thorne, S., Kirkham, S.R., O'Flynn-Magee, K. (2004). The analytic challenge in interpretive description. International Journal of Qualitative Methods, 3(1), 1-21. 
Verplanken, B. (2004). Value congruence and job satisfaction among nurses: A human relations perspective. International Journal of Nursing Studies, 41, 599-605.

Van Laar, D., Edwards, J. A., \& Easton, S. (2007). The work-related quality of life scale for healthcare workers. Journal of Advanced Nursing, 60(3) 325-333.

Walsh, K. \& Kowanko, I. (2002). Nurses' and patients' perceptions of dignity. International Journal of Nursing Practice, 8(3), 143-151.

Wolf, Z. R., Serembus, J. F., Smetzer, J., Cohen, H., \& Cohen, M. (2000). Responses and concerns of healthcare providers to medication errors. Clinical Nurse Specialist, 14(6), 278-290.

Wood, A. (n.d.). Human dignity, right, and the realm of ends. Retrieved, November 30, 2008, from, http:www.stanford.edu/ allenw/webpapers/keynote2007.doc

Wright, P. (1993). How will I collect data? Methods for exploratory studies. Journal of Pediatric Oncology Nursing, 10(3), 115-116.

YourDictionary.com. Inviolable. (n.d.). Retrieved February 3, 2009, from http://www.yourdictionary.com/inviolable

Zhang, Y., \& Wildemuth, B.M. (2006). Qualitative analysis of content. University of North Carolina. Retrieved August 8, 2008, from http://ils.unc.edu/ yanz/Content analysis.pdf

Zuniga, G. (2004). An ontology of dignity. Metaphysica, 5(2), 112-131.

Zuzelo, P.R. (2007). Exploring the moral distress of registered nurses. Nursing Ethics, 14 (3), 344-359. 